\title{
Human Capital Development: New Evidence on the Production of Socio-emotional Skills
}

\author{
Mark Mitchell, Marta Favara, Catherine Porter and Alan Sánchez
}

The Department of Economics

Lancaster University Management School

Lancaster LA1 4YX

UK provided that full acknowledgement is given. 


\title{
Human Capital Development: New Evidence on the Production of Socio-emotional Skills
}

\author{
Mark Mitchell, Marta Favara, Catherine Porter and Alan Sánchez*
}

October, 2020

\begin{abstract}
We estimate a dynamic model of multidimensional human capital development from childhood through adolescence and into early adulthood for a Peruvian cohort born in 1994. We exploit multiple measures of cognitive and socio-emotional skills and a latent factor structure to estimate flexible skills production functions between the ages of 8 and 22. We focus particularly on socio-emotional skill development, and provide the first estimates of such skill production over such a long period in a developing country context. In the last period, when individuals reach adulthood at age 22 , we show that socio-emotional skills can be separated into two distinct domains - social skills and task effectiveness skills- which develop differently especially with regard to time use and cross-productivity with cognition. We find that individuals with higher task effectiveness are less likely to have engaged in risky behaviours such as smoking, taking drugs, and engaging with gangs.
\end{abstract}

Keywords: Human capital, child development, dynamic factor analysis, socio-emotional skills JEL codes: C38, J13, J24, O15, O54

*Mitchell: The University of Edinburgh \& Fraser of Allander Institute, mark.mitchell@ed.ac.uk (corresponding author); Favara: University of Oxford; Porter: University of Lancaster; Sánchez: Grupo de Análisis para el Desarrollo (GRADE). The authors thank Alessandra Hidalgo for excellent research assistance. We thank Paul Glewwe, Steve Dieterle and Andy Snell for useful comments. Funding was received by Favara, Porter and Sánchez from ESRC-GCRF Grant ES/S004564/1 Inequality of Opportunity in Peru. 


\section{Introduction}

Understanding how inequalities in skills emerge through childhood into adulthood is one of the most important questions for policy in both developed and developing countries. Inequalities appear very early in life and may perpetuate intergenerational differences in income. Economic research has established that skills which influence earnings are multidimensional in nature and documented the importance of socio-emotional skills ${ }^{1}$ in determining life outcomes such as career, income, marriage and health, beyond the effect of cognitive skills (Heckman and Rubinstein, 2001; Chiteji, 2010; Almlund et al., 2011; Heckman and Kautz, 2012). Econometric research shows multidimensional skills development can (and should) be modelled taking into account its dynamic nature, using a latent variable approach to account for imperfect measurement (Heckman, 2006, 2007; Cunha and Heckman, 2007; Cunha et al., 2010). This has generated important insights into skill formation, including the existence of critical periods for skills development, the role of parental investments, and the potential "cross-productivity", between cognitive and socio-emotional skills (Heckman et al., 2006).

Most of the evidence on the formation of socio-emotional skills comes from research on developed countries, arguably due to data availability. However understanding these processes and how skills themselves determine social and economic outcomes is equally, or perhaps even more important for developing countries (Roy et al., 2018).

This paper makes three contributions to the literature on skill formation: first, it estimates a production function for human capital that includes a full treatment of socio-emotional skills throughout childhood into early adulthood, in a developing country. Our data come from the Young Lives Survey in Peru which has surveyed this cohort from the age of eight to 22. Second, we exploit the careful design of our dataset in the latest rounds that allows us to disaggregate socio-emotional skill formation during early adulthood (between the ages of 19 and 22) into two latent skills which are relevant to future labour market outcomes. They are 1) 'social skills' - the skills needed to get on with others, such as working in teams and leadership skills; 2) 'task effectiveness'- the skills related to successful achievement in life and work - incorporating aspects of organisational skills, self-efficacy and persistence (or grit). We show that these two types of socio-emotional skills develop differently during early adulthood, especially with respect to effects of time use (studying, working at home, outside the home and caring for others), as well as in relation to cognitive skills in the previous period. Finally, we consider the effect of socio-emotional skills on outcomes at 22 . Given that earnings are not yet fully informative as many in the sample have not yet completed their education, we focus on risky behaviours that are predictive of future earnings. We are able to show that only one of the socio-emotional skills we identify- task effectiveness- predicts a reduced probability of engaging in in a range of risky behaviours by early adulthood such as smoking, taking drugs or engaging with gangs.

Peru is a middle-income country with persistent levels of inequality according to World Bank estimates (monetary poverty: 20.2\% in 2019; Gini coefficient: 0.44 in 2016). A recent survey of

\footnotetext{
${ }^{1}$ We use the term socio-emotional skills in this paper, though noncognitive is also in common usage in the economics literature. They have variously been referred to as soft, social, psychosocial or personality skills in the economics literature to date, as well as personality traits, social-emotional competencies. We discuss the composition of the measures we use in detail in section 3 .
} 
employers in Peru found that despite improvements in access to education, socio-emotional skills are those that employers have most difficulty finding in potential employees (Novella et al., 2019). The case of Peru can provide insights for other Latin American countries. Despite great progress in educational attainment in the region, Cunningham et al. (2016) show that this has not translated into higher workplace productivity, arguing that increases in efficiency in the continent could be realised through improvements in socio-emotional skills.

The literature on human capital production, particularly in developed countries, has expanded a great deal over the past two decades; Del Boca et al. (2013) and Almond et al. (2018) review much of the evidence. Within this literature, socio-emotional skills have been shown to play a key role in the developmental process. Heckman et al. (2013) document that the influential Perry pre-school program improved later life outcomes mainly through its lasting effect on socio-emotional skills. There is now a convincing body of evidence that socio-emotional skills matter for academic achievement and labor market success. Cunha et al. (2010) find that whilst $16 \%$ of the variation in educational attainment among a sample of adults in the US is explained by adolescent cognitive skills, $12 \%$ is due to adolescent socio-emotional traits (see also Duckworth et al. (2007); Almlund et al. (2011)). Kautz et al. (2014) suggest that the window for intervention in socio-emotional skills may be longer than that of cognitive skills, and that the productivity of later-age investment in socio-emotional skills is substantial. There is recent evidence that preferences and socio-emotional skills can be influenced through interventions (Bettinger et al., 2018; Kosse et al., 2020), including a a very small body evidence on socio-emotional skills in low- and middle-income countries from small experiments on older girls or young women (Krishnan and Krutikova, 2013; Ashraf et al., 2020; Edmonds et al., 2020). Alan and Ertac (2018) and Alan et al. (2019) showed the effectiveness of a larger elementary school-based intervention on the socio-emotional skills of patience and grit (persistence) respectively in Turkey, though for younger children, around the age of ten.

Glewwe et al. (2017) provide reduced-form evidence that a diverse set of socio-emotional skills at age 9-12 are predictive of school to work transitions at age 17-21 after controlling for cognitive skills, using a cohort study in China. Our work builds on theirs by formalising the process of socio-emotional skill accumulation, and investigating how its dynamic nature gives way to such gradients. There are only a handful of studies which estimate production functions for skills in developing countries (e.g Attanasio et al. (2017, 2020b), Keane et al. (2018)), and these focus mainly on cognitive skills and health. Only three papers to our knowledge estimate the production function for both cognitive and socio-emotional skills in a developing country context, however all cover only the period of early childhood. Attanasio et al. (2020a) investigate socio-emotional skill development in Colombia aged up to four years. Helmers and Patnam (2011) estimate the technology of cognitive and socio-emotional skill formation in India from ages 8 to 12 (the first period in our model), and Sánchez (2017) provides estimates for a similar model in Peru, but only from ages 1 to 8 . Notably, the latter two studies utilise the same data source as we do, the Young Lives survey, which is one of the few available in developing countries that includes detailed longitudinal information on children and families through childhood. We build on this work by providing new evidence on the production of socio-emotional skills going beyond the period of very early childhood that has been studied previously. 
We consider how initial conditions (parental background) and measures of household investment, cognition and socio-emotional skills interact from the age of 8 , and then through ages 12, 15, 19 to our 'final' outcomes at 22 years. This adolescent development period has received relatively little attention in the literature on socio-emotional skill development. However, certain features of the developmental process in adolescence not present (or commonly assumed not to be) in early childhood make analysing skill formation over this period challenging. For example, during adolescence individuals increasingly self-invest and self-determine: investments aren't only made by the parents/caregivers, as the individual gains more independence and gains more experiences outside of the home, in school and/or work. We attempt to examine how these experiences might impact on the formation of socio-emotional skills in early adulthood by accounting for the effect of time use, including paid and unpaid work, leisure, time studying etc, following Keane et al. (2018).

To do so, we estimate flexible production functions of socio-emotional skill between the ages of 8 and 22 that capture several key aspects of the skill development process uncovered in the literature to date (eg. Cunha et al. (2010), Attanasio et al. (2017, 2020a,b), Agostinelli and Wiswall (2016a)). We allow future socio-emotional skill to be determined by present stocks of itself (self-productivity) and cognition (cross-productivity), and allow the impact of investments to vary across the distribution of skill (dynamic complementarities). We use a methodology developed by Agostinelli and Wiswall (2016a) which allows us to estimate production functions which depart from much of the current literature and allow for non-constant elasticity of substitution between inputs; a feature that is particularly important given that we study socio-emotional development over a fourteen year period covering primary, secondary and tertiary education (and/or early labour market experience), and enables us to examine how skills and investments interact differently in the developmental process. In the latter most period of our analysis we allow for even more flexibility in the functions mapping aggregate socio-emotional skill at age 19 into social skills and task effectiveness at 22.

Our paper also adds to the discussion on how to measure and conceptualise socio-emotional skills for the labor market in economic research. To measure such skills, economists have mainly been opportunistic and have used a range of measures that were available, often self-reported scales used by psychologists. Flexible econometric methods to take account of imperfectly observed skills discussed above have allowed the literature on skills production to develop almost independently of the discussion on the definition of socio-emotional skills. Lundberg (2017) notes "a lack of consensus about what non-cognitive skills are, and the absence of a consistent set of metrics that can be applied across studies" (p220). The seminal paper establishing that a low-dimensional vector of latent skills (Heckman et al., 2006) was predictive of life outcomes used just two measures: Locus of Control and Self-Esteem, and whilst the paper has spawned a literature that tends to invoke a single factor approach to socio-emotional/non-cognitive skills, the authors note "Since there are many aspects of noncognitive skills - self control, time preference, sociability, and so forth - it is less likely that one trait captures all aspects of these behaviors" (p420). Lindqvist and Vestman (2011) document that the umbrella concept of socio-emotional skills has been proxied by a variety of diverse measurements including locus of control, personal efficacy, willingness to follow rules, self esteem, teacher reports of aggression or other behaviour. In their paper, the authors use a general scale of "noncognitive ability" measured from 
1-10 based on a subjective rating by a psychologist.

We use the latest wave of the Young Lives study (YL) data collected at the age of 22 which was designed (by the authors) to allow researchers to investigate a broad range of skills in early adulthood related to labour market readiness (Porter et al., 2020). In the 2016 wave, we expanded the questionnaire to include extra modules to measure socio-emotional skills, whilst building on information collected in previous rounds. Defining and measuring socio-emotional skills is challenging, particularly in developing countries (Laajaj and Macours, 2019; Laajaj et al., 2019). We drew on the most recent literature in both psychology and economics as well as policy (e.g. OECD (2017)), with carefully piloting of the proposed measures. In the earliest rounds YL had collected information on pride/shame, agency, and aspirations for the future. By 2013, the concepts of generalized self-efficacy (Bandura, 2010) and self-esteem (Rosenberg, 1965) as well as peer and parent relations were also included (Yorke and Ogando, 2018). In 2016 we included new measures for Grit (Duckworth et al., 2007), teamwork and leadership (Richards et al., 2002). We also included Conscientiousness and Emotional Stability (Neuroticism) from the "Big five" stable traits/factors of personality (Costa and MacCrae, 1992) given the evidence that several of the Big Five are strong predictors of economic outcomes such as job performance and wages (Borghans et al., 2008; Gensowski, 2018). ${ }^{2}$

This broad set of instruments allows us to consider more than one personality-related skill dimension that may be productive in the labour market. We disaggregate socio-emotional skills in the final period into: social skills - how well the individual works as part of a team, leads others and relates to their peers - and task effectiveness, or individuals' self-evaluation of their ability to organise, control and form their life circumstances. Social skills have grown in importance over time, as jobs have increasingly required increased social interactions (Weinberger, 2014; Deming, 2017). For task effectiveness (or task performance) we drew on Almlund et al. (2011) summary of psychological evidence that traits such as self-esteem, agency and locus of control are most important for job performance, and are associated with Big Five traits Conscientiousness and Emotional Stability; and that Grit (Duckworth et al., 2007) has additional predictive power of success. In parallel, the literature in personnel psychology has produced a concept called Core Self Evaluation (CSE) (Bono and Judge, 2003) which comprises Emotional Stability, Self-Control, Self-Efficacy and Locus of Control, that is found to be a good general predictor of job performance. Our analysis shows that our measures do load on to two factors in a way that fits well with this intuition from both strands of literature. We are conscious that there are still many more socio-emotional skills that are useful for the labour market and are not included here, such as self-control, growth mindset or executive function, as well as time and risk preferences, however, identifying two distinct factors that are grounded in theory represents a step forward from the single factor approach, and we hope to expand on this in future rounds of YL data collection. We also note that we do not have fully consistent measures of socio-emotional skills across all periods - though we account for this in our methodology, it does make them somewhat noisier than e.g. our cognitive skills measures.

To briefly summarise our findings, we find evidence that household investments are strongly

${ }^{2}$ YL piloted the Big Five survey prior to the fifth round, but found that only Conscientiousness and Neuroticism had construct validity (Porter et al., 2020). 
determined by family resources and, in the early periods of our model, between the ages of 8-12 and 12-15, parental stocks of socio-emotional skills. We also find that across all stages, between the ages of 8 and 19, cognitive skills are by far the most important input of skill development: cognition is not only highly, and increasingly, self-productive over childhood, it is also the driver of socio-emotional skill accumulation. At the same time, we find that socio-emotional skills do not affect cognitive development at any stage between the ages of 8 and 19. Our estimates also suggest that socio-emotional skill is positively affected by investments, particularly in early childhood, between the ages of 8 and 12, and that, their returns differ significantly across the distribution of child skills - investments are most productive for children with low levels of cognitive skill. Similarly, we find evidence that cognition is malleable with respect to investments at all ages, and that their impact also depends on stocks of cognitive skills. These results again show the key role of cognition in skill development, as well as the importance of allowing for flexibility in the production function across different stages and skills.

In early adulthood, between the ages of 19 and 22, we find that bundles of socio-emotional and cognitive skills accumulated by the end of adolescence impact differently on the accumulation of task-effectiveness and social skills. Aggregate socio-emotional skill strongly, positively affects both at 22 , however cognitive skill enters negatively into a production function of the latter, suggesting a substitution effect - those with lower cognitive skills may improve their social skills to compensate. Time use also has differential impacts on the two socio-emotional skill domains. Time spent studying is associated with higher levels of task-effectiveness but hours spent in home production or work have the opposite effect. Time use has no effect on social skills, however. This shows how treating socio-emotional skills as an aggregate might produce misleading results about the skill accumulation process. We then find that having higher levels of task effectiveness is associated with a reduced probability of having engaged in several risky behaviours in early adulthood. Together, our results suggest that early inequalities in cognitive skills, family resources, and parental human capital drive the emergence and widening of inequalities in socio-emotional skills, which are important in determining behaviours predictive of future social and economic outcomes.

The remainder of this paper is structured as follows: Section 2 outlines our empirical model of human capital development; Section 3 describes the data we use to estimate this model and presents some descriptive evidence as to income gradients of cognitive and socio-emotional skills; Section 4 discusses the estimates of the model of human capital development; Section 5 presents evidence on how socio-emotional skills impact risky behaviour in early-adulthood; and Section ?? concludes with a discussion of our results.

\section{An Empirical Model of Skill Development}

Our model of skills development follows Agostinelli and Wiswall (2016a). We assume that socioemotional $(s)$ skill is 'produced' over $T$ discrete periods, where T marks the end of childhood and adolescence. Whilst socio-emotional skills are broad and complex, we focus on the evolution of a one-dimensional aggregate across the early periods, a simplification that is now the norm in the literature on human capital development (discussed above), and is relaxed in our final period. At the 
beginning of the period, $t=0$, the set of initial conditions are a child's human capital, human capital of their parents, and the resources of their family. In subsequent periods $t=1, . ., T$, we assume that the developmental process has two main features: a function governing the development of human capital and another determining how families make investments. The latter of these determines how present $(t)$ human capital of children and parents and family resources determines household investment behaviour, and the former how future $(t+1)$ human capital is determined by the same inputs (except resources) and investments. We assume an identical process for cognitive $(c)$ skill development over the same period. In our data, initial conditions $(t=0)$ are observed at age 8 , and the end of childhood and adolescence $(t=T)$ at age 19 .

In order to capture potential malleability in skills over early adulthood, we then extend this framework by assuming there is some function mapping skills accumulated by the end of adolescence $(T)$ into socio-emotional skills in early adulthood $(T+1)$. Given the relative breadth of data we have available in early adulthood, we disaggregate socio-emotional skills along two dimensions: social skills and task effectiveness. We do not model the evolution of cognitive skills over this period as the data we use in our empirical application does not measure cognition in early adulthood $(T+1)$. In the data we use to estimate the model, early adulthood $(T+1)$ corresponds to age 22 .

Finally, as it is not possible to perfectly measure skills, parental human capital or investments, we follow the literature in assuming a measurement system which specifies a relationship between observable data and the underlying latent variables they measure. Throughout, we denote latent human capital of children and parents by $H_{j, t}$ and $P_{j}$ for $j \in\{s, c\}$ and investments by $I_{t}$. Observable measures are denoted by $Z_{\theta_{t}}$ for $\theta_{t} \in\left\{H_{s, t}, H_{c, t}, P_{s}, P_{c}, I_{t}\right\}_{t=0}^{T}$. Specifying a measurement system in this way allows us to "back out" the underlying latent variables to be used as inputs/outputs of the investment and human capital production functions, and has become standard in the literature on human capital development over the past decade (e.g Cunha and Heckman (2007), Cunha et al. (2010), Attanasio et al. (2017, 2020a,b)). Next we outline in more detail the five main components of our empirical model: the initial conditions; the production function of socio-emotional and cognitive skills and investment functions between $t=0$ and $t=T$; the production function of socio-emotional skill between $T$ and $T+1 ;$ and the measurement system

\subsection{Initial Conditions}

The vector of initial conditions at $t=0$ - the beginning of a developmental stage - can be written as

$$
\mathbf{\Omega}=\left(\ln H_{c, 0}, \ln H_{s, 0}, \ln P_{c}, \ln P_{s}, \ln Y_{0}\right),
$$

where $H_{k, 0}$ and $P_{k}$ for $k \in\{s, c\}$ are child and parental stocks of human capital component $k$ respectively, and $Y_{0}$ is family income at $t=0$. Parents' human capital is assumed to be time invariant and are captured by parental stocks of each component of human capital in the initial period. We assume that these initial conditions are jointly normally distributed:

$$
\boldsymbol{\Omega} \sim N\left(\boldsymbol{\mu}_{\Omega}, \boldsymbol{\Sigma}_{\Omega}\right),
$$


with $\mu_{\Omega}$ and $\Sigma_{\Omega}$ being the mean vector and covariance matrix of the initial conditions respectively. This assumption of joint normality of the latent variables in the initial period does not restrict their subsequent joint distribution - a restriction Cunha et al. (2010) show would implicitly restrict the functional form of the human capital production function.

\subsection{Investment}

Using a reduced form approximation of a parental investment policy function, we specify investment at time $t$ as

$$
\ln I_{t}=\beta_{1, t} \ln H_{c, t}+\beta_{2, t} \ln H_{s, t}+\beta_{3, t} \ln P_{c}+\beta_{4, t} \ln P_{s}+\beta_{5, t} \ln Y_{t}+\pi_{t},
$$

where $Y_{t}, H_{k, t}$ and $P_{k}$ are as in the vector of initial conditions, and $\pi_{t}$ is a shock to investment assumed to be mean zero with variance $\sigma_{\pi_{t}}^{2}$ but is not necessarily normally distributed. Using this approximation means abstracting from both parents' preferences and beliefs regarding the production technology and the returns to their investments in children. The cost of this flexibility is that the parameters of this investment function do not have a strict theoretical interpretation.

Considering this, the parental behaviour consistent with values of the parameters in Equation 1 is ambiguous. However, we interpret $\beta_{i, t}>0$ for $i=1,2$ to indicate reinforcement of skills by parents, and $\beta_{i, t}<0$ for $i=1,2$ to indicate skill compensation. Reinforcement is consistent with parents investing more in their child upon realising they have high stocks of human capital, and compensation with parents investing more upon realising the opposite. ${ }^{3}$ The parameters $\beta_{i, t}$ for $i=3,4$, simply capture how parents' investment decisions are influenced by their own stocks of human capital. If, for example, $\beta_{4, t}<0$, parents with higher levels of cognitive skill would invest less in their child's development.

We acknowledge that there are a vast range of possible investments that can be made in human capital, and that in the later stages of adolescence children themselves likely begin to play a role in investment decisions. In our estimation of this model, in line with similar studies (Attanasio et al., 2020b, 2017) we use measures of investment between the ages of 8-19 that cover expenditure on school resources, nutrition and time spent studying. Although very different, all of these measures are positively associated with one another. Our focus across these ages is to capture some measure of the overall investment-related environment. We treat time use as part of this aggregate investment over these ages given that Peru is a middle-income country in which many families face a high opportunity cost between sending their child to school, encouraging them to spend time on study or needing them to work. In many respects this is similar to parental time-use investments used for example in Cunha et al. (2010) and Del Boca et al. (2013). When children reach age 19 and enter early adulthood, we exploit the added flexibility afforded to us by the data at this age to broaden time-use to incorporate a range of activities that may act as direct determinants of skill accumulation. We discuss the measures of investment in Section 3, and the skill technology we specify between 19-22 below.

\footnotetext{
${ }^{3}$ Again, a consequence of the reduced form nature of the investment function is that we cannot disentangle realisation from expectations - it might be that parents that perceive returns to investments to be higher in fact invest more.
} 


\subsection{Socio-emotional Capital Accumulation}

In periods $t=1, . . T$, we assume socio-emotional skill in $t+1$ to be a function of three types of input: children's stocks of skill, parental human capital and investments. Assuming a flexible trans-log form for the production function and considering one general type of investment, $I_{t}$, the production function of socio-emotional skill can be written as:

$$
\ln H_{s, t+1}=\rho_{1, t}^{s} \ln H_{s, t}+\rho_{2, t}^{s} \ln H_{c, t}+\alpha_{1, t}^{s} \ln P_{s}+\alpha_{2, t}^{s} \ln P_{c}+\gamma_{t}^{s} \ln I_{t}+\kappa_{t}^{s}\left(\ln H_{j, t} \times \ln I_{t}\right)+\eta_{t}^{s},
$$

where $H_{k, t}$ and $P_{k}$ are as in Equation 1, and $I_{t}$ and $\eta_{t+1}^{s}$ parental investment and production shocks respectively. The production shock is assumed to be mean zero with variance $\sigma_{\eta_{t}^{s}}^{2}$. The interaction term $\left(\ln H_{j, t} \times \ln I_{t}\right)$ for $j \in\{s, c\}$ captures complementarity between present stocks of skill and investment. ${ }^{4}$ Assuming, for example, that $\kappa_{t}^{s}=0$, is equivalent to assuming the production function of socio-emotional skills is Cobb-Douglas. If, however, $\kappa_{t}^{s} \neq 0$, investments can be more $\left(\kappa_{t}^{s}>0\right)$ or less $\left(\kappa_{t}^{s}<0\right)$ productive in children with higher stocks of skill.

This form of the production function captures several key aspects of human capital accumulation. For example, it allows for self- and cross-productivities in skills, represented by $\rho_{1, t}^{s}>0$ and $\rho_{2, t}^{s}>0$ respectively. In the case of $\kappa_{t}^{s} \neq 0$, it also captures any dynamic complementarities between already accumulated human capital and investments - the dynamic relationship between skills and investments that could result in the opening and widening of inequalities in human capital (Cunha et al., 2010). The trans-log production function can be expanded with the inclusion of further interaction terms, meaning it allows the elasticity of substitution to vary across inputs. This would not be possible if a Constant Elasticity of Substitution (CES) function was specified, as has been the case in much of the human capital development literature to date (e.g Cunha et al. (2010), Attanasio et al. (2017, 2020a,b)). Doing so, however, is equivalent to assuming that all the inputs on the right-hand-side of Equation 2 can substitute equally for one another in production of socio-emotional skills. For example, in our application of the model we use (among others) expenditures on books and time spent at school as proxies for household investment. A CES production function would impose that these investments can 'make-up' equally for socio-emotional skill and cognitive deficits in the production of socio-emotional skills.

A key interest in estimating Equation 2 is the role of investments. Attanasio et al. (2017) show by using Young Lives data in India that investments are endogenous in the production of skills, and that this endogeneity leads to understating the role of investments in skill production. We do not explicitly account for this endogeneity here, and focus on the relative role of investments in the developmental process as opposed to specific point estimates of its importance. We also bear in mind when interpreting our results that they likely represent underestimates of the impact investments might have.

\footnotetext{
${ }^{4}$ It is possible to include both $\left(\ln H_{s, t} \times \ln I_{t}\right)$ and $\left(\ln H_{s, t} \times \ln I_{t}\right)$ simultaneously. However, in estimating Equation 2 we only include one interaction at a time due to the collinearity between the interaction terms.
} 


\subsection{Socio-emotional Skill and Cognitive Development}

To examine how socio-emotional skill affects cognitive development over childhood and adolescence, we specify the same trans-log functional form as in Equation 2 for cognitive development:

$$
\ln H_{c, t+1}=\rho_{1, t}^{c} \ln H_{c, t}+\rho_{2, t}^{c} \ln H_{s, t}+\alpha_{1, t}^{c} \ln P_{c}+\alpha_{2, t}^{c} \ln P_{s}+\gamma_{t}^{c} \ln I_{t}+\kappa_{t}^{c}\left(\ln H_{j, t} \times \ln I_{t}\right)+\eta_{t}^{c}
$$

In the above equation, all parameters have an identical interpretation to their analogues in Equation 2 and the production shock is again assumed to be mean zero with variance $\sigma_{\eta_{t}^{c}}^{2}$. Of particular interest is the level of cross-productivity between socio-emotional skill and cognition, indicated by the sign and size of $\rho_{2, t}^{c}$. A large, positive value for this coefficient would indicate that socio-emotional skills can have a large influence on cognition, whereas if this parameter close to zero then they have no impact on cognitive development. Given the evidence that cognitive skills are positively associated with a wide range of economic outcomes, estimates of these parameters show the extent to which they can be influenced indirectly through boosting children's socio-emotional skill.

\subsection{Socio-emotional Skill Development in Early Adulthood}

We extend our analysis of socio-emotional skill accumulation beyond adolescence and into early adulthood at $(T+1)$. In our data, this corresponds to age 22 . We treat this period differently to those between $t=0, . ., T$ - covering the ages of 8-19 - given the divergence of circumstances once individuals reach the age of 18 . We extend the model laid out so far in two ways.

First, we depart from discussing socio-emotional skills in the aggregate and assume they develop along different dimensions. As discussed in the Introduction, the survey we are using has been designed precisely for this purpose. Guided by the literature and the data available, we group socio-emotional skills into two dimensions found to be important in determining a range of social and economic outcomes: social skills, and task effectiveness skills. The only study we know of which has attempted to disaggregate skills into multiple dimensions is Glewwe et al. (2017), which extracts two factors for cognitive skills, and three for socio-emotional skills. The measures used are quite different from ours and include internalising and externalising behaviour, self esteem, depression and resilience.

The benefit of this breakdown is threefold. It firstly allows us to understand how specific socioemotional skills which have been shown as important in the labour market are formed over early adulthood. It also allows us to allow for even more flexibility in the production functions we estimate over this period. In addition, although we do not have complete data on labour market outcomes, it also enables us to analyse how these domains are correlated with intermediate outcomes at over the same period. ${ }^{5}$ Doing so with an aggregate index of socio-emotional skill would not allow us to evaluate which of its domains matters and for what. We discuss how this disaggregation allows for additional flexibility when outlining the measurement system in the next subsection. The next section discusses in

${ }^{5}$ There are some measures of labour market outcomes at age 22, however many are either still in education or have not spent a meaningful amount of time in the labour market. 
more detail the measures and framework used to arrive at this disaggregation.

Second, parents can no longer be expected to be the sole 'investors' in children, and experiences at this age diverge considerably - some individuals continue living at home and in full time education, others are working full time either in the world of paid work; are working without pay for their own family; have set up business for themselves; or they are at home either unemployed or raising a family. We therefore do not include an explicit investment input in to the production functions, but rather use their added flexibility at this stage to include aspects of home and labour market experience that might affect the productivity of skill development.

Formally, between $T$ (the terminal period of 'childhood') and $T+1$ (a point in time in early adulthood), we assume that social skills and task effectiveness are formed as a function of both cognition and socio-emotional skill accumulated by the end of adolescence and Total Factor Productivity (TFP), denoted $\ln A_{t}$. That is, for socio-emotional skill $j \in\{s, t\}$, we assume that:

$$
\ln H_{s, T+1}^{j}=\ln A_{T}+\rho_{1, T}^{s, j} \ln H_{s, T}+\rho_{2, T}^{s, j} \ln H_{c, T}+\eta_{T}^{s, j}
$$

The coefficients of the above equation have an identical interpretation to those in Equation 2. The inclusion of the TFP term allows us to capture the productivity of socio-emotional skill accumulation over the period. We define TFP to include:

$$
\ln A_{T}=\ln \left(e^{\alpha_{T}+\mathbf{x}_{T}^{\prime} \boldsymbol{\beta}_{\mathbf{T}}}\right)=\alpha_{T}+\mathbf{x}_{T}^{\prime} \boldsymbol{\beta}_{\mathbf{T}},
$$

where $\mathbf{x}_{T}$ is a vector of characteristics which affect the productivity of skill development over the period and $\alpha_{T}$ represents residual productivity - the extent to which skill production is unexplained by the inputs and characteristics in $\mathbf{x}_{\mathbf{T}}$. As we discussed in outlining the investment equation, we explicitly model time use as a determinant of skill accumulation here, and include the number hours spent studying, doing paid work, caring for household members and engaging in tasks related to home production in $\mathbf{x}_{T}$. It is difficult to specify investments between these ages as "children" have become young adults, and many have moved out of the family home or are financially independent. Keane et al. (2018) evaluate the impact of similar vector of time-use on cognitive development in Ethiopia, Peru, India and Vietnam, finding that, when they crowd out school or study time, time spent on domestic chores and home production negatively impact on cognition up until the age of 19. Given we are concerned with the evolution of "soft skills" of task-effectiveness and social skills, time-use is arguably even more relevant, as time spent working may arguably improve either of these skills.

\subsection{A Measurement System for Unobservables}

The inputs/outputs of the production and investment equations - $H_{k, t}, P_{k}$, and $I_{t}$ - are unobservable. Often, and in the data we use in this paper, there are only various imperfect measures available with which to analyse how they combine in the process of human capital development. Paramater estimates using these raw measures in such an analysis will suffer from bias induced by their measurement error, however. To exploit the multiplicity of measures and circumvent the issue of measurement error, we 
assume that observable variables in the data are a linear combination of measurement parameters, the log of latent variables they aim to measure, and measurement error. This allows us to use covariances between observable measures to estimate the model laid out in this section using only variation in their respective latent variables.

\subsubsection{The Measurement System Over Childhood and Adolescence}

More precisely, for observable measure $Z_{\theta, m, t}$ and unobservable variable $\theta_{t} \in\left\{H_{c, t}, H_{s, t}, P_{c}, P_{s}, I_{t}\right\}_{t=0}^{t=T}$ we assume that

$$
Z_{\theta, m, t}=\mu_{\theta, m, t}+\lambda_{\theta, m, t} \ln \theta_{t}+\varepsilon_{\theta, m, t} \quad m=1, \ldots, M_{\theta},
$$

where $\mu_{\theta, m, t}$ is an intercept, $\lambda_{\theta, m, t}$ a factor loading, and $\varepsilon_{\theta, m, t}$ a measurement error. The factor loading has a similar interpretation to a regression coefficient in that it indicates how movements in $\theta_{t}$ are observed in $Z_{\theta, m, t}$. Since the latent variables have no location or scale, we impose the normalisations $\lambda_{\theta, 1,0}=1$ and that $E\left(\ln \theta_{0}\right)=0$ for each $\theta_{0} \in\left\{H_{c, 0}, H_{s, 0}, P_{c}, P_{s}\right\} .{ }^{6}$ This anchors its location and scale to that or the normalising measure in that a one unit increase in the latent variable is equivalent to a one unit increase in the normalising measure. Commonly, these restrictions are imposed on the measurement system in each period as oppose to only in the initial period (e.g Cunha et al. (2010), Attanasio et al. (2017)), however Agostinelli and Wiswall (2016b) show that doing so can ex-ante restrict the flexibility of the production function and bias estimates of its parameters, and so recent studies have moved away from imposing such restrictions (Attanasio et al., 2020a,b).

Only normalising in the initial period also means that multiple measures are not required to identify the measurement parameters in subsequent periods, and that they can be directly estimated as part of the estimation algorithm (which we outline below). In our setting this result is particularly beneficial since we do not have consistent measures across periods. We therefore assume that our aggregate "bundle" of socio-emotional skill grows across periods but that its location and scale remains anchored to that of the initial normalising measure. ${ }^{7}$ We can then directly estimate the extent to which the measures we have in each period capture this bundle of socio-emotional skills. It does mean, however, that we have to impose restrictions on the production functions in order to identify their parameters in each period. We discuss this in more detail below.

In addition to the normalizations on the initial period measurement system, we also assume full independence of the measurement errors:

(1) across alternative measures at a point in time, $\operatorname{Cov}\left(\varepsilon_{\theta, m, t}, \varepsilon_{\theta, m^{\prime}, t}\right)=0 \forall m^{\prime} \neq m$;

(2) across all measures at all other points in time, $\operatorname{Cov}\left(\varepsilon_{\theta, m, t}, \varepsilon_{\theta, m^{\prime}, t^{\prime}}\right)=0 \forall m^{\prime}$ and $t^{\prime} \neq t$; and

(3) across all latent skills at every point in time, $\operatorname{Cov}\left(\varepsilon_{\theta, m, t}, \theta_{t^{\prime}}^{\prime}\right)=0 \forall \theta^{\prime}$ and $t^{\prime}$.

\footnotetext{
${ }^{6}$ For a given observable measure with known measurement mean and factor loading, there are an infinite number of latent distributions - mean and variance - consistent with observing the distribution of the observed measure. Agostinelli and Wiswall (2016a) refer to this as a problem of location and scale.

${ }^{7}$ We use "anchoring" here in the standard, classical factor analysis sense that normalising ties the location and scale of the latent variable and normalising measure to one another. This is not the same as the practice of anchoring proposed by Cunha et al. (2010), which is intended to link parameter estimates to cardinal, economic outcomes.
} 
These assumptions are stronger than those required to identify the joint distribution of initial conditions, but are exhaustive for consistent estimation of the investment and production function parameters using the methodology we employ, which we outline at the end of this section.

\subsubsection{The Measurement System in Early Adulthood}

At $T+1$ we disaggregate socio-emotional skill into two domains: social skills $(s)$ and task effectiveness $(t)$. We therefore specify a new measurement system for latent stocks of these skills. For each socio-emotional skill $H_{s, T+1}^{j}$ for $j \in\{s, t\}$, we again assume a linear-log relationship between observable measures and latent skill:

$$
Z_{H_{s}^{j}, m, t}=\mu_{H_{s}^{j}, m, T+1}+\lambda_{H_{s}^{j}, m, t} \ln H_{s, T+1}^{j}+\varepsilon_{H_{s}^{j}, m, t} \quad m=1, \ldots, M_{H_{s}^{j}}
$$

To save on notation, we omit the time subscript on stocks of socio-emotional skill $j, H_{s, T+1}^{j}$ when it is used as a subscript. To identify the measurement parameters of observables and the distributions of latent socio-emotional skills, we impose normalizations on this $T+1$ measurement system identical to those imposed on the measurement system in the initial period. For each $H_{s, T+1}^{j}$ we centre their distribution around zero and fix one factor loading to be equal to one. That is, for $j \in\{s, t\}$, we impose $E\left(\ln H_{s, T+1}^{j}\right)=0$ and $\lambda_{H_{s}^{j}, 1, T+1}=1$. This again fixes the location and scale of each domain of socio-emotional skill to that of one of its measures. As we are departing from using an aggregate measure of socio-emotional skill as in the $T$ periods of childhood, these restrictions are normalizations as opposed to re-normalizations that might bias estimates of the production functions (Agostinelli and Wiswall, 2016b).

\subsubsection{Measurement Signal and Noise}

The form of the measurement system in Equation 6 allows us to straightforwardly decompose the variance of the observable measures in to the portions attributable to the unobservables - the signal and to measurement error - the noise. The signal, $s_{\theta, m, t}$, in each latent variable $\left(\theta_{t}\right)$ can be written in terms of the components of Equation 6 as:

$$
s_{\theta, m, t}=\frac{\lambda_{\theta, m, t}^{2} V\left(\ln \theta_{t}\right)}{\lambda_{\theta, m, t}^{2} V\left(\ln \theta_{t}\right)+V\left(\varepsilon_{\theta, m, t}\right)},
$$

with the noise given by $\left(1-s_{\theta, m, t}\right)$. We can estimate both of these measures directly and evaluate how well the observables measure their latent counterparts.

\subsection{Empirical Specification and Estimation}

\subsubsection{Production and Investment Function Restrictions}

We estimate Equations 1, 2, 3 and the measurement system across 3 periods of childhood and adolescence. The starting point of the model, $t=0$, is age 8 , and the three period cover the ages of 8-12, 12-15, and 15-19 respectively. In each of these periods, we restrict both the investment and production 
functions to have constant returns to scale (CRS) which, in Equations 1-2 respectively, requires:

$$
\sum_{i=1}^{5} \beta_{i, t}=1
$$

and

$$
\rho_{1, t}^{k}+\rho_{2, t}^{k}+\alpha_{1, t}^{k}+\alpha_{2, t}^{k}+\kappa_{t}^{k}=1 \quad \text { for } \quad k \in\{s, c\}
$$

This restriction is, in part, imposed by the available data. Relaxing the CRS constraint would require that we either impose restrictions on the measurement parameters or re-normalise the latent variables in each period. The data we use do not contain any measures that satisfy the assumption of age-invariance which Agostinelli and Wiswall (2016a) show is sufficient to relax the CRS assumption, however, and re-normalising in every period would mean repeatedly altering the location and scale of the latent variable. ${ }^{8}$ Agostinelli and Wiswall (2016b) show that this could unnecessarily restrict the production functions and limit our ability to make comparisons over time: our assumption - as outlined in our description of the measurement system - is that an initial bundle of socio-emotional (and cognitive) skill as measured and normalised in the initial period is propagated through the model, and captured by the measures we subsequently have available.

Agostinelli and Wiswall (2016a) are able to relax the CRS assumption due to the presence of an age-invariant measure in their data and find that there returns to scale of cognitive production are different from one only between the ages of 5 and 8 . Between 8 and 12, however, they are unable to reject that it is constant. Attanasio et al. (2020b) use Young Lives data from India in which they also have available an age invariant measure and do not find any evidence that the production functions of health and cognition are not CRS. ${ }^{9}$ If the data we use contained a similar measure of, for example, socio-emotional skill then it would be possible to test whether or not the technology is in fact CRS. Faced with trade-off between imposing re-normalisations on the measurement system or restricting the production functions, and due to our interest in the dynamic relationships between the inputs of the developmental process, we choose the latter.

We then estimate the socio-emotional skill measurement system and Equation 4 in period $T+1$, between the ages of 19-22. Here, as a consequence of the normalizations imposed on latent socioemotional skills, we do not impose the restriction of CRS on the production function and allow its returns to scale to be freely estimated. That is, we only assume:

$$
\mathrm{RTS}=\rho_{1, T}^{s, j}+\rho_{2, T}^{s, j}=k>0
$$

Given the normalizations on the measurement system in this period, we are able to estimate this more general function shown in Equation 4, which also includes a free TFP term. The next subsection

\footnotetext{
${ }^{8}$ Formally, Agostinelli and Wiswall (2016a) define a measure as age-invariant between two points in time if, $\mu_{\theta, m, t}=$ $\mu_{\theta, m, t+1}$ and $\lambda_{\theta, m, t}=\lambda_{\theta, m, t+1}$

${ }^{9}$ They do find that the returns to scale of the cognitive production function was less than one, but conclude that jointly they cannot reject that the process governing the development of health and cognition has CRS. The Indian YL cohort contains the Peabody Picture Vocabulary Test, which Attanasio et al. (2020b) use as age-invariant - at all ages, whereas the older Peruvian cohort only has this measure at ages 12 an 15 .
} 
provides a simple example of our estimation algorithm and the restrictions we impose on the production functions and/or measurement system, and Appendix A outlines in detail its full application.

\subsubsection{Estimating the Model}

We estimate the model from 8 until 22 using an algorithm developed by Agostinelli and Wiswall (2016a), which, in our application, has three main steps:

(1) Estimating the initial period measurement parameters, and the joint distribution of the initial conditions by exploiting the normalisations and covariances in observable measures.

(2) Estimating the first period investment measurement and structural parameters using instrumental variables (IV), with measures of the initial conditions acting as instruments for one another.

(3) Estimating the first period skill measurement and structural parameters using IV, with measures of initial conditions (except resources) and investment acting as instruments for one another.

We then repeat (2) and (3) for periods 2 and 3, and use the same methods to estimate the functions describing the development of social skills and task effectiveness between 19-22. To see how the algorithm works, consider a simplified model with only child and parental stocks of socio-emotional skill, $H_{s, t}$ and $P_{S}$ respectively. With three measures of each, and the normalisations that $E\left(\ln H_{s, 0}\right)=0$, $\lambda_{H_{s, 0}, 1,0}=1$, and $E\left(\ln P_{S}\right)=0, \lambda_{P_{s}, 1,0}=1$ the factor loadings can be recovered as:

$$
\lambda_{\theta, m, 0}=\frac{\operatorname{Cov}\left(Z_{\theta, m, 0}, Z_{\theta, m^{\prime}, 0}\right)}{\operatorname{Cov}\left(Z_{\theta, 1,0}, Z_{\theta, m^{\prime}, 0}\right)}=\frac{\lambda_{\theta, m, 0} \lambda_{\theta, m^{\prime}, 0} \operatorname{Var}(\theta)}{\lambda_{\theta, m^{\prime}, 0} \operatorname{Var}(\theta)} \quad \text { for } \theta \in\left\{H_{s, 0}, P_{s}\right\}
$$

With the factor loadings identified and the scale and location of the latent variables fixed, their joint distribution is identified. We then construct the following residual measures:

$$
\frac{Z_{\theta, m, 0}-\mu_{\theta, m, 0}}{\lambda_{\theta, m, 0}}-\frac{\varepsilon_{\theta, m, 0}}{\lambda_{\theta, m, 0}}=\tilde{Z}_{\theta, m, 0}-\tilde{\varepsilon}_{\theta, m, 0}=\ln \theta_{0} \quad \text { for } \theta \in\left\{H_{s, 0}, P_{s}\right\}
$$

Substituting the investment function into one investment measurement equation, using the above definition of $\ln \theta_{0}$, and re-arranging gives a simple reduced form investment equation:

$$
\begin{gathered}
Z_{I, m, 0}=\mu_{I, m, 0}+\lambda_{I, m, 0}\left(\beta_{1,0} \ln H_{s, t}+\beta_{2,0} P_{s}+\pi_{0}\right)+\varepsilon_{I, m, 0} \\
Z_{I, m, 0}=\mu_{I, m, 0}+\lambda_{I, m, 0}\left(\beta_{1,0}\left(\tilde{Z}_{H_{s}, m, 0}-\tilde{\varepsilon}_{H_{s}, m, 0}\right)+\beta_{2,0}\left(\tilde{Z}_{P_{s}, m, 0}-\tilde{\varepsilon}_{P_{s}, m, 0}\right)+\pi_{t}\right)+\varepsilon_{I, m, 0} \\
Z_{I, m, 0}=\delta_{0,0}+\delta_{1,0} \tilde{Z}_{H_{s}, m, 0}+\delta_{2, t} \tilde{Z}_{P_{s}, m, 0}+\delta_{3, t} \ln Y_{t}+v_{0}
\end{gathered}
$$

where the coefficients $\delta_{i, 0}, i=1,2,3$ are a mixture of the structural investment and measurement parameters, and $v_{0}$ a mixture of the measurement errors and investment shocks: 


$$
\begin{aligned}
\tilde{Z}_{\theta, m, 0} & =\frac{Z_{\theta, m, 0}-\mu_{\theta, m, 0}}{\lambda_{\theta, m, 0}} \text { for } \quad \theta \in\left\{H_{s, 0}, P_{s}\right\} \\
\delta_{0,0} & =\mu_{I, m, 0} \\
\delta_{i, 0} & =\lambda_{I, m, 0} \beta_{i, 0} \quad \text { for } \quad i=1,2,3 \\
v_{0} & =\varepsilon_{I, m, 0}+\lambda_{I, m, 0}\left(\pi_{0}-\beta_{1,0} \tilde{\varepsilon}_{H_{s}, m, 0}-\beta_{2,0} \tilde{\varepsilon}_{P_{s}, m, 0}\right)
\end{aligned}
$$

Given that the residual measures $(\tilde{Z} s)$ are not independent of $v_{0}$, we estimate the parameters of Equation 9 using the alternative measures of socio emotional skills for children and parents as instruments. Under the assumptions that measurement errors are independent of one another and of latent variables, these are valid instruments. The structural parameters can then be recovered using the CRS restriction:

$$
\beta_{i, 0}=\frac{\delta_{i, 0}}{\sum_{i} \delta_{i, 0}}=\frac{\lambda_{I, m, 0} \beta_{i, 0}}{\lambda_{I, m, 0}}
$$

Residual investment measures can then be constructed, and the production function of next periods socio-emotional skill estimated in an identical manner. Using a Cobb-Douglas functional form, its analogous reduced form representation is:

$$
Z_{H_{s}, m, 1}=\tau_{0,0}+\tau_{1,0} \tilde{Z}_{H_{s}, m, 0}+\tau_{2, t} \tilde{Z}_{P_{s}, m, 0}+\tau_{3, t} \tilde{Z}_{I, m, 0}+v_{0}
$$

with

$$
\begin{aligned}
\tau_{0,0} & =\mu_{H_{s}, m, 1} \\
\tau_{1,0} & =\lambda_{H_{s}, m, 1} \rho_{0}^{s} \\
\tau_{2,0} & =\lambda_{H_{s}, m, 1} \alpha_{0}^{s} \\
\tau_{3,0} & =\lambda_{H_{s}, m, 1} \gamma_{0}^{s} \\
v_{0} & =\varepsilon_{H_{s}, m, 1}+\lambda_{H_{s}, m, 1}\left(\eta_{0}^{s}-\rho_{0}^{s} \tilde{\varepsilon}_{H_{s}, m, 0}-\alpha_{0}^{s} \tilde{\varepsilon}_{P_{s}, m, 0}-\gamma_{0}^{s} \tilde{\varepsilon}_{I, m, 0}\right)
\end{aligned}
$$

Again, we estimate the reduced form parameters in Equation 10 using alternative measures of socio-emotional skill and investment, their validity being based on the assumption that measurement errors are fully independent. The structural parameters can again be backed out by using the assumption of CRS: 


$$
\begin{aligned}
& \rho_{0}^{s}=\frac{\tau_{2,0}}{\sum_{i} \tau_{i, 0}}=\frac{\lambda_{H_{1}, m, 1} \rho_{0}^{s}}{\lambda_{H_{1}, m, 1}} \\
& \alpha_{0}^{s}=\frac{\tau_{2,0}}{\sum_{i} \tau_{i, 0}}=\frac{\lambda_{H_{1}, m, 1} \alpha_{0}^{s}}{\lambda_{H_{1}, m, 1}} \\
& \gamma_{0}^{s}=\frac{\tau_{3,0}}{\sum_{i} \tau_{i, 0}}=\frac{\lambda_{H_{1}, m, 1} \gamma_{0}^{s}}{\lambda_{H_{1}, m, 1}}
\end{aligned}
$$

This gives an intuition as to how imposing CRS - and the methodology more generally - facilitates comparisons over time when measures are not consistent and not age-invariant. Intuitively, the restriction scales each of the reduced form parameters by the factor loading of the left-hand-side measure. It is this re-scaling that "adjusts" the reduced form coefficient to remove the effect of having a different scale than the latent variable (which in this first period is defined by the normalising measures). If, however, we had one measure of socio-emotional skill for which we could assume $\mu_{H_{s}, m, 0}=\mu_{H_{s}, m, t}$ and $\lambda_{H_{s}, m, 0}=\lambda_{H_{s}, m, t}$ for all $t>0$, then we could allow the RTS of the socio-emotional skill production function to be free, recovering its structural parameters as, for example,:

$$
\rho_{0}^{s}=\frac{\tau_{1,0}}{\lambda_{H_{s}, m, 0}}=\frac{\lambda_{H_{1}, m, 1} \rho_{0}^{s}}{\lambda_{H_{s}, m, 0}}
$$

This would also allows us to augment the production functions with a TFP term, recovering it as:

$$
\ln A_{t}=\tau_{0,0}-\mu_{H_{1}, m, 0}=\left(\mu_{H_{s}, m, 1}+\ln A_{t}\right)-\mu_{H_{1}, m, 0}
$$

In this case, both the nature of the measure and its presence over time would mean this re-scaling does not require direct estimation of the factor loading and measurement mean, and so no restriction must be made on the parameters of the production function.

In estimating the investment and human capital production functions, a choice must be made as to which measures should be used as lead measures, i.e as outputs and inputs, and which should be used as instruments. We choose to use the measure that shares the the most variation with the unobserved bundle of skills in each period as a lead measure, and instrument it with others. Appendix A provides a full description of the estimation algorithm, and the next section describes the data and measures we use in more detail.

\section{Data and Measures}

In our estimations we use data from the Young Lives (YL) longitudinal survey in Peru. The survey was first administered in 2002 to two cohorts of children: 2,052 aged 1 (the younger cohort) and 714 aged 8 
(the older cohort). ${ }^{10}$ Follow-up surveys have been conducted at ages 5, 8, 12, and 15 for the younger cohort, and 12,15, 19, and 22 for the older cohort. Although the sample is smaller, we use the older cohort due to the fact it covers adolescence and early adulthood and because there are measures of socio-emotional skills available at all ages. To select the children, a multi-stage sampling procedure was used. First, 20 clusters (districts) were selected within the country at random, then, within each cluster, a village/town (or a group of villages/towns) and a group of eligible households within each village/town was chosen at random respectively. The sample is representative of all but those in the top $5 \%$ of the income distribution (Escobal and Flores, 2008). ${ }^{11}$ The survey provides information on a variety of aspects related to child development, including child and maternal indicators of perceptions, attitudes and aspirations, cognitive test scores, child and maternal anthropometric measures, as well as a wide array of information on child, family and other contextual characteristics. Attrition in the older cohort sample ( $14.1 \%$ over 15 years, equivalent to an annual rate of $0.9 \%$ ) is relatively low compared to other longitudinal studies in developing countries. There is evidence that the attrition from the YL survey is not random, with those that remain in the sample more likely to be males, from wealthier households and from urban areas. There is very little evidence, however, that this should induce any bias once household characteristics from the first visit are controlled for (Sánchez and Escobal, 2020).

\subsection{Sample Characteristics}

Table 1 shows the characteristics of the older Peruvian cohort in the baseline survey and in each sample we use to estimate our model. For example, comparing the age 12 to the age 8 column shows how the estimation sample in our first period differs to the baseline sample. Given the samples in columns (2)-(5) are our estimation samples, they exclude children with any missing values for the measures we use in these estimations. As mentioned above, attrition is very low in the YL sample so the vast majority of differences in sample sizes across columns comes from missing answers to questions we use in our analysis. One thing to note in the baseline sample (column (1)) is the large mean and standard deviation of household income. This is due to the presence of one large, outlying value. Given that we use monetary measures as proxies for investments, we exclude this one observation from our main analysis so it does not skew our results. For this reason, columns (2) -(5) of Table 1, which contains descriptive statistics on the samples used in our estimations, have significantly lower mean incomes which are much closer to the median. In practice, our results are not change qualitatively by this exclusion.

\subsection{Specifying the Measurement System for Unobservables}

In each of its waves, the Young Lives survey has detailed information on the developmental, economic, and family circumstances of children. An important feature of the measurement system laid out in Section 2 is that it is dedicated - it assumes that observables measure only one latent variable. Given the multi-dimensional nature of socio-emotional skills, and the different measures of its constituents

\footnotetext{
${ }^{10}$ The survey has also been carried out in Ethiopia, India, and Vietnam. As in Peru the younger cohort samples are 2000 in each country, however with 1000 participants the older cohort is slightly larger than in Peru.

${ }^{11}$ There were around 1,818 districts in Peru in 2002. From them, the wealthiest $5 \%$ was excluded using information from the Peru Map of Poverty from year 2000.
} 
Table 1: Sample characteristics in the age 8 baseline and estimation samples

\begin{tabular}{|c|c|c|c|c|c|}
\hline & $\begin{array}{c}(1) \\
\text { Age } 8\end{array}$ & $\begin{array}{c}(2) \\
\text { Age } 12\end{array}$ & $\begin{array}{c}(3) \\
\text { Age } 15\end{array}$ & $\begin{array}{c}(4) \\
\text { Age } 19\end{array}$ & $\begin{array}{c}(5) \\
\text { Age } 22\end{array}$ \\
\hline Wealth index & $\begin{array}{c}0.47 \\
(0.23)\end{array}$ & $\begin{array}{c}0.52 \\
(0.22)\end{array}$ & $\begin{array}{c}0.58 \\
(0.18)\end{array}$ & $\begin{array}{c}0.64 \\
(0.16)\end{array}$ & $\begin{array}{c}0.67 \\
(0.14)\end{array}$ \\
\hline $\begin{array}{l}\text { Household income (USD) } \\
\text { s.d } \\
\text { Median }\end{array}$ & $\begin{array}{c}434 \\
(4,937) \\
160\end{array}$ & $\begin{array}{c}284 \\
(290) \\
220\end{array}$ & $\begin{array}{c}344 \\
(507) \\
239\end{array}$ & & \\
\hline Female caregiver & 0.97 & 0.98 & 0.96 & . & . \\
\hline Female cohort member & 0.46 & 0.46 & 0.47 & 0.47 & 0.48 \\
\hline \multicolumn{6}{|l|}{ Caregiver's education } \\
\hline None & 0.13 & 0.12 & 0.11 & . & . \\
\hline Primary & 0.38 & 0.38 & 0.37 & . & . \\
\hline Secondary & 0.37 & 0.38 & 0.38 & . & . \\
\hline Technical/Vocational & 0.09 & 0.09 & 0.10 & . & . \\
\hline University & 0.02 & 0.03 & 0.03 & . & . \\
\hline Adult literacy & 0.00 & 0.00 & 0.01 & . & . \\
\hline \multicolumn{6}{|l|}{ Dependent children } \\
\hline None & 0.09 & 0.12 & 0.18 & 0.26 & 0.30 \\
\hline One & 0.32 & 0.33 & 0.31 & 0.35 & 0.39 \\
\hline Between 2 and 4 & 0.51 & 0.50 & 0.47 & 0.37 & 0.30 \\
\hline More than 5 & 0.08 & 0.04 & 0.03 & 0.02 & 0.01 \\
\hline \multicolumn{6}{|l|}{ Language } \\
\hline Spanish & 0.88 & 0.90 & 0.88 & 0.90 & 0.90 \\
\hline Quechua & 0.10 & 0.08 & 0.10 & 0.09 & 0.09 \\
\hline Other & 0.00 & 0.00 & 0.00 & 0.00 & 0.00 \\
\hline $\mathrm{N}$ & 714 & 606 & 607 & 571 & 550 \\
\hline
\end{tabular}

Notes: All numbers are proportions. The sex, education, and age of the caregiver were not recorded at age 19 or 22, nor was the income of the cohort member's household. Dependent children refers to the number of children aged between 0 and 17 years in the household of the cohort member. Standard errors for the mean wealth index and household income are in parentheses. For household income, the median value is also shown below the mean and its standard deviation.

in the YL data, we first verify this structure by using an Exploratory Factor Analysis and drawing on measures that satisfy the properties of Core Self Evaluation (CSE).

In the case of socio-emotional skill measures, we first excluded those which could be viewed as measuring some dimension of socio-emotional skill, but that relied on the evaluation of external circumstances or other people as opposed to the children/adolescents themselves. For example, the data contains a measure of trust, however the items of which it comprises ask children about whether or not 
"Most people in the community are honest", or whether they "believe the government does what is right for people like me". We then ensured the remaining observables shared enough variation with which to back out the latent variables. Finally, we grouped measures into those of children's human capital, endowments, and investments and excluded those that loaded heavily on more than on factor, or on the "wrong" factor based on our ex-ante belief about the measure. For example, if a socio-emotional measure loaded heavily on latent cognition it was excluded from our analysis. Below we list the measures of socio-emotional skill, cognition, investments, and endowments we use to estimate the model outlined in Section 2. Appendix B describes the YL socio-emotional measures in full, and Appendix $\mathrm{C}$ shows the results of the EFA and discusses in more detail how we narrowed measures to the subset used in our analysis.

Socio-emotional skills: In the initial period, $t=0$, we use five measures from the Child Strengths and Difficulties (SDQ) questionnaire on children's conduct, emotional regulation, hyperactivity, relationships with peers and their social skills. The questions that make up the SDQ are administered to the children's caregiver, and are centered on discerning the number of symptoms of, for example, hyperactivity they display. Similar behavioural indices to these have often been used to identify bundles of early socio-emotional skill (e.g Cunha et al. (2010), Attanasio et al. (2020a)). Thereafter, however, these behavioural indices are not available, and we use some combination of measures of children's agency, pride, self-efficacy and self-esteem. All of these measures are calculated from children's responses to questions regarding their degree of agreement or disagreement to a number of statements using Likert scales. Prior to its administration, these instruments were piloted and, where necessary, adapted to the local context to they were understood by children (Yorke and Ogando, 2018).

Treating socio-emotional skill as an aggregate in periods $1-3$, covering the ages of $8-19$, is a constraint imposed mainly by the data as opposed to representing an explicit assumption regarding the dimensionality of socio-emotional skills over this period. This is very similar to many papers in the literature. The majority of the socio-emotional assessments in the YL data are not administered in the initial wave of the YL survey, nor are there multiple measures of particular domains until age 22. As a result, we cannot disaggregate socio-emotional skills until the final period of our model at age 22. At this age we use three measures of each of children's social skills, two of which are sub-scales of the ROPELOC self-evaluation (Richards et al., 2002) scale measuring leadership and teamwork, and one from the Marsh Self-Description Questionnaire Yorke and Ogando (2018) assessing relationships with peers. Task effectiveness skills comprise agency, grit, conscientiousness, emotional stability.

Cognitive skills: For cognitive skill in the initial period we use children's score on a series of Ravens progressive matrices alongside measures of the child's general writing and reading level as assessed through various other assessments. In the periods thereafter, we use combinations of scores on maths and language tests administered as part of the YL survey, and the Peabody Picture Vocabulary Test (PPVT) to measure cognitive skill. Appendix B provides detailed information on the cognitive assessments administered as part of the the Young Lives survey that we use.

Investments: As measures of latent investment, we use caregivers' responses to a number of questions about the material and time investments made in children's development. We use measures of expenditure on books, uniforms and food per child in the household alongside those of the time children 
spend in school and studying. In using hours of schooling and study we assume that caregivers have an important role in determining how time is allocated to these activities. Again, Appendix B describes all the measures considered and Appendix $\mathrm{C}$ describes how they were reduced to a subset for analysis.

Parental human capital: As measures of cognitive endowments, we use the level of education of the caregiver, an assessment of their ability to understand text written in their native language, and a measure of the degree of difficulty they have reading in general. For socio-emotional skill of the caregiver, we use their responses to questions about their agency, pride and a subjective evaluation of their life circumstances. We use the caregiver as opposed to the mother's and/or father's information for two reasons. Firstly, doing so allows to make use of as much of the sample as possible - for 5\% of children their caregiver is not a biological parent. Secondly, measures of socio-emotional skill are available only for the household member recorded as the caregiver, not the parents separately.

Family resources: The YL survey contains household income information for the older Peruvian cohort up until age 15 . We use family income as a measure of family resources up until this age. Given there is no information on household income available at age 19, we use the YL wealth index as a measure of family resources at that age. This is a measure of the material resources of the family which ranges from 0 to 1 , and is constructed as the average of three sub-indices measuring housing quality, access to services and ownership of a range of durable goods. Briones (2017) describes the construction of the YL wealth index in detail.

\subsection{Observable Skill Gradients}

Our main interest is the process of human capital development as it relates to the emergence of skill inequalities and the intergenerational transmission of disadvantage. To first look at this question descriptively, we correlate observable measures of socio-emotional skill with the available measures of the economic wellbeing of the YL children. Figure 1 shows the raw correlation between the five available measures of socio-emotional skill at the baseline survey - the SDQ measures of conducts problems, emotional instability, difficulty with peers, prosociality, and hyperactivity - and household wealth. The scale of all of these measures except for prosociality (which is already, in theory, a positive measure) have been reversed to be positive so a higher value means more "skill". Of the five measures, there only appears to be a somewhat moderate positive relationship between the number of symptoms of emotional instability a child displays and wealth. For the other measures their correlation with wealth is very close to zero. As proxied by these measures then, it appears as though there is only a small gradient in children's socio-emotional skill across the distribution of wealth at age 8 .

Figure 2 shows analogous plots, correlating the socio-emotional skill measures we use at age 19 agency, self-efficacy and self-esteem - with wealth at age 8. ${ }^{12}$ Across the measures there is evidence of a moderate, positive relationship with family wealth. The measure of self-esteem has the smallest correlation with wealth at 0.13 , whereas both agency and self-efficacy have a correlation of around 0.25. The consistent positive correlation across measures suggests that a wealth gradient in socio-emotional skill exists at the end of adolescence. Given that the relationship appears to be stronger than at age 8 ,

\footnotetext{
${ }^{12}$ We use wealth at age 8 for comparability and to focus on the correlation between earlier conditions and later skills skills. Using wealth at age 19 does not in fact alter the results as wealth is persistent across rounds of the YL survey.
} 
Figure 1: Socio-emotional skill measures and household wealth at baseline (Age 8)
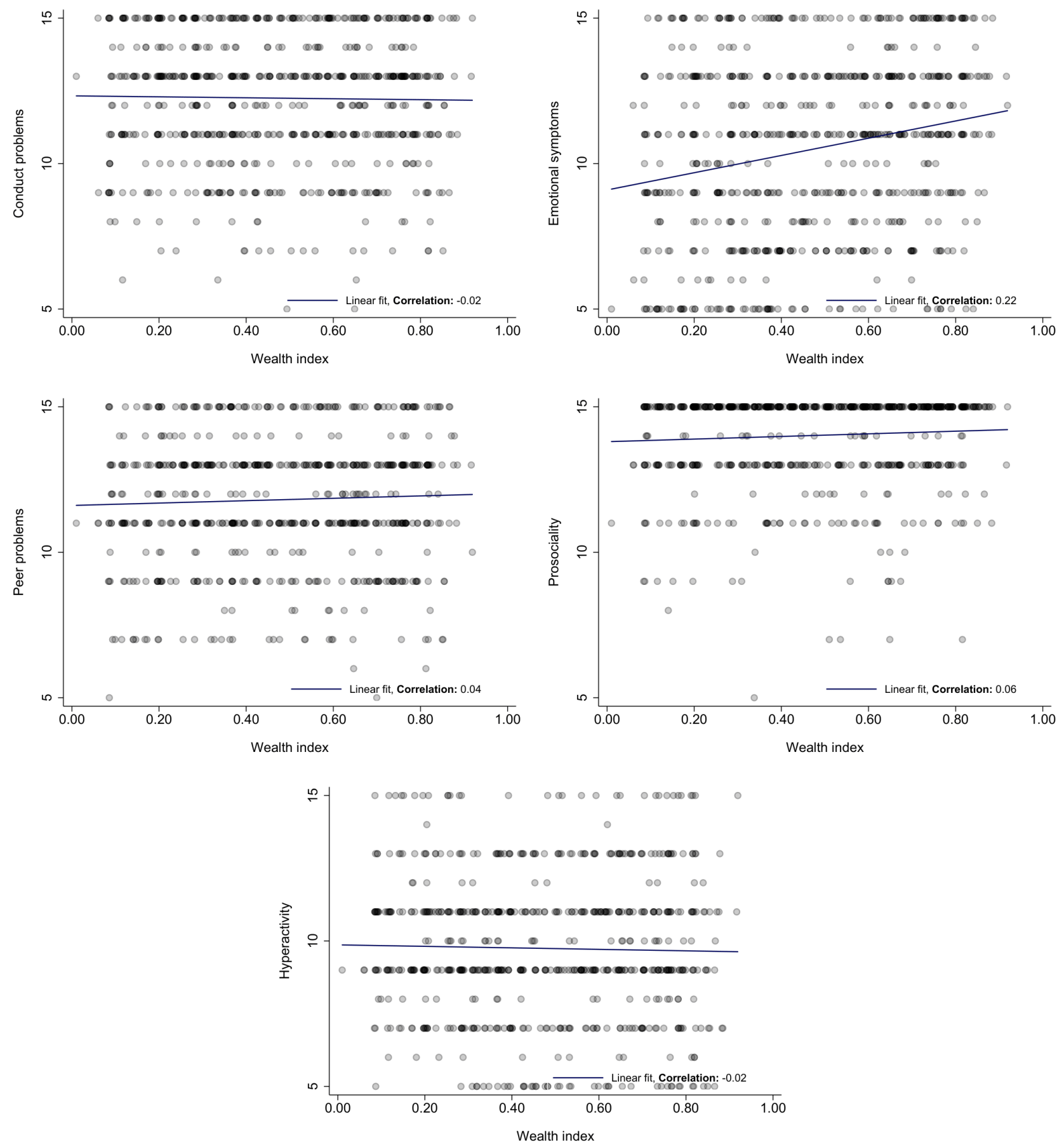

Note: The measures used are part of the Strengths and Difficulties Questionnaire, described in Subsection 3.2 and Appendix B. The scale of all measures except prosociality have been reversed so a higher value indicates more "skill". The wealth index is constructed to range between 0 and 1 and is an average of three subindices: housing quality, access to services, and ownership of certain consumer durables. See Briones (2017) for further details. 
there is - at least descriptively - evidence that small gradients apparent in childhood widen over time. The gradients in measures of socio-emotional skills show similar correlations with wealth at age 8 (Appendix Figures C1 and C2).

Figure 2: The correlation between socio-emotional skill measures at 19 and initial (age 8) household wealth
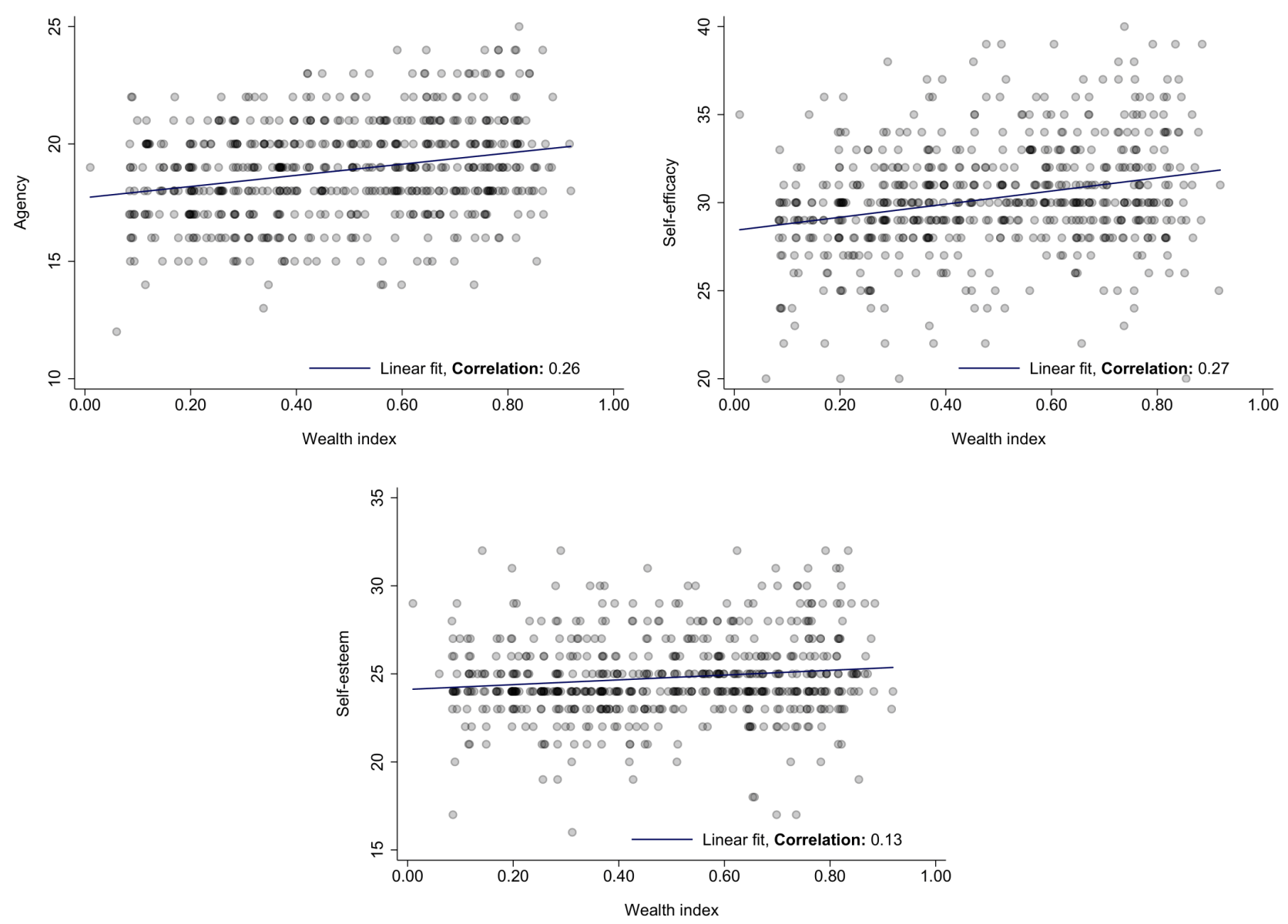

Note: The measures of, clockwise from top left, agency, self-efficacy and self-esteem are described in detail in Appendix B. The wealth index is constructed to range between 0 and 1 and is an average of three subindices: housing quality, access to services, and ownership of certain consumer durables. See Briones (2017) for further details. 
One of the drawbacks in a descriptive analysis of this nature is that it relies on comparing different measures of aggregate socio-emotional skill over time. From a survey design perspective, this is mainly due to the fact it is often deemed unsuitable to assess certain socio-emotional skills in children at particular ages. For example, it would perhaps make little sense to try and assess the (self-reported) generalised self-efficacy of an 8 year old, or to ascertain the strength of the relationships with their peers. Likewise, it might not be suitable to continue to ask parents about the conduct and hyperactivity of their children when they are aged 19.

Over and above the problems in comparing mis-measured proxies, this adds another complication in descriptively interpreting how socio-emotional skill develops over time. Here, we interpret the descriptive results at a high-level, and, in estimating the model laid out in Section 2, we aim to understand in more detail if and how skill gradients emerge. The availability of different measures across periods is much less of a concern in this analysis given the normalisations on the measurement system, the estimation method we use, and our focus on the development of a composite (or aggregate) measure of socio-emotional skill over childhood.

In Appendix Figure C3 we also show that there is a moderate, positive correlation between the baseline measures of cognitive skill and family resources. Children's level of writing and reading as well as their score in the Ravens math test at age 8 all appear to be increasing with the level of household wealth as measured in the YL. It also appears that the relationship between the cognitive measures and wealth is stronger than in the case of baseline socio-emotional skill measures.

\section{Results}

\subsection{Measurement System}

Table 2 shows the estimated socio-emotional skill measurement parameters and the proportion of variance in each measure attributable to signal and noise. It shows that there is heterogeneity in the extent to which observable measures capture variation in latent aggregate socio-emotional skill, both across and within the four periods. For example, in the initial period, at age 8, a reasonable portion of the variance in all five measures is explained by variation in latent socio-emotional skill: three measures are estimated to have roughly a third of their variance attributable to latent skill, and all more than $10 \%$. In the next period, however, the measure of pride has a signal of $87 \%$, compared with a signal of $1.3 \%$ in agency. Both social skills and task effectiveness appear to be well measured by observables in period 4 , with no measure sharing less than roughly a fifth of its variance with its respective unobservable. This highlights the importance of using a latent factor structure to estimate the skill production functions: using raw measures as inputs/outputs of the production (and investment) functions would mean estimating their parameters without adjusting for bias induced by measurement error.

Section 2 highlighted that the estimation algorithm we use requires selecting "lead" measures of skill to be used as inputs/outputs of the investment and production equations, while others are used as instruments. Although this was partly determined by our EFA of the measures (outlined in Appendix 
C, Table C4) Table 2 confirms our selections - in periods 1 and 2 we used pride $\&$ self esteem as lead measures and in period 3 agency. In estimating the investment production functions we exploit only the signal in each observable measure, however there would be efficiency gains if measures consistently shared, for example, two thirds of their variance with latent skill. This has direct implications for the precision of our parameter estimates during periods in which measures are noisy - if observable measures have little shared variation attributable to latent socio-emotional skill, our estimates of the production and investment parameters will imprecise. Given that we use an IV strategy to estimate the production and investment functions, measures having little shared variation - and so being weak instruments - also has implications for consistency. In period 2, for example, the measure of children's agency is used as an instrument, and shares only $1 \%$ of its variation with latent skill. In all other periods, the relationship between latent skills and measures appears sufficiently strong.

Table 2: Measurement parameters associated with observable socio-emotional skill

\begin{tabular}{|c|c|c|c|c|}
\hline & $\mu_{\theta, m, t}$ & $\lambda_{\theta, m, t}$ & $s_{\theta, m, t}$ & $1-s_{\theta, m, t}$ \\
\hline \multicolumn{5}{|c|}{ Initial (age 8) socio-emotional skill } \\
\hline SDQ conduct problems* & 12.263 & 1.000 & 0.363 & 0.637 \\
\hline SDQ emotional symptoms* & 10.513 & 1.326 & 0.329 & 0.671 \\
\hline SDQ hyperactivity* & 9.752 & 1.070 & 0.333 & 0.667 \\
\hline SDQ peer problems* & 11.815 & 0.788 & 0.225 & 0.775 \\
\hline SDQ peer pro-sociality & 14.013 & 0.387 & 0.105 & 0.895 \\
\hline \multicolumn{5}{|l|}{ Period 1 (age 12) } \\
\hline Agency & 6.991 & 0.032 & 0.013 & 0.987 \\
\hline Pride \& self-esteem & 11.906 & 1.244 & 0.865 & 0.135 \\
\hline \multicolumn{5}{|l|}{ Period 2 (age 15) } \\
\hline Agency & 17.920 & 0.316 & 0.212 & 0.788 \\
\hline Pride \& self-esteem & 22.112 & 0.280 & 0.263 & 0.737 \\
\hline \multicolumn{5}{|l|}{ Period 3 (age 19) } \\
\hline Agency & 18.357 & 1.160 & 0.479 & 0.521 \\
\hline Self-esteem & 30.342 & 1.243 & 0.193 & 0.807 \\
\hline Self-efficacy & 24.841 & 0.234 & 0.042 & 0.958 \\
\hline \multicolumn{5}{|l|}{ Period 4 (age 22) social skills } \\
\hline Leader & 9.586 & 1.000 & 0.374 & 0.626 \\
\hline Peers & 9.228 & 1.340 & 0.562 & 0.438 \\
\hline Teamwork & 22.921 & 2.427 & 0.310 & 0.690 \\
\hline \multicolumn{5}{|c|}{ Period 4 (age 22) task effectiveness } \\
\hline Agency & 16.181 & 1.000 & 0.189 & 0.811 \\
\hline Grit & 27.393 & 2.095 & 0.640 & 0.360 \\
\hline Conscientiousness & 25.428 & 1.517 & 0.292 & 0.708 \\
\hline Emotional stability & 33.064 & 1.504 & 0.416 & 0.584 \\
\hline
\end{tabular}

Note:* indicates negative measures that were reversed so a higher value represented a higher level of skill. The initial and periods 1-4 represent ages 8, 12, 15, 19, and 22 respectively. From left to right the columns represent the observable measure and its estimated mean, factor loading, signal, and noise respectively. All parameters are estimated as outline in Appendix A.

Table 3 shows the measurement parameters and signal/noise proportions associated with measures 
of cognitive skill, parental human capital and investments. Again, the Table shows the extent to which observable measures share variance with their respective latent variable varies both within and across periods. Measures of cognitive skill - for both the child and caregiver - tend to have relatively large portions of their variance explained by latent cognition. There are larger differences in signal across measures for investments parental socio-emotional skill, however, again highlighting the importance of accounting for measurement error in observable measures. 
Table 3: Measurement parameters associated with observable cognitive skill, parental human capital and investment

\begin{tabular}{|c|c|c|c|c|}
\hline & $\mu_{\theta, m, t}$ & $\lambda_{\theta, m, t}$ & $s_{\theta, m, t}$ & $1-s_{\theta, m, t}$ \\
\hline \multicolumn{5}{|l|}{ Initial (age 8) cognitive skill } \\
\hline Ravens test score & 20.822 & 1.000 & 0.135 & 0.865 \\
\hline Writing level & 2.418 & 0.190 & 0.631 & 0.369 \\
\hline Reading level & 3.582 & 0.236 & 0.521 & 0.479 \\
\hline \multicolumn{5}{|l|}{ Period 1 (age 12) } \\
\hline PPVT score & 72.729 & 9.026 & 0.583 & 0.417 \\
\hline Writing level & 2.840 & 0.132 & 0.251 & 0.749 \\
\hline Reading level & 3.938 & 0.098 & 0.167 & 0.833 \\
\hline Maths test score & 5.742 & 1.062 & 0.620 & 0.380 \\
\hline \multicolumn{5}{|l|}{ Period 2 (age 15) } \\
\hline PPVT score & 97.137 & 16.289 & 0.656 & 0.344 \\
\hline Cloze language test score & 14.749 & 4.282 & 0.562 & 0.438 \\
\hline Maths test score & 13.764 & 4.658 & 0.490 & 0.510 \\
\hline \multicolumn{5}{|l|}{ Period 3 (age 19) } \\
\hline Language test score & 67.531 & 15.351 & 0.751 & 0.249 \\
\hline Maths test score & 59.656 & 17.959 & 0.659 & 0.341 \\
\hline \multicolumn{5}{|c|}{ Parental socio-emotional skill } \\
\hline Agency & 12.974 & 1.000 & 0.079 & 0.921 \\
\hline Pride & 8.297 & 1.214 & 0.375 & 0.625 \\
\hline Subjective wellbeing & 4.848 & 0.961 & 0.072 & 0.928 \\
\hline \multicolumn{5}{|l|}{ Parental cognitive skill } \\
\hline Caregiver's education & 7.251 & 1.000 & 0.533 & 0.467 \\
\hline Literacy (first language) & 2.502 & 0.198 & 0.693 & 0.307 \\
\hline Understands paper & 2.604 & 0.163 & 0.571 & 0.429 \\
\hline \multicolumn{5}{|l|}{ Period 1 (age 12) investment } \\
\hline No. food groups consumed & 21.569 & 2.702 & 0.433 & 0.567 \\
\hline School uniform expenditure & 62.311 & 66.103 & 0.150 & 0.850 \\
\hline Hours at school & 4.741 & 0.597 & 0.168 & 0.832 \\
\hline Hours studying & 2.857 & 0.197 & 0.032 & 0.968 \\
\hline Book expenditure & 127.540 & 98.787 & 0.117 & 0.883 \\
\hline \multicolumn{5}{|l|}{ Period 2 (age 15) } \\
\hline No. food groups consumed & 24.000 & 3.465 & 0.332 & 0.668 \\
\hline School uniform expenditure & 186.408 & 84.414 & 0.209 & 0.791 \\
\hline Hours at school & 6.514 & 1.233 & 0.199 & 0.801 \\
\hline Hours studying & 2.523 & 0.946 & 0.278 & 0.722 \\
\hline Book expenditure & 216.107 & 129.214 & 0.227 & 0.773 \\
\hline \multicolumn{5}{|l|}{ Period 3 (age 19) } \\
\hline Hours at school & 3.587 & 1.507 & 0.323 & 0.677 \\
\hline Hours studying & 1.403 & 0.754 & 0.236 & 0.764 \\
\hline No. food groups consumed & 8.496 & -0.237 & 0.015 & 0.985 \\
\hline Non-food expenditure & 616.067 & 250.154 & 0.026 & 0.974 \\
\hline Education expenditure & 728.966 & 615.501 & 0.239 & 0.761 \\
\hline
\end{tabular}

Note: Parental human capital is assumed to be time invariant so are measured at only one point in time. From left to right the columns represent the observable measure and its estimated mean, factor loading, signal, and noise respectively. All parameters are estimated as outlined in Appendix A. All expenditure variables are per dependent child in the household. 


\subsection{The Determinants of Investment}

Table 4 shows the estimates of our investment function parameters through childhood and adolescence. There is no strong evidence of reinforcement or compensation at any stage. Although there is a compensatory effect with respect to cognition in the first period, its $90 \%$ confidence interval marginally covers zero and so we fail to reject that it is equal to zero. The elasticities of investment with respect to cognitive and socio-emotional skill are small and are not statistically different from zero in any other period. It therefore appears that in our sample, parents do not invest in response to revealed human capital. This is broadly in line with findings in studies in similar settings, where there is limited evidence of household investment responding to child stocks of human capital. Attanasio et al. (2017, 2020a,b) find some evidence of investments' responsiveness to cognitive skill in childhood, but very little of any parental response to revealed health or socio-emotional capital. Whilst Attanasio et al. $(2020 \mathrm{a}, \mathrm{b})$ focus mostly on earlier periods of childhood (until 12 and 4 years respectively), the results of Attanasio et al. (2017), who estimate investment functions up until the age of 15, overlap with the analysis in our earlier periods.

We do find that parental socio-emotional skill has a large impact on parental investment behaviours, particularly between the ages of 8-12 and 12-15. Their effect is similarly large but not statistically different from zero between the ages of 15-19. Although using data from the US, Agostinelli and Wiswall (2016a) find similarly large impacts on investment of parents' socio-emotional relative to cognitive skill, whereas Attanasio et al. (2020a) find the reverse in Colombia albeit at much younger ages. Family resources are estimated to strongly determine investments to an increasing degree in each period. ${ }^{13}$ We also find that the variance of the production shock is decreasing over time, suggesting that in later adolescence, there are fewer external factors over and above income (and the other inputs) that explain household investments.

\subsection{Skill Production in Childhood and Adolescence}

We first present estimates of restricted Cobb-Douglas production functions for both socio-emotional and cognitive skill. In terms of Equations 2 and 3, this means estimating the production functions excluding the interaction of investments with human capital. We then estimate versions of the production function with interactions between skills and investment in order to test whether or not any complementarities exist between them.

\section{Socio-emotional skill}

In table 5 we show estimates of the Cobb-Douglas production function for socio-emotional skill up to age 19. First focusing on the role of lagged human capital, we find some evidence of self-productivity in late childhood, between 15-19, but not in the earliest stage. We also find evidence of cross-productivity between cognitive skill and socio-emotional skill in all periods, however in period two, when it is at its

\footnotetext{
${ }^{13}$ In the last period we use a wealth index, not family income, as a proxy for family resources. This is because Family income is not available for age 19 in the YL survey. We use income in the first two rounds due to its ease with which its elasticity can be interpreted. Using the wealth index in each period does not change the results of Table 4 qualitatively.
} 
Table 4: Estimates of investment function parameters

\begin{tabular}{cccc}
\hline & $\begin{array}{c}\text { Period 1 } \\
\text { Ages 8-12 }\end{array}$ & $\begin{array}{c}\text { Period 2 } \\
\text { Ages 12-15 }\end{array}$ & $\begin{array}{c}\text { Period 3 } \\
\text { Ages 15-19 }\end{array}$ \\
\hline Lagged human capital & & & \\
$\ln H_{s, t-1}$ & -0.023 & 0.028 & -0.017 \\
& $(0.097)$ & $(0.193)$ & $(0.026)$ \\
& {$[-0.183,0.137]$} & {$[-0.290,0.345]$} & {$[-0.061,0.026]$} \\
$\ln H_{c, t-1}$ & 0.110 & 0.027 & -0.021 \\
& $(0.077)$ & $(0.132)$ & $(0.275)$ \\
Parental human capital (fixed over time) & {$[-0.017,0.238]$} & {$[-0.190,0.245]$} & {$[-0.474,0.432]$} \\
$\ln P_{s}$ & & & -0.022 \\
& $0.563^{* *}$ & $0.398^{*}$ & $(0.212)$ \\
$\ln P_{c}$ & $(0.241)$ & $(0.220)$ & {$[-0.371,0.327]$} \\
& {$[0.166,0.960]$} & {$[0.035,0.761]$} & 0.069 \\
Resources & -0.019 & 0.002 & $(0.067)$ \\
$\ln Y_{t}$ & $(0.064)$ & $(0.039)$ & {$[-0.041,0.180]$} \\
& {$[-0.124,0.087]$} & {$[-0.061,0.066]$} & \\
\hline$\sigma_{\pi_{c}}^{2}$ & & & $0.991^{* * *}$ \\
\hline
\end{tabular}

Notes: Standard errors are in parentheses and $90 \%$ confidence intervals are in square brackets. Both are calculated using the delta method. $t-1=$ ages 8,12 , and 19 for the three columns respectively. The output in each column is investment. The inputs in the left column are are lagged child socio-emotional skill and cognitive skill; parental socio-emotional and cognitive skill; and family income, respectively. In period 3 (ages 15-19) the we use the YL wealth index as a proxy for family income as this information is not available. The wealth index is a measure of the material resources of the family which ranges from 0 to 1 , and is constructed as the average of three sub-indices measuring housing quality, access to services and ownership of a range of durable goods. See Briones (2017) for detail. All inputs except of family income are treated as unobservable. The observables used as measures of each and their associated measurement parameters estimated from the measurement system outlined in Section 3 are provided in Appendix B. 
largest, then it is estimated imprecisely. Although smaller in magnitude in the first period, cognition plays an important role on the development of socio-emotional skill given there is no evidence of self-productivity in this period. Together, these results suggest that cognition is a key actor in the development of socio-emotional skill across childhood. These findings are similar to those of Helmers and Patnam (2011), who use YL data from India for ages 8 to 12 and find cognitive skills to influence socio-emotional skill accumulation to a greater extent than lagged stocks of themselves. However, they contrast slightly with Cunha et al. (2010), who use data from the US and find socio-emotional skill to be unaffected by cognitive skill in both early and late childhood, and to be increasingly self-productive over time between the birth and the age of 14 .

Table 5: Estimates of Cobb-Douglas socio-emotional production function parameters

\begin{tabular}{|c|c|c|c|}
\hline & $\begin{array}{c}\text { Period } 1 \\
\text { Ages } 8-12\end{array}$ & $\begin{array}{c}\text { Period } 2 \\
\text { Ages } 12-15\end{array}$ & $\begin{array}{c}\text { Period } 3 \\
\text { Ages 15-19 }\end{array}$ \\
\hline \multicolumn{4}{|c|}{ Lagged human capital } \\
\hline $\ln H_{s, t-1}$ & $\begin{array}{c}-0.062 \\
(0.084) \\
{[-0.200,0.077]}\end{array}$ & $\begin{array}{c}0.028 \\
(0.844) \\
{[-1.360,1.415]}\end{array}$ & $\begin{array}{c}0.073^{* * *} \\
(0.024) \\
{[0.034,0.112]}\end{array}$ \\
\hline $\ln H_{c, t-1}$ & $\begin{array}{c}0.233^{* *} \\
(0.114) \\
{[0.046,0.421]}\end{array}$ & $\begin{array}{c}0.818 \\
(0.745) \\
{[-0.407,2.044]}\end{array}$ & $\begin{array}{c}0.705^{\text {*** }} \\
(0.207) \\
{[0.365,1.046]}\end{array}$ \\
\hline \multicolumn{4}{|c|}{ Parental human capital (fixed over time) } \\
\hline $\ln P_{s}$ & $\begin{array}{c}0.577^{* * *} \\
(0.147) \\
{[0.335,0.820]}\end{array}$ & $\begin{array}{c}-0.187 \\
(1.041) \\
{[-1.900,1.525]}\end{array}$ & $\begin{array}{c}0.091 \\
(0.193) \\
{[-0.226,0.408]}\end{array}$ \\
\hline $\ln P_{c}$ & $\begin{array}{c}0.039 \\
(0.076) \\
{[-0.086,0.164]}\end{array}$ & $\begin{array}{c}0.104 \\
(0.201) \\
{[-0.226,0.434]}\end{array}$ & $\begin{array}{c}-0.068^{*} \\
(0.041) \\
{[-0.136,-0.001]}\end{array}$ \\
\hline \multicolumn{4}{|l|}{ Investments } \\
\hline $\ln I_{t-1}$ & $\begin{array}{c}0.212^{* * *} \\
(0.076) \\
{[0.087,0.338]}\end{array}$ & $\begin{array}{c}0.237 \\
(0.379) \\
{[-0.386,0.861]}\end{array}$ & $\begin{array}{c}0.199 \\
(0.129) \\
{[-0.013,0.410]}\end{array}$ \\
\hline $\begin{array}{l}\sigma_{\eta_{n}}^{2} \\
\mathrm{~N}\end{array}$ & $\begin{array}{l}1.5 \\
601\end{array}$ & $\begin{array}{l}13.9 \\
600\end{array}$ & $\begin{array}{l}.833 \\
565\end{array}$ \\
\hline
\end{tabular}

Notes: Standard errors are in parentheses, and $90 \%$ confidence intervals are in square brackets. Both are calculated using the delta method. $t-1=$ ages $8,12,15$, and 19 for the three columns respectively. The output in each column is socio-emotional skill. The inputs in the left column are are lagged child socio-emotional skill and cognitive skill; parental socio-emotional and cognitive skill; and investment. All inputs are treated as unobservable. The observables used as measures of each and their associated measurement parameters estimated from the measurement system outlined in Section 3 are provided in Appendix B.

It should be noted that Cunha et al. (2010) study human capital development in a sample of children in the US, whereas our sample is from Peru, a developing country. Given that, to our knowledge, there are no other studies that estimate socio-emotional production functions over an extended period similar to our study (Helmers and Patnam (2011) analysis overlaps only with period 1 in our model), it is conceivable that the developmental process differs in these two settings due to country and/or sample 
specific factors. It should also be considered throughout this section that Cunha et al. (2010), and indeed all other similar studies, do not necessarily use measures that identify an identical composite socio-emotional skill as here.

Moving to the role of parental human capital, there is not consistent evidence of their influence on socio-emotional development other than in the first period, between the ages of 8-12. We estimate that parents' cognitive skill has little effect on on the production of socio-emotional skill except in the last period, between 15-19, where it is estimated they have a small negative impact on skills. In the first period, between 8-12, children's skill is highly malleable with respect to parental socio-emotional skill - its corresponding elasticity is estimated to be 0.58 . The results in Table 5 also show that investments strongly, positively affect socio-emotional skill in all periods to roughly the same extent - the estimated elasticities are $0.21,0.24$, and 0.2 respectively. Only in the first period, however, is this effect estimated with real precision - the same period in which skills are being influenced by parents' socio-emotional skill and early cognition. In the second period, the estimated $90 \%$ confidence interval comfortably straddles zero, and in the last it does so marginally. We note here that throughout this section we do not necessarily interpret the estimates of large confidence intervals as strong evidence of absence of an effect for any input. Our sample size is relatively small in comparison with other similar studies, and, as Table 2 shows, our measures of socio-emotional skill are sometimes noisy. These two features of our data might then manifest in noisy parameter estimates.

To explore whether or not these effects differ across the distribution of cognitive and socioemotional skill, Appendix Tables C7 and C8 show the estimated production function parameters when an interaction of cognitive and socio-emotional with investment is included respectively. We include the interactions separately rather than in the same equation due to the small size of our sample and the high-degree of collinearity between inputs induced by their inclusion, a common problem when estimating trans-log production functions. ${ }^{14}$ We estimate that investments in the initial period are decreasing in children's cognitive skill in Table C7, but there is no evidence of any complementarity in any other period. There is a large negative interaction effect in the last period, however we cannot reject that it is equal to zero. From Table C8, we infer that there are no strong interaction effects with respect to socio-emotional skill. This is in spite of there a being statistically significant interaction effect in the first period, as the point estimates and precision of the skill elasticities are sensitive to the inclusion of the interaction terms. This is unsurprising given the the noise with which self-productivities were estimated, and the relatively low level of variation in socio-emotional measures relative to cognitive measures which leaves them more likely to introduce collinearities when used as interactions. We therefore do not draw any conclusions from Table C8. ${ }^{15}$

Turning finally to the estimated role of shocks to production, we find that their variance increases between the first two periods and then decreases significantly in late adolescence. This suggests that factors other than the inputs in Table C8 impact the socio-emotional development most between the

\footnotetext{
${ }^{14}$ Collinearity is also a concern due to the estimation method we use, which relies on instrumental variables. The estimation algorithm is outlined in detail in Appendix A

${ }^{15} \mathrm{It}$ is also caused by features of the estimation method that, in its present application, mean calculating the non-linear combinations of coefficients that have 1) been affected by the inclusion of the interaction and 2) are already estimated imprecisely.
} 
ages of 12-15 and that by the final period, between 15-19, there is relatively less external factors influencing socio-emotional development. In the middle period covering ages 12-15, however, the variance of the shocks increases substantially. Given the imprecision of the estimates between these ages, this is perhaps unsurprising. It is likely that socio-emotional skill development across this period is somewhat more malleable to external factors.

\section{Cognitive skill}

Table 6 shows analogous estimates to those in 5 for the production function of cognitive skill. In line with the much of the skill development literature, we find strong self-productivity in cognitive skill that is increasing over time (e.g Cunha et al. (2010), Helmers and Patnam (2011),Agostinelli and Wiswall (2016a),Attanasio et al. (2017, 2020a,b)). We cannot reject zero cross-productivity in any period, however. Again, these results are comparable with studies that find little or small effects of socio-emotional skills on cognition (e.g Cunha et al. (2010), Helmers and Patnam (2011) and Attanasio et al. (2020a)).

For parental human capital, we find a strong positive effect on socio-emotional skills in the initial period. The elasticity is estimated to be of roughly the same magnitude as in the production of socio-emotional skills, suggesting that parental socio-emotional skill plays a larger role in the early development of both skills in our sample. We do not estimate any large role for parental cognitive skill, however. We also find that investments influence cognitive development in all periods to a similar extent. The variance of production shocks is largest in the last period, however it is small and broadly similar in all periods, suggesting that cognitive production is influenced by little other than the inputs at any stage.

In Tables C9 and $\mathrm{C} 10$ we provide estimates of the production function with interactions of investment with cognition and socio-emotional skill respectively. There is a large, negative interaction effect between cognition and investments in the first and last periods in Table C9, meaning that investments are more productive in children with low stocks of cognitive skill. In the last period, however, this effect is not statistically different from zero. In Table C10 there is a large positive interaction effect between investments and socio-emotional skill in the second period, which would suggest that across the period investments have higher returns in high-skilled children. The $90 \%$ confidence interval of this interaction contains zero, however. 
Table 6: Estimates of Cobb-Douglas cognitive production function parameters

\begin{tabular}{|c|c|c|c|}
\hline & $\begin{array}{c}\text { Period } 1 \\
\text { Ages } 8-12\end{array}$ & $\begin{array}{c}\text { Period } 2 \\
\text { Ages 12-15 }\end{array}$ & $\begin{array}{c}\text { Period } 3 \\
\text { Ages 15-19 }\end{array}$ \\
\hline \multicolumn{4}{|c|}{ Lagged human capital } \\
\hline $\ln H_{s, t-1}$ & $\begin{array}{c}0.048 \\
(0.075) \\
{[-0.075,0.172]}\end{array}$ & $\begin{array}{c}-0.033 \\
(0.114) \\
{[-0.220,0.154]}\end{array}$ & $\begin{array}{c}0.016 \\
(0.012) \\
{[-0.005,0.036]}\end{array}$ \\
\hline $\ln H_{c, t-1}$ & $\begin{array}{c}0.361^{* * *} \\
(0.089) \\
{[0.214,0.508]}\end{array}$ & $\begin{array}{c}0.595^{* * *} \\
(0.079) \\
{[0.466,0.724]}\end{array}$ & $\begin{array}{c}0.927^{* * *} \\
(0.095) \\
{[0.770,1.084]}\end{array}$ \\
\hline \multicolumn{4}{|c|}{ Parental human capital (fixed over time) } \\
\hline $\ln P_{S}$ & $\begin{array}{c}0.366^{* * *} \\
(0.133) \\
{[0.147,0.585]}\end{array}$ & $\begin{array}{c}0.205 \\
(0.143) \\
{[-0.031,0.440]}\end{array}$ & $\begin{array}{c}-0.039 \\
(0.079) \\
{[-0.169,0.092]}\end{array}$ \\
\hline $\ln P_{c}$ & $\begin{array}{c}0.048 \\
(0.050) \\
{[-0.034,0.130]}\end{array}$ & $\begin{array}{c}-0.016 \\
(0.026) \\
{[-0.058,0.026]}\end{array}$ & $\begin{array}{c}-0.018 \\
(0.021) \\
{[-0.052,0.016]}\end{array}$ \\
\hline \multicolumn{4}{|l|}{ Investments } \\
\hline $\ln I_{t-1}$ & $\begin{array}{c}0.177^{* * *} \\
(0.051) \\
{[0.093,0.260]}\end{array}$ & $\begin{array}{c}0.249^{* * *} \\
(0.085) \\
{[0.109,0.390]}\end{array}$ & $\begin{array}{c}0.114^{* * *} \\
(0.043) \\
{[0.043,0.185]}\end{array}$ \\
\hline $\begin{array}{l}\sigma_{\eta_{c}}^{2} \\
\mathrm{~N}\end{array}$ & $\begin{array}{l}.058 \\
597\end{array}$ & $\begin{array}{l}.0771 \\
594\end{array}$ & $\begin{array}{l}.142 \\
551\end{array}$ \\
\hline
\end{tabular}

Notes: Standard errors are in parentheses, and $90 \%$ confidence intervals are in square brackets. Both are calculated using the delta method. $t-1=$ ages $8,12,15$, and 19 for the three columns respectively. The output in each column is cognitive skill. The inputs in the left column are are lagged child socio-emotional skill and cognitive skill; parental socio-emotional and cognitive skill; and investment. All inputs are treated as unobservable. The observables used as measures of each and their associated measurement parameters estimated from the measurement system outlined in Section 3 are provided in Appendix B. 


\subsection{Socio-emotional Skill Accumulation Over Early Adulthood}

Table 7 shows estimates of the production functions of two disaggregated domains of socio-emotional skill between the ages of 19 and 22: social skills (column 1) and task effectiveness (column 2). The production functions estimated here - shown in Equation 4 - include TFP and allow the RTS to be freely estimated.

The estimates show that over early adulthood, the stock of socio-emotional skill accumulated by the end of adolescence has a very strong, positive impact on both domains of socio-emotional skills, to a roughly similar extent. In terms of cross-productivity, we in fact find that task effectiveness is positively affected by cognition, but the opposite is true for social skills: over the period, a $1 \%$ increase in cognition associated with roughly a $0.41 \%$ increase in task effectiveness, but a $0.47 \%$ decrease in social skills. This to us suggests substitution, rather than complementarity - individuals with lower cognitive skills may develop higher social skills to compensate.

Moving to the vector of time-use included in TFP, we estimate that no allocation of time has an impact on the accumulation of social skills over early adulthood. However, in the case of task effectiveness, the coefficients on all of the time-use factors are are estimated to be significantly different from zero, although in different directions. Specifically, the number of hours in paid work, caring for household members, and carrying out tasks related to home production negatively affects task effectiveness, whereas time spent studying outside of any formal education has a strong positive impact on its development over and above the effect of cognitive skill.

These results highlight the importance of disaggregating skills along different domains. When aggregating measures of different facets of socio-emotional skills into one composite index, the effects of inputs will be either averaged across domains, or skewed to the the sign and size of one domain that has a disproportionate signal.

For social skills, the technology is estimated as having decreasing returns to scale, suggesting, for example, that doubling socio-emotional skills and cognition at the end of adolescence would result in roughly a 50\% increase in social skills. The technology for task effectiveness, however is estimated to have a RTS of roughly 1.3 , and its corresponding $90 \%$ confidence interval only marginally contains 1. This would suggest that that the same doubling of inputs would lead to a $130 \%$ increase in task effectiveness at age 22. The variance of the shocks is also larger for task effectiveness suggesting there are more external factors influencing its development relative to social skills and that task effectiveness is far more malleable than social skills over early adulthood. 
Table 7: Estimates of socio-emotional production functions in adulthood

\begin{tabular}{|c|c|c|}
\hline & $\begin{array}{c}\text { (1) } \\
\text { Social skills }\end{array}$ & $\begin{array}{c}\text { (2) } \\
\text { Task effectiveness }\end{array}$ \\
\hline \multicolumn{3}{|l|}{ Lagged human capital } \\
\hline $\ln H_{s, t-1}$ & $\begin{array}{c}0.933^{* * *} \\
(0.136) \\
{[0.709,1.157]}\end{array}$ & $\begin{array}{c}0.892^{* * *} \\
(0.199) \\
{[0.565,1.219]}\end{array}$ \\
\hline $\ln H_{c, t-1}$ & $\begin{array}{c}-0.473^{* * *} \\
(0.123) \\
{[-0.675,-0.271]}\end{array}$ & $\begin{array}{c}0.413^{* *} \\
(0.196) \\
{[0.091,0.735]}\end{array}$ \\
\hline \multicolumn{3}{|c|}{ Total Factor Productivity $\left(\ln A_{T}\right)$} \\
\hline Hours studying & $\begin{array}{c}-0.070 \\
(0.112) \\
{[-0.255,0.115]}\end{array}$ & $\begin{array}{c}0.707^{* * *} \\
(0.132) \\
{[0.490,0.923]}\end{array}$ \\
\hline Hours working & $\begin{array}{c}-0.015 \\
(0.028) \\
{[-0.061,0.031]}\end{array}$ & $\begin{array}{c}-0.078^{* *} \\
(0.032) \\
{[-0.130,-0.026]}\end{array}$ \\
\hline Hours caring & $\begin{array}{c}-0.019 \\
(0.030) \\
{[-0.068,0.031]}\end{array}$ & $\begin{array}{c}-0.122^{* * *} \\
(0.044) \\
{[-0.194,-0.049]}\end{array}$ \\
\hline Hours home production & $\begin{array}{c}-0.009 \\
(0.036) \\
{[-0.069,0.051]}\end{array}$ & $\begin{array}{c}-0.100^{* * *} \\
(0.030) \\
{[-0.149,-0.051]}\end{array}$ \\
\hline$\alpha_{T}$ & $\begin{array}{c}-0.095 \\
(0.477) \\
{[-0.879,0.690]}\end{array}$ & $\begin{array}{c}-1.311^{* * *} \\
(0.470) \\
{[-2.084,-0.538]}\end{array}$ \\
\hline Returns to scale & $\begin{array}{c}0.460^{* * *} \\
(0.143) \\
{[0.224,0.696]}\end{array}$ & $\begin{array}{c}1.305^{* * *} \\
(0.185) \\
{[1.000,1.610]}\end{array}$ \\
\hline$\overline{\sigma_{\eta_{s}^{j}}^{2}}$ & .555 & 1.2 \\
\hline $\mathrm{N}$ & 550 & 550 \\
\hline
\end{tabular}

Notes: Standard errors are in parentheses, and $90 \%$ confidence intervals are in square brackets. Both are calculated using the delta method. $T=$ age 19 in each column. The left column contains lagged child socio-emotional skill and cognitive skill; the variables included in $\ln A_{T}$; residual productivity $\alpha_{T}$; and the estimates Returns to Scale (RTS). Lagged human capital is treated as unobservable. The observables used as measures for each are described in Appendix B. Appendix A outlines the method used to obtain all estimates in the table. 


\section{Socio-emotional Skills and Risky Behaviour}

The discussion of the estimated parameters of the investment and production functions to this point has necessarily been centred on relating the stocks of latent variables to one another over time. Even with the measurement system and normalizations, this discussion remains somewhat abstract. In order to provide a more socially or economically meaningful measure of the importance of human capital, we investigate the effect of skills on risky behaviours in early adulthood, given that many young people have not yet fully completed their education and begun earning. Risky behaviours are both predictive of future economic success, and may also reduce life-expectancy (Cawley and Ruhm, 2011). We define adult outcome $O_{T+1}$ to be a function of our two $T+1$ socio-emotional domains (social skills and task effectiveness), cognitive skill at $T$ and a vector of individual characteristics $\mathbf{x}_{T+1}$ :

$$
O_{T+1}=\mu_{o}+\gamma_{1}^{o} H_{s, T+1}^{t}+\gamma_{2}^{o} H_{s, T+1}^{s}+\gamma_{3}^{o} H_{c, T}+\mathbf{x}_{T+1}^{\prime} \boldsymbol{\delta}+\eta_{T+1}^{o} \quad \text { for } \quad j \in\{t, s\}
$$

We assume the error term, $\eta_{T+1}^{o}$ is independent of the inputs, and that the outcome is measured without error. As outcomes, we use six indicators of risky behaviour collected as part of the YLS (in a self-administered questionnaire for sensitive items): smoked at least once a month; ever been drunk; ever taken illegal drugs; ever had unprotected sex; carried a weapon in the last month; been arrested for being part of a gang or carrying a weapon in the last month; or has a child or is pregnant (or has a partner who is pregnant) at age 22. As controls, included in $\mathbf{x}_{T+1}$, we use individuals' gender and wealth. Using cognitive skill as captured by measures at $T$ is somewhat analogous to assuming that cognitive skill is fixed from age 18 onward. Given our estimates of the increasing self-productivity of cognitive skill, and the evidence that cognition is much less malleable than socio-emotional skills over the lifecourse, this assumption is not overly restrictive. ${ }^{16}$

All of the outcomes we use to estimate Equation 11 are binary. There are several possible ways to estimate its parameters for each outcome, however we use an IV linear probability model as it does not require us to make additional assumptions about the distribution of the measurement error, given the findings of Laajaj and Macours (2019), and it is robust to miss-specification of the first stage. Appendix A discusses the estimation of Equation 11 in more detail. Table 8 reports the estimated marginal effects for each outcome. The marginal effect of task effectiveness is negative for every risky behaviour, and statistically different from zero for the likelihood of having smoked once a month (column 1), taken illegal drugs (column 3) and having been arrested for being part of a gang (column 6).

The pattern is not so clear for social skills, and none of these effects are estimated with precision; we cannot reject that they are zero for every outcome. The marginal effects of cognition are positive and significant for having smoked once a month (column 1) and having taken illegal drugs (column 3). For the latter of these outcomes, wealth also has a large, positive marginal effect - a relationship that is perhaps unsurprising considering that illegal drugs include those that might be considered "recreational" - for example marijuana. These results are slightly different from those of Heckman et al. (2006), who

\footnotetext{
${ }^{16}$ Kautz et al. (2014) discuss in detail how the development of socio-emotional and cognitive skills differs. Walsh and Walsh (2014) discuss how the slow-development of the pre-frontal cortex means personality traits are unstable over adolescence and later life stages.
} 
find cognitive skills also decrease the probability of risky behaviour. Further, in their analysis, they measure latent socio-emotional skills by self esteem and locus of control, which is a subset of our task effectiveness skill. Our results show that social skills do not have the same effect, highlighting that the definition of socio-emotional skills is important when drawing policy conclusions regarding skills and behaviour. The higher risk of smoking and drug taking for individuals with higher cognitive skills may be related also to the difference in context between US and Peru - but our results suggest that it is even more important to cultivate task effectiveness skills, if improved cognition does not reduce risky behaviour in this context.

Table 8: Estimates of the impact of age 22 socio-emotional skills on risky behaviours

\begin{tabular}{lccccccc}
\hline & $\begin{array}{c}(1) \\
\text { Smoked }\end{array}$ & $\begin{array}{c}(2) \\
\text { Drank }\end{array}$ & $\begin{array}{c}(3) \\
\text { Drugs }\end{array}$ & $\begin{array}{c}(4) \\
\text { Unprotected sex }\end{array}$ & $\begin{array}{c}(5) \\
\text { Carried weapon }\end{array}$ & $\begin{array}{c}(6) \\
\text { Gang }\end{array}$ & $\begin{array}{c}(1) \\
\text { Child }\end{array}$ \\
\hline $\ln H_{s, T+1}^{t}$ & $-0.084^{*}$ & -0.007 & $-0.096^{*}$ & -0.022 & -0.019 & $-0.067^{*}$ & -0.041 \\
& $(0.049)$ & $(0.068)$ & $(0.053)$ & $(0.059)$ & $(0.024)$ & $(0.038)$ & $(0.053)$ \\
$\ln H_{s, T+1}^{s}$ & 0.015 & -0.050 & 0.016 & -0.023 & 0.022 & 0.044 & 0.018 \\
& $(0.058)$ & $(0.074)$ & $(0.057)$ & $(0.067)$ & $(0.033)$ & $(0.045)$ & $(0.066)$ \\
$\ln H_{c, T}$ & 0.144 & 0.099 & $0.166^{*}$ & 0.046 & 0.021 & 0.081 & -0.067 \\
& $(0.098)$ & $(0.124)$ & $(0.100)$ & $(0.120)$ & $(0.045)$ & $(0.073)$ & $(0.100)$ \\
Female & $-0.253^{* * *}$ & $-0.293^{* * *}$ & $-0.106^{* *}$ & $0.181^{* * *}$ & -0.019 & $-0.082^{* *}$ & $0.252^{* * *}$ \\
& $(0.050)$ & $(0.063)$ & $(0.044)$ & $(0.059)$ & $(0.020)$ & $(0.037)$ & $(0.047)$ \\
Wealth index & 0.024 & 0.026 & 0.305 & -0.267 & -0.060 & -0.033 & -0.031 \\
& $(0.173)$ & $(0.202)$ & $(0.199)$ & $(0.184)$ & $(0.103)$ & $(0.136)$ & $(0.147)$ \\
\hline Outcome mean & 0.23 & 0.51 & 0.15 & 0.30 & 0.05 & 0.12 & 0.30 \\
$\mathrm{~N}$ & 531 & 523 & 441 & 499 & 535 & 534 & 551 \\
\hline
\end{tabular}

Note: $* * *$ and $* * *$ denote statistical significance it $10 \%, 5 \%$ and $1 \%$ respectively. Standard errors in parentheses are calculated from 1,000 bootstrap replications. The outcomes in each column are whether not an individual has: smoked least once a month (1); ever been drunk (2); ever taken illegal drugs (3); ever had unprotected sex (4); carried a weapon in the last month (5); been arrested for being part of a gang or carrying a weapon in the last month (6); or has a child or is pregnant at age 22 (7). Female is a dummy indicating whether or not an individual is female, and the wealth index a measure of the material resources of the family which ranges from 0 to 1 , constructed as the average of three sub-indices measuring housing quality, access to services and ownership of a range of durable goods. See Briones (2017) for detail. The number of observations differs in across columns due to missing responses.

The results in Table 8 highlight the complexity of the relationship between skills and outcomes. Firstly, they show again the importance if disaggregating socio-emotional skills along its domains. Not doing so, and treating socio-emotional skills as an aggregate, would mean overlooking how they affect outcomes differently - a key question for policy given the abstractness of aggregate "bundles" of skills. Secondly, the results show the potential interplay of skills in determining outcomes - even though being smarter is considered to be an improvement, it is likely that socio-emotional skills like task-effectiveness drive individuals to make life choices commensurate with social and economic success. Of course, we cannot know from this analysis the extent to which these skills are related to 
future social and economic outcomes, however evidence suggests risky behaviours are driven by the same factors that correlate with wages, employment and schooling attainment (Heckman et al., 2006).

\section{Conclusion}

In this paper we examined the accumulation of socio-emotional skills between the ages of 8 and 22 in Peru. We also estimate the developmental path of cognitive skill between $8-19$, and the role played by socio-emotional skill in this process (and vice-versa). To do so, we estimate a dynamic latent factor model of household investment and skill production using a framework developed by Agostinelli and Wiswall (2016a) that captures key aspects of the skill accumulation process.

We find that household investments are largely determined by family resources and parents' socioemotional skills, and no evidence that parents invest in response to their children's revealed human capital. Our estimates of human capital production functions suggest that these investments positively affect socio-emotional skill accumulation in the early periods of our model, and that the impact varies across the distribution of skills. Our results also show that socio-emotional skills' self-productivity is increasing with age and that cognition is highly self-productive across all of adolescence. We also find that socio-emotional skills are determined by stocks of cognitive skills to a far greater extent than past socio-emotional skills at all stages.

In early adulthood between 19-22, we disaggregate socio-emotional skills along two domains: social skills and task-effectiveness and relax some of the functional form restrictions required to estimate the technology of skill formation between 8-19. This portion of our analysis provides evidence that socio-emotional skills accumulated by the end of adolescence are important in building both these two domains in early adulthood, but a negative relationship between cognitive skill and the development of social skills, suggesting substitution effects. Over this period, we find that time spent studying positively affects the accumulation of task effectiveness, whereas the reverse is true for time in home production or caring for household members. Finally, we estimate the returns to scaling up the inputs of the socio-emotional skill functions are far greater for task effectiveness than for social skills. At age 22, we also find that task-effectiveness has a negative effect on the probability of individuals engaging in a range of risky behaviours, in particular drinking, smoking, taking drugs and engaging in gang related behaviour. Social skills on the other hand have no effect on these intermediate outcomes.

Together, these results suggest that gaps in socio-emotional skills arise and persist through differences in household investments and the cross-productivity of cognition in socio-emotional skill production. Socio-emotional skills are then highly self-productive across early adulthood, and lead to differences in engagement with a range of risk behaviours, this being predictive of likely lower economic success in future years. Gaining knowledge as to how human capital develops over childhood and adolescence is crucial in understanding the transmission of poverty and inequality across generations. The results of this paper offer several additions to the growing evidence base that has come from the literature on the economics of early skill accumulation over the past decade. 


\section{References}

Agostinelli, F., and M. Wiswall. 2016a. "Estimating the technology of children's skill formation.’'Technical report, National Bureau of Economic Research.

Agostinelli, F., and M. Wiswall. 2016b. "Identification of dynamic latent factor models: The implications of re-normalization in a model of child development.'Technical report, National Bureau of Economic Research.

Alan, S., T. Boneva, and S. Ertac. 2019. "Ever failed, try again, succeed better: Results from a randomized educational intervention on grit." The Quarterly Journal of Economics, 134(3): $1121-1162$.

Alan, S., and S. Ertac. 2018. "Fostering patience in the classroom: Results from randomized educational intervention.” Journal of Political Economy, 126(5): 1865-1911.

Almlund, M., A. L. Duckworth, J. Heckman, and T. Kautz. 2011. "Personality psychology and economics." In Handbook of the Economics of Education. 4 Elsevier, 1-181.

Almond, D., J. Currie, and V. Duque. 2018. "Childhood circumstances and adult outcomes: Act ii." Journal of Economic Literature, 56(4): 1360-1446.

Ashraf, N., N. Bau, C. Low, and K. McGinn. 2020. "Negotiating a better future: How interpersonal skills facilitate intergenerational investment." The Quarterly Journal of Economics, 135(2): 10951151.

Attanasio, O., S. Cattan, E. Fitzsimons, C. Meghir, and M. Rubio-Codina. 2020a. "Estimating the production function for human capital: results from a randomized controlled trial in Colombia." American Economic Review, 110(1): 48-85.

Attanasio, O., C. Meghir, and E. Nix. 2020b. "Human capital development and parental investment in India." Review of Economic Studies, online publication.

Attanasio, O., C. Meghir, E. Nix, and F. Salvati. 2017. "Human capital growth and poverty: Evidence from Ethiopia and Peru." Review of Economic Dynamics, 25 234-259.

Bandura, A. 1993. "Perceived self-efficacy in cognitive development and functioning." Educational Psychologist, 28(2): 117-148.

Bandura, A. 2010. "Self-efficacy." The Corsini Encyclopedia of Psychology 1-3.

Bettinger, E., S. Ludvigsen, M. Rege, I. F. Solli, and D. Yeager. 2018. "Increasing perseverance in math: Evidence from a field experiment in norway." Journal of Economic Behavior \& Organization, $1461-15$.

Blundell, R. W., and J. L. Powell. 2004. "Endogeneity in semiparametric binary response models." The Review of Economic Studies, 71(3): 655-679. 
Bono, J. E., and T. A. Judge. 2003. "Core self-evaluations: A review of the trait and its role in job satisfaction and job performance.” European Journal of Personality, 17(S1): S5-S18.

Borghans, L., A. L. Duckworth, J. J. Heckman, and B. Ter Weel. 2008. "The economics and psychology of personality traits." Journal of human Resources, 43(4): 972-1059.

Briones, K. 2017. “'How many rooms are there in your house?' constructing the Young Lives wealth index.’Technical Report 43.

Cantril, H. et al. 1965. "Pattern of human concerns."

Cattell, R. B. 1966. "The scree test for the number of factors." Multivariate Behavioral Research, 1(2): 245-276.

Cawley, J., and C. J. Ruhm. 2011. "The economics of risky health behaviors." In Handbook of health economics. 2 Elsevier, 95-199.

Chiteji, N. 2010. "Time preference, noncognitive skills and well being across the life course: do noncognitive skills encourage healthy behavior?" American Economic Review, 100(2): 200-204.

Costa, P. T., and R. R. MacCrae. 1992. Revised NEO personality inventory (NEO PI-R) and NEO five-factor inventory (NEO-FFI): Professional manual. Psychological Assessment Resources, Incorporated.

Cunha, F., and J. Heckman. 2007. “The technology of skill formation.” American Economic Review, 97(2): 31-47.

Cunha, F., J. J. Heckman, and S. M. Schennach. 2010. "Estimating the technology of cognitive and noncognitive skill formation." Econometrica, 78(3): 883-931.

Cunningham, W., P. Acosta, and N. Muller. 2016. Minds and behaviors at work: boosting socioemotional skills for Latin America's workforce. World Bank Publications.

Del Boca, D., C. Flinn, and M. Wiswall. 2013. "Household choices and child development." Review of Economic Studies, 81(1): 137-185.

Deming, D. J. 2017. “The growing importance of social skills in the labor market." The Quarterly Journal of Economics, 132(4): 1593-1640.

Duckworth, A. L., C. Peterson, M. D. Matthews, and D. R. Kelly. 2007. "Grit: perseverance and passion for long-term goals.." Journal of Personality and Social Psychology, 92(6): , p. 1087.

Duckworth, A. L., and P. D. Quinn. 2009. "Development and validation of the short grit scale (grit-s)." Journal of Personality Assessment, 91(2): 166-174.

Edmonds, E. V., B. Feigenberg, and J. Leight. 2020. "Advancing the agency of adolescent girls.'Technical report, National Bureau of Economic Research. 
Escobal, J., and E. Flores. 2008. "An assessment of the Young Lives sampling approach in Peru.’Technical report, Young Lives.

Gensowski, M. 2018. “Personality, IQ, and lifetime earnings.” Labour Economics, 51 170-183.

Glewwe, P., Q. Huang, and A. Park. 2017. "Cognitive skills, noncognitive skills, and school-to-work transitions in rural China.” Journal of Economic Behavior \& Organization, 134 141-164.

Goodman, R. 2001. "Psychometric properties of the strengths and difficulties questionnaire." Journal of the American Academy of Child \& Adolescent Psychiatry, 40(11): 1337-1345.

Heckman, J. J. 2006. "Skill formation and the economics of investing in disadvantaged children." Science, 312(5782): 1900-1902.

Heckman, J. J. 2007. "The economics, technology, and neuroscience of human capability formation." Proceedings of the national Academy of Sciences, 104(33): 13250-13255.

Heckman, J. J., and T. Kautz. 2012. "Hard evidence on soft skills." Labour economics, 19(4): 451-464.

Heckman, J. J., and Y. Rubinstein. 2001. "The importance of noncognitive skills: Lessons from the GED testing program.” American Economic Review, 91(2): 145-149.

Heckman, J. J., J. Stixrud, and S. Urzua. 2006. "The effects of cognitive and noncognitive abilities on labor market outcomes and social behavior." Journal of Labor economics, 24(3): 411-482.

Heckman, J., R. Pinto, and P. Savelyev. 2013. "Understanding the mechanisms through which an influential early childhood program boosted adult outcomes." American Economic Review, 103(6): 2052-86.

Helmers, C., and M. Patnam. 2011. "The formation and evolution of childhood skill acquisition: Evidence from India..” Journal of Development Economics, 95(2): 252-266.

Horn, J. L. 1965. “A rationale and test for the number of factors in factor analysis.” Psychometrika, 30(2): 179-185.

Jerusalem, M., and R. Schwarzer. 1979. "The general self-efficacy scale.”

Kaiser, H. F. 1960. "The application of electronic computers to factor analysis." Educational and Psychological Measurement, 20(1): 141-151.

Kautz, T., J. J. Heckman, R. Diris, B. Ter Weel, and L. Borghans. 2014. "Fostering and measuring skills: Improving cognitive and non-cognitive skills to promote lifetime success.”Technical report, National Bureau of Economic Research.

Keane, M. P., S. Krutikova, and T. Neal. 2018. "The impact of child work on cognitive development: results from four low to middle income countries.'Technical report, IFS Working Papers. 
Kosse, F., T. Deckers, P. Pinger, H. Schildberg-Hörisch, and A. Falk. 2020. "The formation of prosociality: causal evidence on the role of social environment." Journal of Political Economy, 128(2): 434-467.

Kotlarski, I. 1967. "On characterizing the gamma and the normal distribution.” Pacific Journal of Mathematics, 20(1): 69-76.

Krishnan, P., and S. Krutikova. 2013. "Non-cognitive skill formation in poor neighbourhoods of urban India." Labour Economics, 24 68-85.

Laajaj, R., and K. Macours. 2019. "Measuring skills in developing countries.” Journal of Human Resources.

Laajaj, R., K. Macours, D. A. P. Hernandez, O. Arias, S. D. Gosling, J. Potter, M. Rubio-Codina, and R. Vakis. 2019. "Challenges to capture the big five personality traits in non-weird populations." Science Advances, 5(7): , p. eaaw5226.

Lindqvist, E., and R. Vestman. 2011. "The labor market returns to cognitive and noncognitive ability: Evidence from the Swedish enlistment." American Economic Journal: Applied Economics, 3(1): $101-28$.

Lundberg, S. 2017. "Noncognitive skills as human capital." In Education, Skills, and Technical Change: Implications for Future US GDP Growth. Eds. by C. R. Hulten, and V. A. Ramey University of Chicago Press, 219-243.

Muris, P., C. Meesters, and F. van den Berg. 2003. "The strengths and difficulties questionnaire (sdq)." European Child \& Adolescent Psychiatry, 12(1): 1-8.

Novella, R., A. Alvarado, D. Rosas-Shady, and C. González-Velosa. 2019. "Encuesta de habilidades al trabajo (ENHAT) 2017-2018: causas y consecuencias de la brecha de habilidades en Perú."

OECD. 2017. "Social and Emotional Skills: Well-being, Connectedness and Success."

Porter, C., G. McQuade, and M. Favara. 2020. "Selection and validation of socioemotional skill measures in round 5 of the young lives survey.’Technical report, Young Lives.

Raven, J. C. 1958. "Guide to using the coloured progressive matrices.."

Reddy, V., G. Diedericks, and L. Meintjes. 2003. "The trends in international mathematics and science study: 2003."

Revollo, P. E. 2018. "Cognitive and achievement tests in the Young Lives Study.'Technical report, Young Lives.

Richards, G., L. Ellis, and J. Neill. 2002. "Review of personal effectiveness and locus of control: a comprehensive instrument for reviewing life effectiveness." In Paper presented at the Self-concept Research: Driving International Research Agendas Conference, Sydney, Australia. 
Rosenberg, M. 1965. Society and the adolescent self-image. Princeton university press.

Rotter, J. B. 1966. "Generalized expectancies for internal versus external control of reinforcement.." Psychological monographs: General and applied, 80(1): , p. 1.

Roy, S., M. Morton, and S. Bhattacharya. 2018. "Hidden human capital: Self-efficacy, aspirations and achievements of adolescent and young women in India." World Development, 111 161-180.

Shavelson, R. J., J. J. Hubner, and G. C. Stanton. 1976. "Self-concept: Validation of construct interpretations." Review of educational research, 46(3): 407-441.

Sánchez, A. 2017. "The structural relationship between early nutrition, cognitive skills and noncognitive skills in four developing countries..” Economics and Human Biology, 27 33-54.

Sánchez, A., and J. Escobal. 2020. "Survey attrition after 15 years of tracking children in four developing countries: The Young Lives Survey." Reviev of Development Economics, Early view.

Walsh, D., and E. Walsh. 2014. Why Do They Act That Way?-Revised and Updated: A Survival Guide to the Adolescent Brain for You and Your Teen. Simon and Schuster.

Weinberger, C. J. 2014. "The increasing complementarity between cognitive and social skills." Review of Economics and Statistics, 96(4): 849-861.

Yorke, L., and M. Ogando. 2018. "Psychosocial scales in the Young Lives round 4 survey: Selection, adaptation and validation.’Technical Report 45. 


\section{A Identification and Estimation}

We estimate equations 2 and 1 in between the ages of 8-12, 12-15, and 15-19 following Agostinelli and Wiswall (2016a). The starting point in estimating this system is the identification of the initial period measurement parameters and the joint distribution of the initial conditions. Given that we have three measures of each of the latent variable in the initial period and have assumed full independence of the measurement errors, we are able to identify and estimate both. With the initial period measurement parameters and the joint distribution of the initial conditions recovered, Agostinelli and Wiswall (2016a) show that the technologies in Equations 2 and 1 can be sequentially identified in each subsequent period.

Estimation of the model of human capital accumulation between the ages of 8 and 19 laid out in Section 2 consists of four main steps:

1. First, we estimate of the joint distribution of the initial conditions.

2. We then estimate of the investment function of Equation 1 and recover the investment measurement parameters in the first period.

3. Next, we estimate of the production function and measurement parameters for socio-emotional and cognitive skill in period 1.

4. We then repeat of steps 2 and 3 for in periods 2 and 3.

We then estimate the measurement system of three domains of socio-emotional skill at age 22: relationships, wellbeing, and agency. We impose normalisations on this measurement system that all us to identify and estimate the flexible production functions - shown in Equation 4 - of these skills between the ages of 19 and 22 .

\section{A.1 The Joint Distribution Of Initial Conditions}

The factor loadings of to the measures of the initial conditions are retrieved by taking the ratio of the covariances of observed measures. For example:

$$
\lambda_{\theta, m, 0}=\frac{\operatorname{Cov}\left(Z_{\theta, m, 0}, Z_{\theta, m^{\prime}, 0}\right)}{\operatorname{Cov}\left(Z_{\theta, 1,0}, Z_{\theta, m^{\prime},}\right)} \quad \forall m^{\prime} \neq m
$$

Imposing the normalisation that the initial period latent variables all have a mean of zero, the measurement intercepts $\mu_{\theta, m, 0}$, can be estimated by $\mathbb{E}\left(Z_{\theta, m, 0}\right)$. We the residualise measures as follows:

$$
\tilde{Z}_{\theta, m, 0}=\frac{Z_{\theta, m, 0}-\mu_{\theta, m, 0}}{\lambda_{\theta, m, 0}}=\ln \theta_{0}+\tilde{\varepsilon}_{\theta, m, 0}=\ln \theta_{0}+\frac{\varepsilon_{\theta, m, 0}}{\lambda_{\theta, m, 0}} \quad \forall m
$$

The latent variables are then equivalent to:

$$
\tilde{Z}_{\theta, m, 0}^{*}=\tilde{Z}_{\theta, m, 0}-\tilde{\varepsilon}_{\theta, m, 0}=\ln \theta_{0}
$$

Having identified and estimated the factor loadings, the theorem of Kotlarski (1967) can be applied 
to the set of residual measures, $\left\{\tilde{Z}_{\theta, m, 0}\right\}_{m=1}^{M_{\theta, 0}}$, to identify the distributions of $\ln \theta_{0}$ and $\varepsilon_{\theta, m, 0}$ conditional on $\mathbf{I}_{0}$. This then allows identification of the joint distribution of the initial conditions and investments at $t=0$. Agostinelli and Wiswall (2016a) show that the production technologies are sequentially identified in each of the following periods $t=0, \ldots, T$.

The diagonal and off diagonal elements of the covariance matrix of the initial conditions can be estimated by

$$
\frac{\operatorname{Cov}\left(Z_{\theta, 1,0}, Z_{\theta, 2,0}\right) \operatorname{Cov}\left(Z_{\theta, 1,0}, Z_{\theta, 3,0}\right)}{\operatorname{Cov}\left(Z_{\theta, 2,0}, Z_{\theta, 2,0}\right)}=\frac{\lambda_{\theta, 2,0} \lambda_{\theta, 3,0} \operatorname{Var}\left(\ln \theta_{0}\right)^{2}}{\lambda_{\theta, 2,0} \lambda_{\theta, 3,0} \operatorname{Var}\left(\ln \theta_{0}\right)}=\operatorname{Var}\left(\ln \theta_{0}\right)
$$

and

$$
\operatorname{Cov}\left(Z_{\theta, 1,0}, Z_{\theta^{\prime}, 1,0}\right)=\operatorname{Cov}\left(\ln \theta_{0}, \ln \theta_{0}^{\prime}\right)
$$

respectively. Since $\ln Y_{0}$ and $\ln S_{i z} e_{0}$ are measured without error, their respective variance is easily computed, and their covariancex with a given unobservable initial condition, $\theta_{0}$, are:

$$
\operatorname{Cov}\left(\ln Y_{0}, \ln \theta_{0}\right)=\operatorname{Cov}\left(\ln Y_{0}, Z_{\theta, 1,0}\right)
$$

Given the assumption that unobservanles are mean zero in the initial period, the mean vector is

$$
\mu_{\Omega}=\left(0,0,0,0,0,0, \mu_{Y, 0}\right)
$$

\section{A.2 Investment Functions}

Substituting Equation 1 in to one measurement equation for investment in the first period gives the following expression:

$$
\begin{aligned}
Z_{I_{0}, m, 0}=\mu_{I_{0}, m, 0}+\lambda_{I_{0}, m, 0}\left(\beta_{1,0} \ln H_{s, 0}\right. & +\beta_{2,0} \ln H_{c, 0}+\beta_{3,0} \ln P_{S} \\
+\beta_{4,0} & \left.\ln P_{c}+\beta_{5,0} \ln Y_{0}+\pi_{0}\right)+\varepsilon_{I_{0}, m, 0}
\end{aligned}
$$

Substituting the corresponding proxies of latent inputs in to the investment equations - $\tilde{Z}_{\theta, m, 0}^{*}$ for each $\theta_{0} \in\left\{H_{s, 0}, H_{c, 0}, P_{s}, P_{c}\right\}$ - in to Equation A6 in place of the unobservables this can be re-written as

$$
\begin{aligned}
Z_{I_{0}, m, 0}=\mu_{I_{0}, m, 0}+\lambda_{I_{0}, m, 0}\left(\beta_{1,0} \tilde{Z}_{H_{s}, m, 0}^{*}\right. & +\beta_{2,0} \tilde{Z}_{H_{c}, m, 0}^{*}+\beta_{3,0} \tilde{Z}_{P_{s}, m}^{*} \\
& \left.+\beta_{4,0} \tilde{Z}_{P_{c}, m}^{*}+\beta_{5,0} \ln Y_{0}+\pi_{0}\right)+\varepsilon_{I_{0}, m, 0}
\end{aligned}
$$

and so 


$$
\begin{aligned}
Z_{I_{0}, m, 0}=\mu_{I_{0}, m, 0}+\delta_{1,0} \tilde{Z}_{H_{s}, m, 0}+\delta_{2,0} \tilde{Z}_{H_{c}, m, 0} & +\delta_{3,0} \tilde{Z}_{P_{s}, m} \\
& +\delta_{4,0}^{j} \tilde{Z}_{P_{c}, m}+\delta_{5,0} \ln Y_{0}+v_{0}
\end{aligned}
$$

where

$$
\begin{gathered}
\delta_{i, 0}=\lambda_{I_{0}, m, 0} \beta_{i, 0} \quad \text { for } i=1, \ldots, 5 \\
v_{0}=\varepsilon_{I_{0}, m, 0}+\lambda_{I_{0}, m, 0}\left(\pi_{0}-\beta_{1,0} \tilde{\varepsilon}_{H_{s}, m, 0}-\beta_{2,0} \tilde{\varepsilon}_{H_{c}, m, 0}-\beta_{3,0}^{j} \tilde{\varepsilon}_{P_{s}, m, 0}-\beta_{4,0}^{j} \tilde{\varepsilon}_{P_{c}, m, 0}\right)
\end{gathered}
$$

Since we are using error contaminated proxies for the latent inputs persists of Equation A8, $\mathbb{E}\left(\tilde{Z}_{\theta, m, 0} v_{j, 0}\right) \neq 0$. We therefore use, all other measures of each latent variable as instruments to estimate of the reduced form parameters in Equation A8. Given the assumptions on the measurement errors, $\mathbb{E}\left(Z_{\theta, m^{\prime}, 0} v_{j, 0}\right)=0 \quad \forall \theta_{0}$ and $m^{\prime} \neq m$ and so these alternative measures are valid instruments. With the CRS assumption we can recover the measurement and structural parameters of the investment equation as:

$$
\beta_{i, 0}=\frac{\delta_{i, 0}}{\sum_{i=1}^{6} \delta_{i, 0}}=\frac{\lambda_{I_{0}, m, 0} \beta_{i, 0}}{\sum_{i=1}^{6} \lambda_{I_{0}, m, 0} \beta_{i, 0}^{j}} \text { for } \quad i=1, . ., 5
$$

We then construct residual investment measures as:

$$
\tilde{Z}_{I, m, 0}=\frac{Z_{I, m, 0}-\mu_{I, m, 0}}{\lambda_{I, m, 0}}=\ln I_{0}+\tilde{\varepsilon}_{I, m, 0},
$$

and investment is equal to:

$$
\tilde{Z}_{I_{j}, m, 0}^{*}=\tilde{Z}_{I_{0}, m, 0}-\tilde{\varepsilon}_{I, m 0}=\ln I_{0}
$$

\section{A.3 Production Functions}

The parameters of Equation 2 are estimated in an identical manner. Again, we start by substituting Equation 2 in to that of an observable measurement of period 1 stock of socio-emotional skill, giving:

$$
\begin{aligned}
Z_{H_{s}, m, 1}=\mu_{H_{s}, m, 1}+\lambda_{H_{s}, m, 1}\left(\rho_{1,0}^{s} \ln H_{s, 0}\right. & +\rho_{2,0}^{s} \ln H_{c, 0}+\alpha_{1,0}^{s} \ln P_{s}+\alpha_{2,0}^{s} \ln P_{c} \\
& \left.+\gamma_{0}^{s} \ln I_{0}+\kappa_{0}^{s}\left(\ln H_{s, 0} \ln I_{0}\right)+\eta_{0}^{s}\right)+\varepsilon_{H_{s}, m, 1}
\end{aligned}
$$

Once again using the fact that, based on the measurement system laid out in Equation $6, \tilde{Z}_{\theta, m, 0}^{*}=\ln \theta_{0}$ for $\theta_{0} \in\left\{H_{s, 0}, H_{c, 0}, P_{s}, P_{c}, I_{0}\right\}$, Equation A10 can be written as 


$$
\begin{aligned}
Z_{H_{s}, m, 1}=\mu_{H_{s}, m, 1}+\lambda_{H_{s}, m, 1}\left(\rho_{1,0}^{s} \tilde{Z}_{H_{s, 0}, m, 0}^{*}\right. & +\rho_{2,0}^{s} \tilde{Z}_{H_{c, 0}, m, 0}^{*}+\alpha_{1,0}^{s} \tilde{Z}_{P_{s}, m, 0}^{*}+\alpha_{2,0}^{s} \tilde{Z}_{H_{c}, m, 0}^{*} \\
& \left.+\gamma_{0}^{s} \tilde{Z}_{I_{0}, m, 0}^{*}+\kappa_{0}^{s}\left(\tilde{Z}_{H_{s, 0}, m, 0}^{*} \tilde{Z}_{I_{0}, m, 0}^{*}\right)+\eta_{0}^{s}\right)+\varepsilon_{H_{s}, m, 1},
\end{aligned}
$$

which can be re-arranged as:

$$
\begin{aligned}
Z_{H_{s}, m, 1}=\mu_{H_{s}, m, 1}+\phi_{1,0}^{s} \tilde{Z}_{H_{s, 0}, m, 0}+\phi_{2,0}^{s} \tilde{Z}_{H_{c, 0}, m, 0} & +\chi_{1,0}^{s} \tilde{Z}_{P_{s}, m, 0}+\chi_{2,0}^{s} \tilde{Z}_{H_{c}, m, 0} \\
& +\tau_{0}^{s} \tilde{Z}_{I_{0}, m, 0}+\psi_{0}^{s}\left(\tilde{Z}_{H_{s, 0}, m, 0} \tilde{Z}_{I_{0}, m, 0}\right)+v_{1}^{s}
\end{aligned}
$$

where

$$
\begin{aligned}
\phi_{i, 0}^{s} & =\lambda_{H_{s}, m, 1} \rho_{i, 0}^{s} \text { for } i=1,2 \\
\chi_{i, 0}^{s} & =\lambda_{H_{s}, m, 1} \alpha_{i, 0}^{s} \text { for } i=3,4 \\
\tau_{0}^{s} & =\lambda_{H_{s}, m, 1} \gamma_{0}^{s} \\
\psi_{0}^{s} & =\lambda_{H_{s}, m, 1} \kappa_{0}^{s}
\end{aligned}
$$

and

$$
\begin{array}{r}
v_{1}^{j}=\varepsilon_{H_{s}, m, 1}+\lambda_{H_{j}, m, 1}\left[\eta_{0}^{s}-\rho_{1,0}^{s} \tilde{\varepsilon}_{H_{s, 0}, m, 0}-\rho_{2,0}^{s} \tilde{\varepsilon}_{H_{c, 0}, m, 0}-\alpha_{1,0}^{s} \tilde{\varepsilon}_{P_{s}, m, 0}-\alpha_{2,0}^{s} \tilde{\varepsilon}_{P_{c}, m, 0}-\gamma_{0}^{s} \tilde{\varepsilon}_{I_{0}, m, 0}\right. \\
\left.\quad-\kappa_{0}^{s}\left(\tilde{Z}_{H_{s, 0}, m, 0} \tilde{\varepsilon}_{I_{0}, m, 0}+\tilde{Z}_{I_{0}, m, 0} \tilde{\varepsilon}_{H_{s, 0}, m, 0}+\tilde{\varepsilon}_{H_{s, 0}, m, 0} \tilde{\varepsilon}_{I_{0}, m, 0}\right)\right]
\end{array}
$$

As in estimation of the production functions, all alternative measures of the inputs are used as instrumental variables with their validity implied by assumptions regarding the joint distribution of the unobservables and measurement errors. The assumption of CRS again allows the structural parameters of Equation 2 to be calculated as 


$$
\begin{aligned}
\rho_{i, 0}^{s} & =\frac{\phi_{i, 0}^{s}}{\phi_{1,0}^{s}+\phi_{2,0}^{s}+\chi_{1,0}^{s}+\chi_{2,0}^{s}+\tau_{0}^{s}+\psi_{0}^{s}} \quad \text { for } i=1,2 \\
\alpha_{i, 0}^{s} & =\frac{\chi_{i, 0}^{s}}{\phi_{1,0}^{s}+\phi_{2,0}^{s}+\chi_{1,0}^{s}+\chi_{2,0}^{s}+\tau_{0}^{s}+\psi_{0}^{s}} \text { for } i=3,4 \\
\gamma_{0}^{s} & =\frac{\tau_{0}^{s}}{\phi_{1,0}^{s}+\phi_{2,0}^{s}+\chi_{1,0}^{s}+\chi_{2,0}^{s}+\tau_{0}^{s}+\psi_{0}^{s}} \\
\kappa_{0}^{s} & =\frac{\psi_{0}^{s}}{\phi_{1,0}^{s}+\phi_{2,0}^{s}+\chi_{1,0}^{s}+\chi_{2,0}^{s}+\tau_{0}^{s}+\psi_{0}^{s}}
\end{aligned}
$$

The denominator in each of the above equations gives the factor loading relating period 1 stock of socio-emotional skill to the observable measure $Z_{H_{s}, m, 1}$. That is,

$$
\lambda_{H_{s}, m, 1}=\phi_{1,0}^{s}+\phi_{2,0}^{s}+\chi_{1,0}^{s}+\chi_{2,0}^{s}+\tau_{0}^{s}+\psi_{0}^{s}
$$

Again, a residual measure of socio-emotional skill in period 1 can than be constructed as:

$$
\tilde{Z}_{H_{s}, m, 1}=\frac{Z_{H_{s}, m, 1}-\mu_{H_{s}, m, 1}}{\lambda_{H_{s}, m, 1}}=\ln H_{s, 1}+\tilde{\varepsilon}_{H_{s}, m, 1},
$$

and latent socio-emotional skill can be defined as being equal to:

$$
\tilde{Z}_{H_{j}, m, 1}^{*}=\tilde{Z}_{H_{j}, m, 1}-\tilde{\varepsilon}_{H_{j}, m, 1}=\ln H_{j, 1}
$$

The parameters of the cognitive production function and measurement system are estimated, and a residual measure of cognitive skill constructed, in the same way. An identical process for estimating the investment and production functions is then used in each subsequent period.

\section{A.4 Variance of Investment and Production Shocks}

The variance of shocks to investment and production are estimated by as the covariance between the residual from equations A8 and A12 with an alternative measure of their output respectively. Alternative residual measures are constructed by estimating equations A8 and A12 using $Z_{H_{j}, m^{\prime}, 0}$ for $j \in\{s, c\}$ and $Z_{I_{s}, m^{\prime}, 0}$ as outcomes and retrieving their measurement parameters. Given the assumptions on the measurement errors the variance of shocks can be estimated in each $t$ as:

$$
\operatorname{Cov}\left(\frac{v_{t}}{\lambda_{I, m, t}}, \tilde{Z}_{I, m^{\prime}, t}\right)=\operatorname{Var}\left(\pi_{t}\right)=\sigma_{\pi, t}^{2},
$$

and

$$
\operatorname{Cov}\left(\frac{v_{t}^{j}}{\lambda_{H_{j}, m, t}}, \tilde{Z}_{H_{j}, m^{\prime}, t}\right)=\operatorname{Var}\left(\eta_{t}^{j}\right)=\sigma_{H_{j}, t}^{2}
$$




\section{A.5 Signal to Noise Ratios}

The proportion of the variance in an observable measure attributable to the latent variable it proxies as opposed to measurement error is estimated as a function of its measurement parameters and the variance of the unobservable. In the initial period, these are calculated as in Section A.1. In subsequent periods, they are recovered by estimating Equations A8 and A12 using each measure of investment and human capital as the dependent variable. The signal in, for example, a measure of socio-emotional skill at time $t$ is then given by

$$
s_{H_{s, 1}, m, t}=\frac{\lambda_{H_{s, 1}, m, t}^{2} V\left(\ln H_{s, 1}\right)}{\lambda_{H_{s, 1}, m, t}^{2} V\left(H_{s, 1}\right)+V\left(\varepsilon_{H_{s, 1}, m, t}\right)}=\frac{\lambda_{H_{s, 1}, m, t}^{2} \operatorname{Cov}\left(\tilde{Z}_{H_{s, 1}, m, t}, \tilde{Z}_{H_{s, 1}, m^{\prime}, t}\right)}{V\left(Z_{H_{s, 1}, m, t}\right)}
$$

\section{A.6 Socio-emotional Skills in Early Adulthood}

For the measures of three domains of socio-emotional skill - task-effectiveness (t) and social skills (s) at age $22(T+1)$, we estimate the measurement system laid out in Equation 6 imposing the following normalizations for $j \in\{t, s\}$ :

$$
\begin{aligned}
E\left(\ln H_{s, T+1}^{j}\right) & =0 \\
\lambda_{H_{s, 1, T+1}^{j}} & =1
\end{aligned}
$$

These normalisations fix the location and scale of each of these latent socio-emotional skills to one of their observable measures. They also allow us to estimate the measurement means as $E\left(Z_{H_{s}, m, T+1}\right)=\mu_{H_{s}, m, T+1}$. Given these measurement parameters, we take one measurement equation for socio-emotional skill $Z_{H_{s}^{j}, m,+T+1}$ and substitute in to it Equation 4, giving:

$$
Z_{H_{s}^{j}, m, T+1}=\mu_{H_{s}^{j}, m, T+1}+\lambda_{H_{s, m, T+1}^{j}}\left(\ln A_{T}+\rho_{1, T}^{s, j} \ln H_{s, T}+\rho_{2, T}^{s, j} \ln H_{c, T}+\eta_{T}^{s, j}\right)+\varepsilon_{H_{s}^{j}, m, T+1}
$$

After substituting in to this equation residual measures of period $T$ socio-emotional and cognitive skill and rearranging, we arrive at an expression similar to Equations A8 and A12:

$$
Z_{H_{s}^{j}, m, T+1}=\mu_{H_{s}, m, T+1}+\phi_{1, T+1}^{s, j} \tilde{Z}_{H_{s}, m, T}^{*}+\phi_{2, T+1}^{s, j} \tilde{Z}_{H_{c}, m, T}^{*}+\lambda_{H_{s, m, T+1}^{j}} \ln A_{T}+v_{T+1}^{s, j}
$$

Substituting in our expression of $\ln A_{T}$, this can be re-written as:

$$
Z_{H_{s}^{j}, m, T+1}=\phi_{0, T+1}^{s, j}+\phi_{1, T+1}^{s, j} \tilde{Z}_{H^{s}, m, T}+\phi_{2, T+1}^{s, j} \tilde{Z}_{H_{c}, m, T}+\mathbf{x}_{T}^{\prime} \omega_{T+1}^{s, j}+v_{T+1}^{s, j}
$$

Where: 


$$
\begin{aligned}
\phi_{0, T+1}^{s, j} & =\mu_{H_{s}, m, T+1}+\lambda_{H_{s, m, T+1}^{j}} \alpha_{T} \\
\phi_{i, T+1}^{s, j} & =\lambda_{H_{s, m, T+1}^{j}} \rho_{i, T}^{s, j} \quad \text { for } \quad i=1,2 \\
\omega_{T+1}^{s, j} & =\lambda_{H_{s, m, T+1}^{j}} \boldsymbol{\beta} \\
v_{T+1}^{s, j} & =\varepsilon_{H_{s}^{j}, m, T+1}+\lambda_{H_{s, m, T+1}^{j}}\left(\eta_{T}^{s, j}-\rho_{1, T}^{s, j} \tilde{\varepsilon}_{H_{s}, m, T}-\rho_{2, T}^{s, j} \tilde{\varepsilon}_{H_{c}, m, T}\right)
\end{aligned}
$$

Given the normalisations on the period $T$ measurement system, both $\mu_{H_{s}, m, T+1}$ and $\lambda_{H_{s, m, T+1}^{j}}$ are known, and the location and scale of socio-emotional skill $j$ is anchored in one of its measures. Using the same instrumental variables strategy as om estimating the investment and production functions of periods 1-3, we can then recover $\alpha_{T}, \boldsymbol{\beta}$ and $\rho_{i, T}^{s, j}$, for $i=1,2$ without the restriction of CRS. We estimate the returns to scale (RTS) as:

$$
\frac{\phi_{2, T+1}^{s, j}+\phi_{1, T+1}^{s, j}}{\lambda_{H_{s, m, T+1}^{j}}}=\frac{\lambda_{H_{s, m, T+1}^{j}}\left(\rho_{1, T}^{s, j}+\rho_{2, T}^{s, j}\right)}{\lambda_{H_{s, m, T+1}^{j}}}
$$

\section{A.7 The Parameters of the Adult Outcome Equation}

Substituting a residual measure of $T+1$ task effectiveness and and social skills, and a time $T$ measure of cognition in to equation 11 gives:

$$
O_{T+1}=\mu_{o}+\gamma_{1}^{o} \tilde{Z}_{H_{s}^{t}, m, T+1}^{*}+\gamma_{2}^{o} \tilde{Z}_{H_{s}^{s}, m, T+1}^{*}+\gamma_{3}^{o} \tilde{Z}_{H_{c}, m, T}^{*}+\mathbf{x}_{T+1}^{\prime} \boldsymbol{\delta}+\eta_{T+1}^{o}
$$

As in estimating the production and investment equations across period 1-4, this can be rearranged as:

$$
O_{T+1}=\mu_{o}+\gamma_{1}^{o} \tilde{Z}_{H_{s}^{t}, m, T+1}+\gamma_{2}^{o} \tilde{Z}_{H_{s}^{s}, m, T+1}+\gamma_{3}^{o} \tilde{Z}_{H_{c}, m, T}+\mathbf{x}_{T+1}^{\prime} \boldsymbol{\delta}+v_{T+1}^{o}
$$

where

$$
v_{T+1}^{o}=\eta_{T+1}^{o}+\gamma_{1}^{o} \varepsilon_{H_{s}^{p}, m, T+1}+\gamma_{2}^{o} \varepsilon_{H_{s}^{l}, m, T+1}+\gamma_{3}^{o} \varepsilon_{H_{c}, m, T}
$$

Although we do not have to disentangle the factor loadings from the parameters of the outcome equation, we have an identical measurement error problem as in estimating Equations A8, A12 and A16.

Given we use indicators of risky behaviours as outcomes, we use a similar instrumental variable strategy and estimate a linear probability model using alternative measures of the two socio-emotional skill domains and cognition as instruments - but for binary outcomes with endogenous, continuous independent variables. We favor this method over maximum likelihood or control function methods for two main reasons. Firstly, consistency estimators based on these methods relies on full specification 
of the first stage equations and having continuously distributed endogenous variables (Blundell and Powell, 2004). The variables we use as proxies are not truly continuous (although we assume that the latent variables are), and we know we do not have a complete set of relevant instruments on the latent variables, so these assumptions are not satisfied. An estimator of a LPM using 2SLS will not be inconsistent, however, and only on standard IV assumptions i.e that $\mathbb{E}\left(Z_{H_{s}^{k}, m^{\prime}, T+1} v_{j, 0}\right)=0 \quad \forall H_{s}^{k}$ and $m^{\prime} \neq m$,

Secondly, an IV LPM makes no assumptions about the distribution of the measurement error, wheres ML/control function methods rely on joint normality of $v_{T+1}^{o}$ and in the error term in the first stage regressions. Given $v_{T+1}^{o}$ is an additive function of the measurement error and outcome equation error, this amounts to assuming that the measurement errors, outcome equation errors, and the errors in the first stage regressions are jointly normally distributed. As alluded to in the main body of this study, the methodology we use to estimate the investment and human capital production functions is robust to non-normal measurement errors (Agostinelli and Wiswall, 2016a), an added benefit given Laajaj and Macours (2019) find evidence that measurement error in socio-emotional skill measures is non-classical among samples in Kenya and Colombia. 


\section{B Additional description of child assessments}

The observable measures of child and parental human capital and investment in the Young Lives data are derived from both caregivers' and children's responses to survey questions across waves. In the case of cognitive skill, all measures are scores on tests administered as part of the survey. Below, we provide more detail on the types of measures used for each of the inputs in to and outputs of the human capital development process.

\section{Socio-emotional Skill Measures}

We do not use all of the socio-emotional measures available in the YL survey. Instead, where possible, we focus on those that can be described as reflecting children's Core Self-Evaluation (CSE) - those that predominantly ask questions about the children themselves, and their evaluation of aspects of their personality. For example, we excluded commonly used measures of subjective wellbeing such as Cantril's ladder (Cantril et al., 1965), and measures of children's trust in others or their social networks. We also use measures in some rounds but not in others because their sub-items had change over time. This is the case, for example, with measures of pride and self-esteem, which change substantially after age 15

\section{Strengths and Difficulties Questionnaire (SDQ)}

In the initial period at age 8 , the children are not asked questions so we used caregivers' responses to the 25 question SDQ. Detailed information on the structure and purpose of the SDQ can be found at https://www.sdqinfo.com/. These 25 questions are designed to measure 5 aspects of the children's socio-emotional skills: emotional symptoms, conduct problems, hyperactivity/inattention, peer/relationship problems, and pro-social behaviour. Each of these sub-scales contains 5 questions about whether a child exhibits certain behaviours, and, traditionally, responses from parents can be not true, somewhat true, or certainly true. If assigned the values of one, two, and three respectively, the responses to these questions can be summed within each sub-scale to give an indication of the extent to which a child is experiencing difficulties.

In the survey administered as part of the Young Lives survey in Peru, the possible responses caregivers could provide were yes, sometimes, and no. Although slightly different in wording, these responses are observationally equivalent, and so we assign them analogous numerical values and sum responses within the 5 sub-scales, giving us 5 measures of socio-emotional skill. Goodman (2001) and Muris et al. (2003) discuss the validity and reliability of the SDQ in measuring these 5 underlying socio-emotional characteristics.

\section{Young Lives Psychosocial Scales}

Across its rounds, the Young Lives survey has adapted several commonly used scales designed to measure specific psychosocial characteristics. At ages 12, 15, 19, and 22 we use a measure of pride and self-esteem, based on Rosenberg (1965) scale. This scale poses statements to children about their self-confidence as it relates to their belongings, home, abilities, work, and achievements. For example, 
the following statements are contained in the scale:

- Ifeel proud the show my friends or other visitors where I live;

- I am often proud because I do have the right books, pencils, and other equipment for school;

- I am proud of my achievement at school; and

- The job I do makes me feel proud.

The children are then asked to what degree these statements represent their beliefs. At age 12, possible responses are on a 3-point scale of no, yes, or more or less respectively. At ages 15, 19, and 22 possible responses were on a 5-point scale from strongly agree to strongly disagree. After being assigned a numeric value, responses were summed to give each child a pride/self-esteem "score".

We also use a scale measuring agency at ages 12, 15, 19, and 22. This scale is based on Rotter (1966) and Bandura (1993), and poses a number of statements to children about the degree of control they have over their life. For example, the scales includes statements such as:

- If I try hard I can improve my situation in life;

- I like to make plans for my future studies and work; and

- If I study hard at school I will be rewarded by a better job in the future. .

The possible responses across ages are the same as in the case of the pride and self-esteem scale. Again, once assigned a numeric value, these responses are summed to give each child a agency/self-efficacy score. More information on the selection, construction, and validity of all of these scales can be found in Yorke and Ogando (2018).

\section{General Self-efficacy}

At ages 19 and 22 we utilise a newly added self-efficacy measure from the Young Lives data. This measure is based on the general self-efficacy scale of Jerusalem and Schwarzer (1979), which is designed to measure individuals' belief in their self-determination and ability to cope with adversity. Again, the scale consists of statements that children are asked to agree/disagree with. It contains statements such as:

- I can always manage to solve difficult problems if I try hard enough;

- It is easy for me to stick to my aims and accomplish my goals; and

- I can solve most problems if I invest the necessary effort.

Responses to these statements are on a 4-point scale from strongly agree to strongly disagree. These responses are assigned numeric values and then summed to prove a general self-efficacy "score" which we use as a measure of socio-emotional skill. Yorke and Ogando (2018) provides more detailed information on the selection and construction of this scale in the Young Lives data. 


\section{Marsh Self Description}

At ages 19 and 22 we also use sub-scales of the Marsh Self-description Questionnaires measuring general self-esteem, peer relations, and parent relations. Each sub-scale is comprised of eight statements about self-concept in the respective domain. They sub-scales are based heavily on the proposed multi-dimensional structure of self-concept of Shavelson et al. (1976). These statements are presented to children, who are then asked to what extent they agree or disagree with them. As examples, the general self-esteem scale includes the statement $a$ lot of things about me are good; the peer relations scale a statement that I get along with other kids easily; and the parent relations scale that my parents understand me. Once again, the possible responses to these statements range from strongly agree to strongly disagree, which we assign numeric values and sum within sub-scales to derive scores for each. Yorke and Ogando (2018) provides more detailed information on theoretical concepts underpinning the Marsh Self-description questionnaires and the validity of their structure.

\section{Duckworth and Quinn Grit Scale}

At age 22, we use measures of two aspects of "grit" as designed by Duckworth and Quinn (2009). These sub-scales are shortened versions of those first proposed in Duckworth et al. (2007) and are designed to measure what they define as consistency of interest and perseverance of effort. As with the vast majority of the psychometric measures we use, these assessments involve presenting children with several statements - in this case four - about the relevant aspect of grit, then asking them the extent to which they agree the statements describe themselves. Respectively, the consistency of interest and perseverance of effort scales contain statements such as I often set a goal but choose to pursue a different one, and I finish whatever I begin. Responses to the statements are on a 5-point scale, from not like me at all to very much like me. We sum responses within each group to construct scores for each aspect of grit.

\section{Review of Personal Effectiveness with Locus of Control (ROPELOC)}

At age 22 we also make use of two, three-question sub-scales from the ROPELOC measuring their leadership and cooperative teamwork abilities (Richards et al., 2002). The two scales contain questions statements such as I am seen as a capable leader and I am good at cooperating with team members respectively. Children are asked to what extent they agree these statements describe themselves, with possible responses being on a 4-point scale from strongly agree to strongly disagree. After being assigned numeric values, we use the sum of responses within each sub-scale as measure of their ability in each domain.

\section{Big Five Inventory}

Also at age 22, we use two components of the Big Five Inventory - conscientiousness and neuroticism. The sub-scales are part of the larger inventory which also seeks to measures openness, agreeableness, and extraversion. They contain eight and nine statements respectively and respondents are asked the extent to which they agree that these statements describe them. For example, the statements 
representing conscientiousness include:

- I am someone who does a thorough job;

- I am someone who tends to be organised; and

- I am someone who makes plans and follows through with them..

Similarly, the statements indicating neuroticism include:

- I am someone who is relaxed, handles stress well;

- I am someone who is emotionally stable, not easily upset; and

- I am someone who gets nervous easily.

Responses are on a 5-point scale from strongly agree to strongly disagree and are assigned a numeric value. The responses are summed within each of the two components to give children a score for conscientiousness and neuroticism.

\section{B.1 Cognitive Skill}

The YL data survey contains cognitive assessments at every age except 22. As with the socio-eomtional skill measures, the assessments administered differ across ages based on suitability, however the measures cover the same three broad domains of cognitive skills: language ability and fluid intelligence, or reasoning.

\section{Reading and Writing Levels}

At ages 8 and 12, the writing level of children in the older cohort was assessed by asking them to read from aloud from cards containing three lines, the first containing individual letters, the second a word, and the third a simple sentence. Figure B1 shows what one of these cards looks like. The children were give a score of 1 if they could read the sentence, 0.66 if they could read the word, and 0.33 if they could read the letters, and 0 if they could not read anything.

For the writing assessment, interviewers read aloud a sentence which children were asked to transcribe. For example, children might have been asked to write down the sentence "the sun is hot". Sentences were adapted based on the country in which the test was administered to ensure comprehension. If children could write the sentence down easily they were awarded 1 point, and were awarded 0.5 or 0 points respectively if they wrote it down with errors or could not write it at all. 
Figure B1: Example of a YL reading card used to asses children's reading level at ages 8 and 12

\section{Example of reading card}

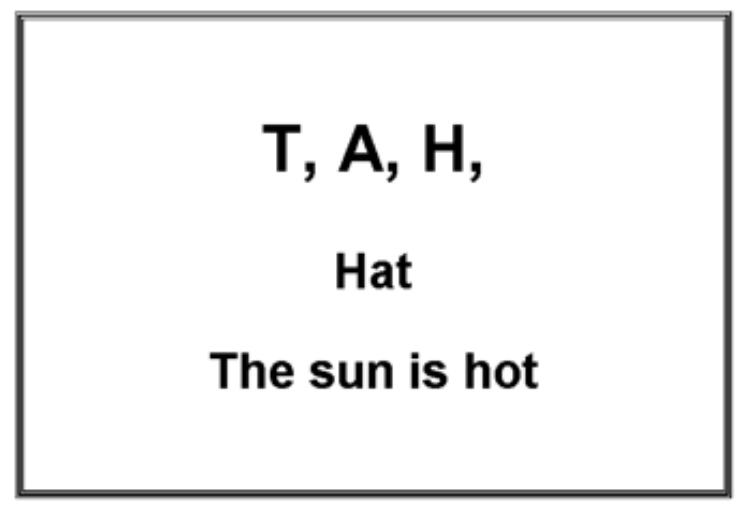

Source: Revollo (2018)

\section{Raven's Coloured Progressive Matrices}

At age 8 children are administered the the Raven's coloured progressive matrices test Raven (1958). This assessment involves showing children patterns with missing blocks, and asking them to identify which block from a choice of six completes it. The test as administered in the YL survey has 36 items, asked in order of difficulty. A child's raw score in the test is calculated as the total number of correct responses.

Figure B2: Examples of straightforward a Raven's matrices at age 8

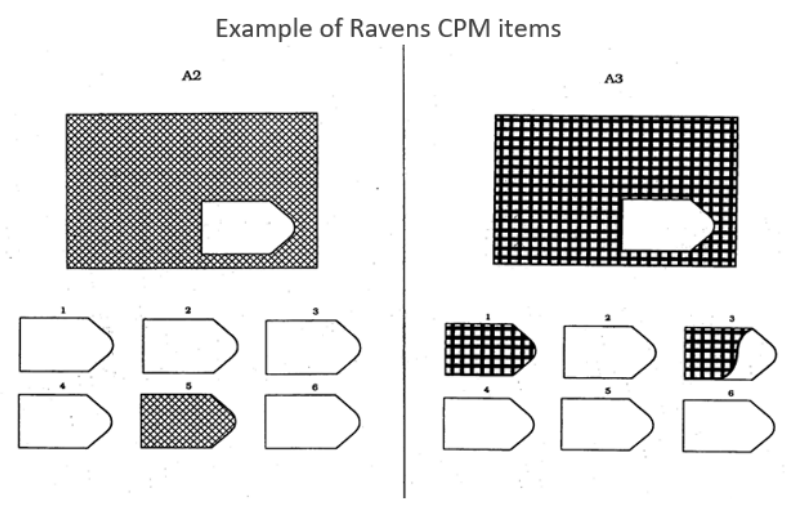

Source: Revollo (2018)

\section{Peabody Picture Vocabulary Test (PPVT)}

The PPVT was administered to children in age ages 12 and 15, and is designed to measure receptive vocabulary in children as young as 2.5 years old. The test involves presenting children with cards depicting four different scenarios, and asking them which picture best shows a sentence or word read 
aloud by the examiner. For example, an examiner might say "point to the picture that shows crying" whilst showing them the card in Figure B3. The questions become increasingly difficult, with the starting point of the test determined by the child's age.

Figure B3: Example of a PPVT picture card at ages 12 and 15

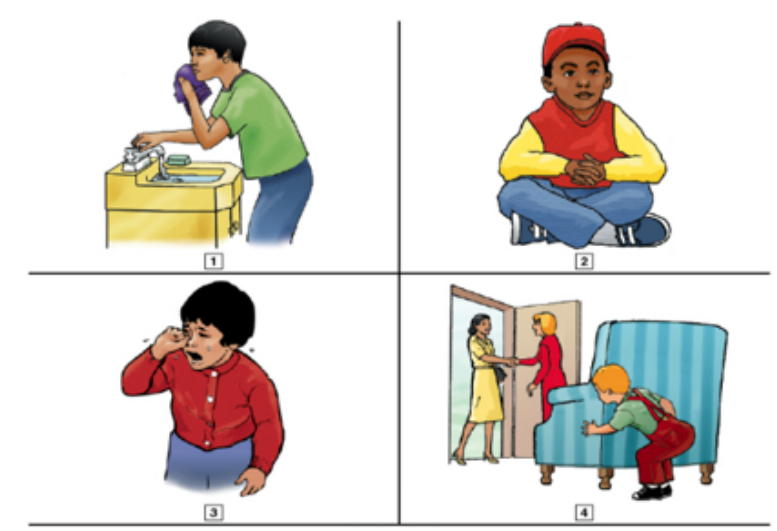

Source: Revollo (2018)

\section{YL Maths Test}

The YL also contains a maths test to measure "mathematical achievement". For the older Peruvian cohort, this test was administered at ages 12, 15, and 19. At age 12 it consisted of 10 mathematics questions from the International Association for the Evaluation of Educational Achievement's (IEA) 2003 Trends in International Mathematics and Science Study Reddy et al. (2003). Children's raw score were simply the total number of correct answers.

At age 15 the test was expanded to include 30 questions in two sections, one with 20 questions on mathematics (addtion, division etc.) and another with 10 problem solving questions. At age 19 the test was further altered to account for differences in competencies across countries. Questions were grouped into three "booklets" of increasing difficulty, and children started on the second, intermediate booklet. If they performed well on intermediate skills they then answered questions on advanced skills, whereas if they performed poorly they moved on to answer questions on basic skills. Revollo (2018) describes the tests and their internal and external validity in detail.

\section{YL Reading Comprehension/Language Test}

At age 19, children's reading comprehension was tested in a similar manner to their mathematical achievement ate the same age, described above. Comprehension questions were grouped into three booklets: (1) basic comprehension, (2) intermediate comprehension and (3) advanced comprehension. Children started with questions in booklet 2, and progressed to booklets 1 or 3 depending on their performance. The items administered were country specific in that they described or asked about day-to-day activities or situations that commonly occur in Peru. Revollo (2018) describes the design of the reading comprehension test in detail. 


\section{Cloze Language Test}

At age 15, the children were administered the Cloze reading comprehension test, developed by the Development Analysis Group in Peru (GRADE - Grupo de Análisis para el Desarrollo). It was made up of 24 items, of increasing difficulty that asked children to fill in missing words in a sentence. Figure B4 shows an example of an item on the test. Ra scores were the total correct answers.

Figure B4: Example of a Cloze test card at age 15

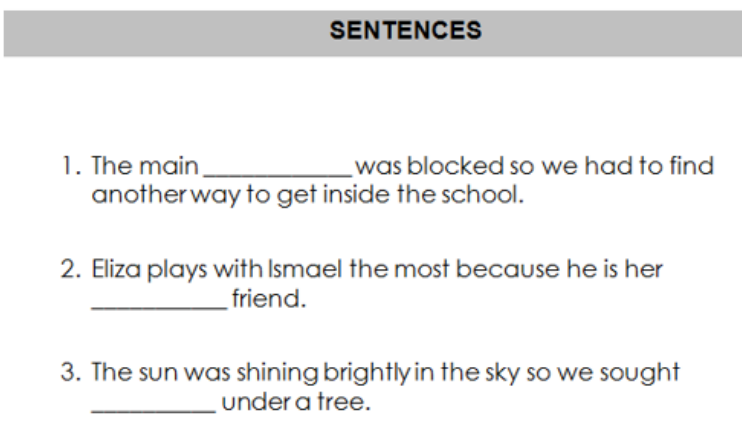

Source: Revollo (2018) 


\section{Additional Tables and Digures}

\section{C.1 Additional Descriptive Figures and Tables}

Figure C1: The correlation between measures of social skills at age 22 and household wealth at age 8
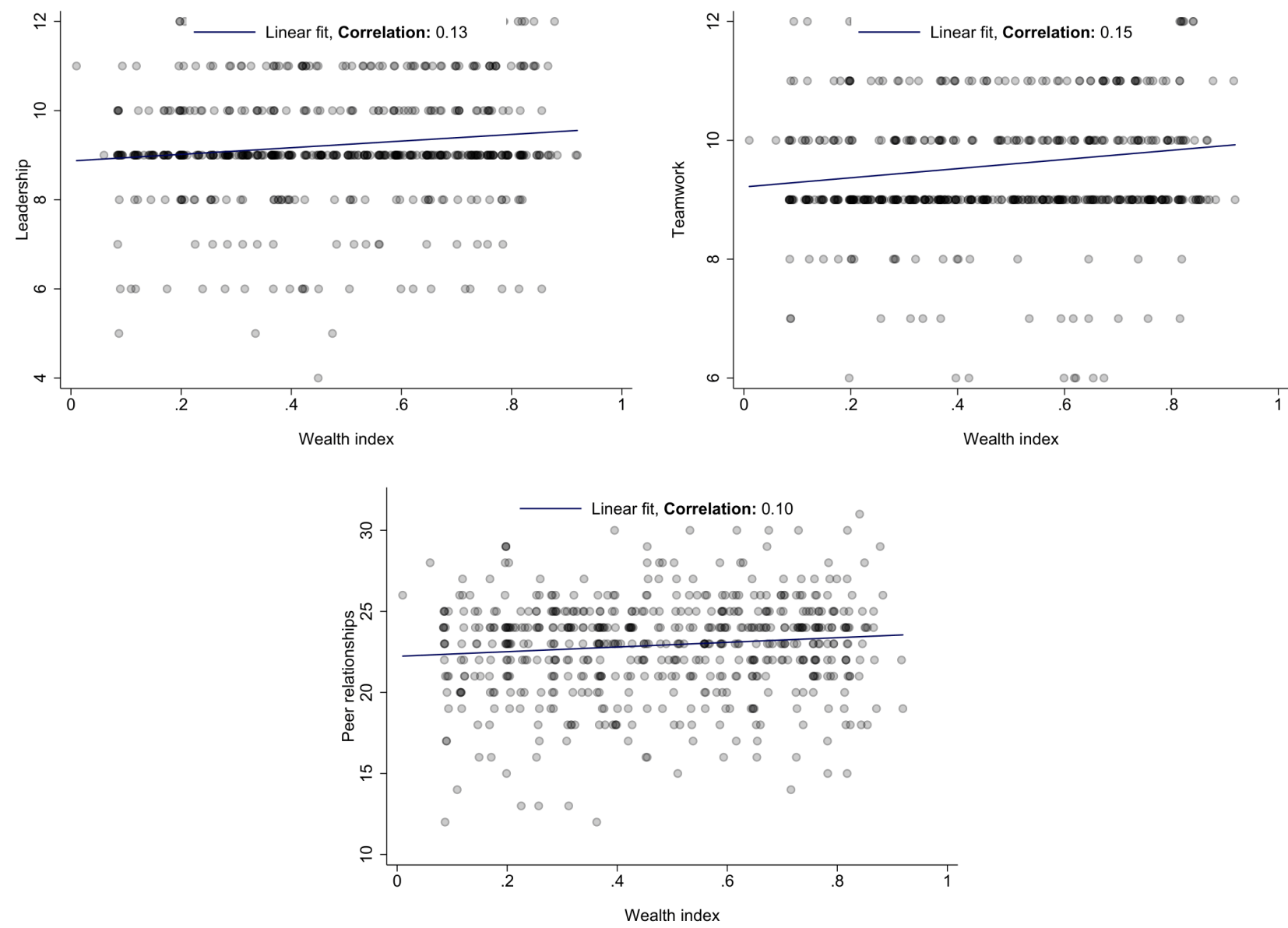

Note: The measures, clockwise from top left, are of leadership qualities, ability to work in a team, and quality of relationships with peers, and are are described in detail in Appendix B. The wealth index is constructed to range between 0 and 1 and is an average of three subindices: housing quality, access to services, and ownership of certain consumer durables. See Briones (2017) for further details. 
Figure C2: The correlation between measures of Task Effectiveness skills at age 22 and household wealth at age 8
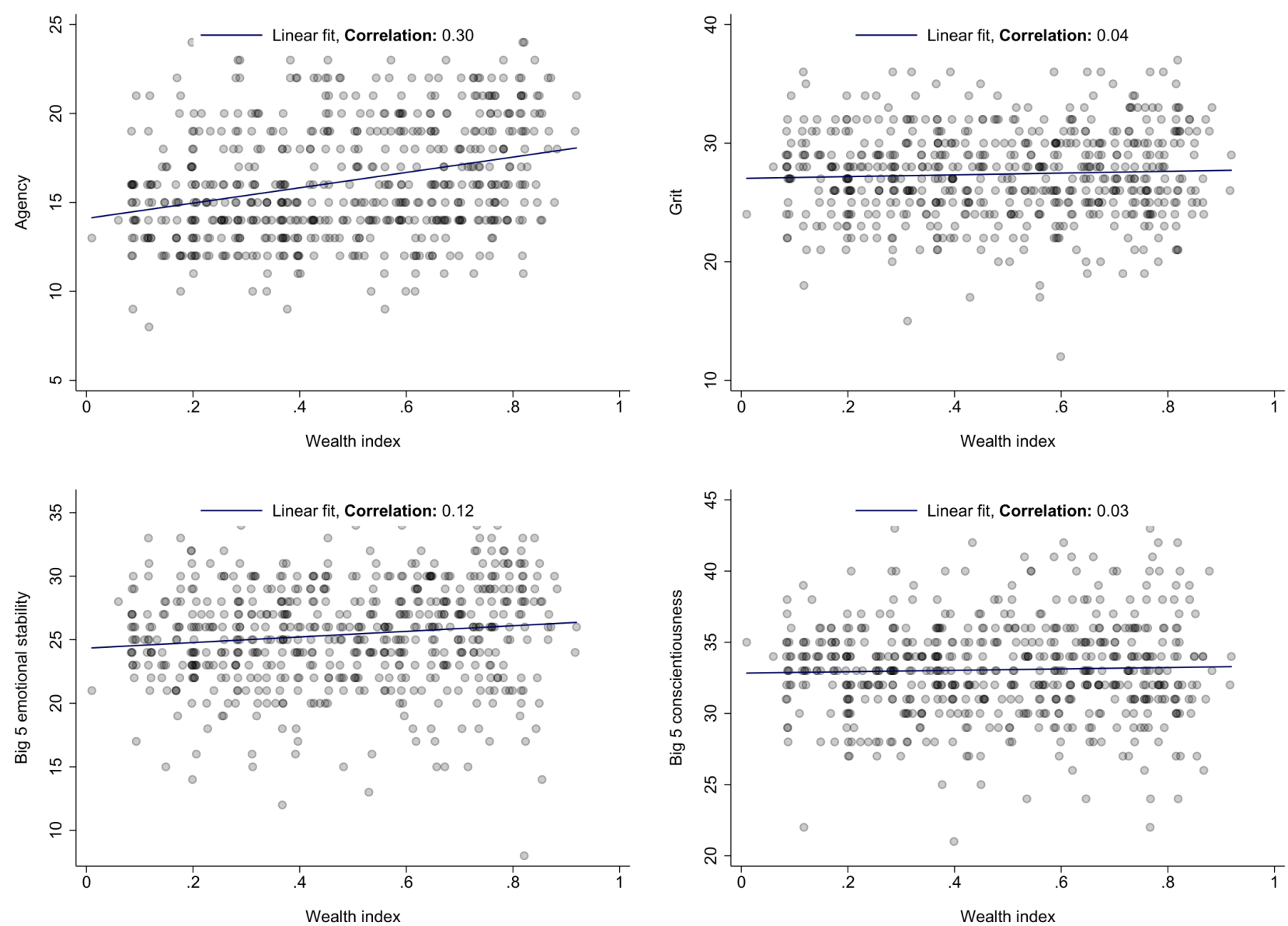

Note: The measures, clockwise from top left, are of agency, grit, emotional stability, and conscientiousness, and are are described in detail in Appendix B. The wealth index is constructed to range between 0 and 1 and is an average of three subindices: housing quality, access to services, and ownership of certain consumer durables. See Briones (2017) for further details. 
Figure C3: The correlation between cognitive skill measures and household wealth at Age 8
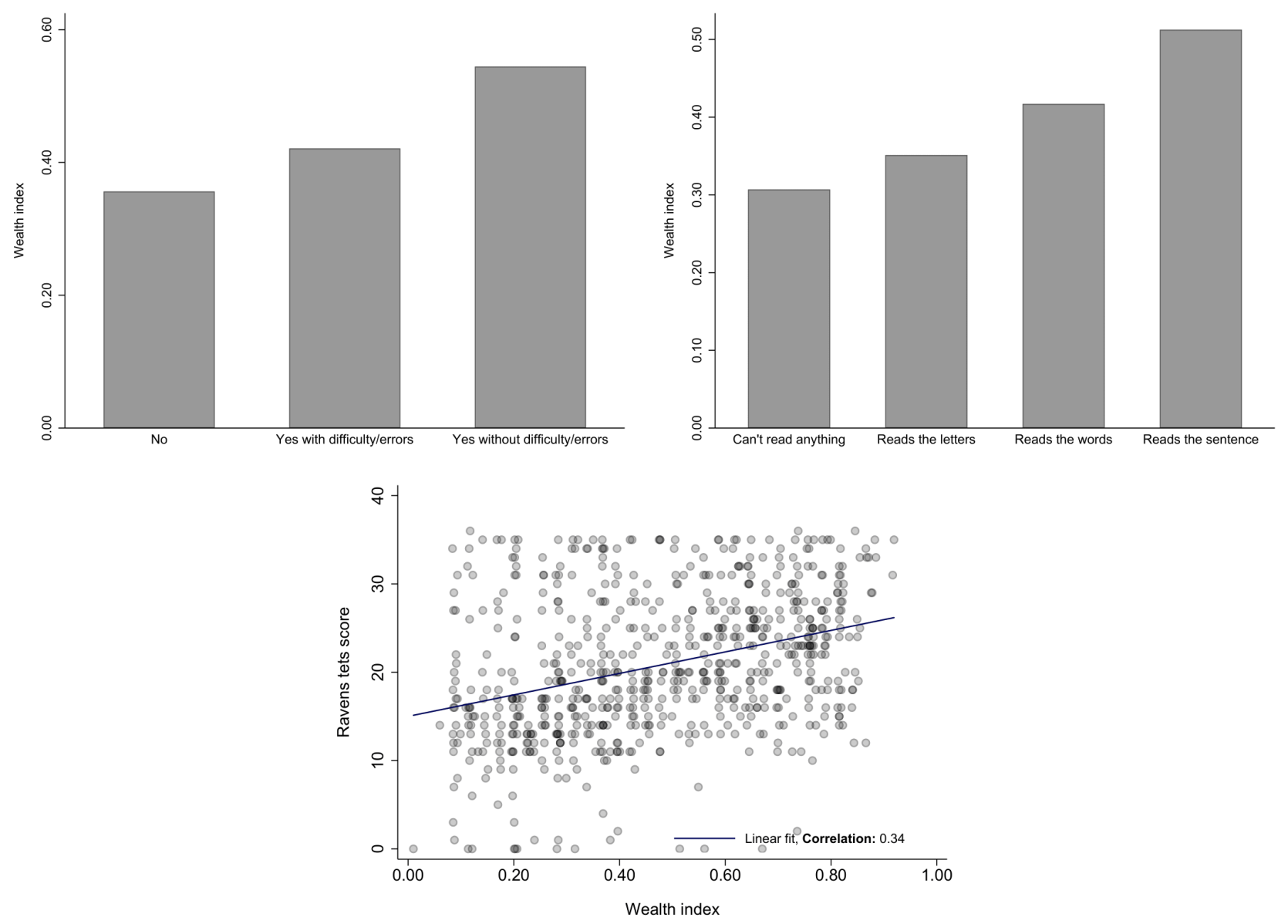

Note: The measures, clockwise from top left, are of the child's writing ability, reading ability, and score on the Ravens progressive matrices test, and are described in detail in Appendix B. The wealth index is constructed to range between 0 and 1 and is an average of three subindices: housing quality, access to services, and ownership of certain consumer durables. See Briones (2017) for further details. 


\section{C.2 Summaries of Observable measures Used in Estimations}

Table C1: summary statistics of observable socio-emotional skill measures used in estimating investment and production functions

\begin{tabular}{|c|c|c|c|c|c|}
\hline & Mean & sd & Max. & Min. & Unique values \\
\hline \multicolumn{6}{|l|}{ Age 8} \\
\hline$\overline{\text { SDQ: }}$ conduct problems* & 12.263 & 2.210 & 15 & 5 & 11 \\
\hline SDQ: hyperactivity* & 9.752 & 2.469 & 15 & 5 & 11 \\
\hline SDQ: pro-sociality & 14.013 & 1.587 & 15 & 5 & 10 \\
\hline SDQ: emotional regulation* & 10.513 & 3.080 & 15 & 5 & 11 \\
\hline SDQ: peer problems* & 11.815 & 2.212 & 15 & 5 & 11 \\
\hline Age 12 & & & 11 & & \\
\hline$\overline{\text { Pride } \&}$ self-esteem & 12.415 & 2.646 & 16 & 2 & 14 \\
\hline Agency & 6.911 & 1.364 & 10 & 2 & 9 \\
\hline \multicolumn{6}{|l|}{ Age 15} \\
\hline$\overline{\text { Pride } \& \text { self-esteem }}$ & 22.936 & 2.905 & 30 & 14 & 17 \\
\hline Agency & 18.168 & 2.054 & 25 & 11 & 14 \\
\hline \multicolumn{6}{|l|}{ Age 19} \\
\hline$\overline{\text { Agency }}$ & 18.865 & 2.088 & 25 & 12 & 14 \\
\hline Self-esteem & 24.778 & 2.335 & 32 & 16 & 17 \\
\hline Self-efficacy & 30.205 & 3.274 & 40 & 8 & 21 \\
\hline Peer relationships & 22.748 & 3.255 & 32 & 10 & 21 \\
\hline \multicolumn{6}{|l|}{ Age 22: task effectiveness } \\
\hline Agency & 16.181 & 3.275 & 25 & 8 & 18 \\
\hline Grit & 27.393 & 3.730 & 40 & 12 & 25 \\
\hline Big 5 emotional stability & 25.428 & 4.002 & 36 & 8 & 26 \\
\hline Big 5 conscientiousness & 33.064 & 3.323 & 44 & 21 & 23 \\
\hline \multicolumn{6}{|l|}{ Age 22: social skills } \\
\hline Leadership & 9.228 & 1.281 & 12 & 4 & 9 \\
\hline Teamwork & 9.586 & 1.172 & 12 & 6 & 7 \\
\hline Peer relationships & 22.921 & 3.124 & 32 & 12 & 21 \\
\hline
\end{tabular}

Note: The measures in this table are those of socio-emotional skill used to estimate the human capital production and investment functions. From left to right, the columns contain the aspect of socio-emotional skill the measures capture, their sample mean and standard deviation (sd), and the maximum, minimum and number of unique values in the sample. A* indicates a the order of a measure was reversed from negative to positive so that a higher value indicates more skill. 
Table C2: summary statistics of observable cognitive skill measures used in estimating investment and production functions

\begin{tabular}{lccccc}
\hline & Mean & sd & Max. & Min. & Unique values \\
\hline Age 8 & & & & & \\
Ravens score & 20.822 & 8.062 & 36 & 0 & 37 \\
Writing level & 2.418 & 0.709 & 3 & 1 & 3 \\
Reading level & 3.582 & 0.968 & 4 & 1 & 4 \\
Age 12 & & & & & \\
Math score & 5.754 & 1.774 & 8 & 0 & 9 \\
PPVT score & 72.025 & 15.554 & 106 & 10 & 71 \\
Writing level & 2.845 & 0.394 & 3 & 1 & 3 \\
Reading level & 3.934 & 0.387 & 4 & 1 & 4 \\
Age 15 & & & & & \\
Math score & 13.139 & 5.722 & 29 & 0 & 29 \\
PPVT score & 96.924 & 17.300 & 125 & 13 & 72 \\
Cloze score & 14.706 & 5.658 & 24 & 0 & 25 \\
Age 19 & & & & & \\
Math score & 16.960 & 5.611 & 28 & 1 & 28 \\
Language score & 15.926 & 3.718 & 24 & 3 & 20 \\
\hline
\end{tabular}

Note: The measures in this table are those of cognitive skill used to estimate the human capital production and investment functions. From left to right, the columns contain either the name of the test through which skill was measured of the aspect of cognition the test captured, their sample mean and standard deviation (sd), and the maximum, minimum and number of unique values in the sample. 
Table C3: summary statistics of observable investment and parental skill measures used in estimating investment and production functions

\begin{tabular}{|c|c|c|c|c|c|}
\hline & Mean & sd & Max. & Min. & Unique values \\
\hline \multicolumn{6}{|l|}{ Age 12} \\
\hline$\overline{\text { Per-child expenditure on books }}$ & 1.341 & 2.822 & 65 & 0 & . \\
\hline Per-child expenditure on unforms & 1.028 & 3.135 & 76 & 0 & . \\
\hline Hours studying & 2.950 & 1.282 & 8 & 0 & 9 \\
\hline Hours in school & 4.776 & 1.585 & 12 & 0 & 10 \\
\hline \multicolumn{6}{|l|}{ Age 15} \\
\hline Per-child expenditure on books & 1.670 & 1.821 & 20 & 0 & , \\
\hline Per-child expenditure on uniforms & 1.302 & 1.841 & 27 & 0 & . \\
\hline Food groups & 22.436 & 4.038 & 32 & 3 & 27 \\
\hline Hours studying & 2.079 & 1.168 & 7 & 0 & 8 \\
\hline Hours in school & 5.908 & 1.966 & 11 & 0 & 10 \\
\hline \multicolumn{6}{|l|}{ Age 19} \\
\hline$\overline{\text { Educational expenditure }}$ & 0.537 & 1.729 & 36 & 0 & . \\
\hline Per-child non-food expenditure & 4.502 & 6.517 & 55 & 0 & . \\
\hline Food groups & 8.914 & 1.923 & 14 & 3 & 12 \\
\hline Hours in school & 3.565 & 3.645 & 15 & 0 & 16 \\
\hline Hours studying & 1.473 & 1.852 & 12 & 0 & 11 \\
\hline \multicolumn{6}{|l|}{ Parental socio-emotional skill } \\
\hline Agency & 12.974 & 2.030 & 15 & 7 & 9 \\
\hline Pride \& self-esteem & 14.458 & 1.154 & 15 & 8 & 8 \\
\hline Cantril's ladder & 4.848 & 2.044 & 9 & 1 & 9 \\
\hline \multicolumn{6}{|l|}{ Parental cognitive skill } \\
\hline Education & 7.251 & 4.539 & 18 & 0 & 17 \\
\hline Can read newspaper & 2.604 & 0.713 & 3 & 1 & 3 \\
\hline Can understand things written in Spanish & 2.502 & 0.787 & 3 & 1 & 3 \\
\hline
\end{tabular}

Note: The measures in this table are those of investment and parental human capital used to estimate the human capital production and investment functions. From left to right, the columns contain a descriptions of the investment or human capital measures, their sample mean and standard deviation (sd), and the maximum, minimum and number of unique values in the sample. Variables with missing number of unique values are continuous. 


\section{C.3 Results of Initial Exploratory Factor Analysis (EFA) Across Ages 8-19}

As part of our EFA, we first examine whether our observable measures have enough variation to capture sufficient variation in the latent variables we use as inputs/outputs of the production and investment functions. To do so, we first analyse the extent of the shared variation in the observable measures, and retain/discard their underlying factors based on their eigenvalues and a parallel analysis as proposed by Horn (1965). The measures we use in this EFA at each age described in the previous Section of this Appendix, and were those that best met the principal of Core Self-Evaluation (CSE).

The parallel analysis first involves randomly simulating data of the same dimension as that being analysed. For example, if preforming an EFA on 6 variables measuring characteristics of $N$ individuals, the resulting simulated dataset would be $N \times 6$. The eigenvalues of the correlation matrix among the randomly simulated data are the calculated and compared with those from the factors underlying the the actual data. Horn (1965) suggests retaining factors from the actual data as long as their eigenvalues are larger than those from the randomly generated correlation matrix. To complement this we generate scree plots as proposed by Cattell (1966), plotting the eigenvalues of factors in order of magnitude. ${ }^{17}$

Figure $\mathrm{C} 4$ shows one of these plots for initial cognitive and socio-emotional skill. Using Horn (1965)'s rule-of-thumb, the figure would suggest these measures have enough variation to retain at most 4 factors. Cattell (1966) suggests retaining only the factors whose eigenvalues are larger than that of the factor at which the first large drop in eigenvalue occurs. In Figure $\mathrm{C} 4$ the first major drop in eigenvalue occurs at factor 3. Additionally, Kaiser (1960) suggests keeping only a number of factors greater or equal to the number of eigenvalues greater than 1, which is true for only 2 latent factors in Figure C4. Together, these criteria suggest that these measures are rich enough to capture at least the two underlying factors we ex-ante believe to be underlying the measures. We repeat this analysis in each round, grouping observables as those measuring child human capital, investments, or parental skills.

Having verified the measures share meaningful variation with which to capture their underlying factor, we then establish the relationship between each measure and retained factor by estimating their factor loadings. Tables C4 and C5 show the rotated factor loadings and unique variance associated with each measure of human capital and investment respectively in each period. We rotate the factor loadings obtained from an EFA using the oblique quartimin rotation, which enables us to obtain a vector of factor loadings allowing for underlying factors to be correlated and so the loadings accurately capture the extent to which observables group around factors. For children's human capital (Table C4) there is a clear divide between those the we ex-ante believe to measure socio-emotional versus cognitive skill. For example, in the initial period the SDQ measures load heavily on Factor 2 - which we define as the socio-emotional factor - whereas the cognitive assessments load heavily on Factor 1 the cognitive factor. There are a couple of slight exceptions to this, however. Agency appears to load on both factors in periods 2 and 3, albeit to a much larger extent on the socio-emotional factors. The same is true for self-efficacy in period 3. This is perhaps unsurprising given the relationship between measures of this type an cognitive skill. We retain these measures given that they are highly correlated with cognition, and are measures of particular interest to the questions of this paper.

\footnotetext{
${ }^{17}$ To conduct this analysis we use Philip B. Ender's -fapra- package in Stata.
} 
Figure C4: Eigenvalues from EFA and parallel analysis of initial (Age 8) child socio-emotional and cognitive skill measures

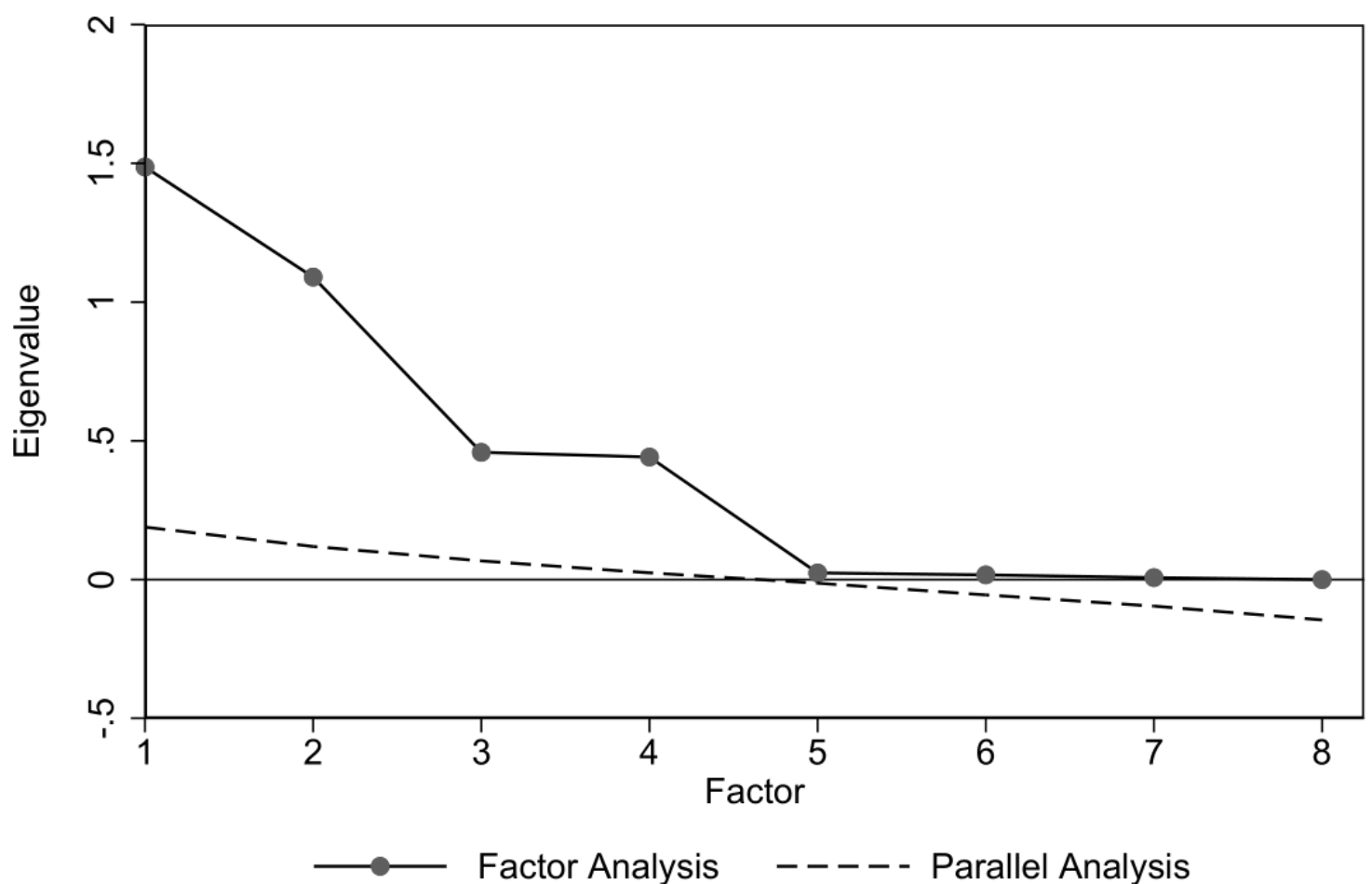

Note: The solid line connects the eigenvalues of the factors underlying 8 measures of socio-emotional (5 measures) and cognitive skill (3) at age 8 in the YL survey. The dotted line connects the eigenvalues of the 8 factors underlying randomly simulated data of the same dimension (i.e $N \times 8$ ). This figure was generated using Philip B. Ender's -fapra- package in Stata.

Although, informed by the data, we only retain one factor for investments, Table C5 shows the estimated rotated factor loadings and unique variance associated with each measure of investment across periods. These are useful in that they provide an ex-ante approximation to the extent of signal in each measure. 
Table C4: Factor loadings and unique variance of observable cognitive and socioemotional skill measures

Factor $1 \quad$ Factor 2 Uniqueness

$\begin{array}{lccc}\text { Age 8 } & & & \\ \text { SDQ conduct problems } & 0.019 & 0.605 & 0.630 \\ \text { SDQ emotional symptoms } & 0.055 & 0.450 & 0.788 \\ \text { SDQ hyperactivity } & -0.035 & 0.620 & 0.621 \\ \text { SDQ peer problems } & -0.007 & 0.274 & 0.925 \\ \text { SDQ prosociality } & 0.026 & 0.185 & 0.964 \\ \text { Ravens test score } & 0.389 & -0.063 & 0.852 \\ \text { Writing level } & 0.790 & -0.048 & 0.385 \\ \text { Reading level } & 0.750 & 0.067 & 0.418\end{array}$

\begin{tabular}{ll}
\hline$N$ & 606 \\
\hline
\end{tabular}

\section{Age 12}

$\begin{array}{lccc}\overline{\text { Agency }} & -0.011 & 0.316 & 0.904 \\ \text { Pride } & 0.002 & 0.853 & 0.270 \\ \text { Current position on ladder } & 0.023 & 0.096 & 0.988 \\ \text { Maths test score } & 0.618 & 0.068 & 0.568 \\ \text { PPVT score } & 0.904 & -0.020 & 0.202\end{array}$

\section{Age 15}

$\overline{\text { Agency }}$

Pride

Cantril's ladder

SDQ: Emotional

Maths test score

PPVT score

Cloze test score

$\begin{array}{ccc}0.106 & 0.326 & 0.875 \\ -0.002 & 1.201 & -0.442 \\ 0.100 & 0.114 & 0.975 \\ 0.279 & 0.078 & 0.911 \\ 0.711 & -0.048 & 0.499 \\ 0.821 & 0.025 & 0.321 \\ 0.875 & 0.002 & 0.233\end{array}$

\section{Age 19}

$\overline{\text { Agency }}$

Self-efficacy

0.197

0.325

0.830

Self-esteem

0.683

0.148

0.473

Peer relationships

0.788

$-0.057$

0.393

Cantril's ladder

0.667

$-0.061$

0.567

SDQ: Emotional

0.304

$-0.030$

0.910

Maths test score

0.205

0.124

0.933

Language test score

$-0.006$

0.821

0.327

$-0.004$

0.839

0.297

$N$

584

Note: The table contains rotated factor loadings and the proportion of variance in each cognitive and socio-emotional skill measure not shared with all others after retaining two factors from an initial exploratory factor analysis. Two factors were retained based on the assumption the measures proxy two latent concepts, socio-emotional and cognitive skill and the rules-of-thumb for factor retention proposed by Kaiser (1960), Horn (1965), and Cattell (1966). Factor loadings were obtained through an oblique quartimin rotation. 
Table C5: Factor loadings and unique variance of observable investment measures

\begin{tabular}{lcc}
\hline & Factor 1 & Uniqueness \\
\hline Age 12 & & \\
\hline Per child book expenditure & 0.584 & 0.659 \\
Per child uniform expenditure & 0.285 & 0.919 \\
Per child non-food expenditure & 0.332 & 0.890 \\
Hours studying & 0.155 & 0.976 \\
Hours in school & 0.327 & 0.893 \\
Food groups & 0.543 & 0.705 \\
\hline$N$ & 593 & \\
\hline
\end{tabular}

\begin{tabular}{lcc} 
Age 15 & & \\
Per child book expenditure & 0.734 & 0.462 \\
Per child uniform expenditure & 0.419 & 0.824 \\
Per child non-food expenditure & 0.338 & 0.886 \\
Hours studying & 0.405 & 0.836 \\
Hours in school & 0.416 & 0.827 \\
Food groups & 0.427 & 0.818 \\
\hline$N$ & 526 & \\
\hline Age 19 & & \\
\hline Education expenditure & 0.319 & 0.898 \\
Non-food expenditure (soles) & 0.051 & 0.997 \\
Hours studying & 0.626 & 0.609 \\
Hours in school & 0.881 & 0.223 \\
Food groups & 0.080 & 0.994 \\
\hline$N$ & 618 & \\
\hline
\end{tabular}

Note: The table contains rotated factor loadings and the proportion of variance in each investment measure not shared with all others after retaining one factors from an initial exploratory factor analysis. One factor was retained based on the assumption the measures proxy one latent investment and the rules-of-thumb for factor retention proposed by Kaiser (1960), Horn (1965), and Cattell (1966). Factor loadings were obtained through an oblique quartimin rotation. 


\section{C.4 Results of EFA on Age 22 Socio-emotional Skill Measures}

At age 22, as was the case between ages 8-19, we again first used the principal of CSE to select measures, excluding those that were measuring subjective wellbeing or relied on assessments of their feelings/reactions to the behaviour of others. This meant, for example, excluding Cantril's ladder (Cantril et al., 1965) and measures of trust and respondents' relationship with their parents, as well as measures of pride and self-esteem that had changed substantially from earlier rounds.

We were then left with 8 measures of leadership qualities, quality of relationships with peers, ability to work in a team, self-efficacy, agency, grit, and the Big 5 emotional stability and conscientiousness scales. Ex-ante, we divided these into two groups, with the former 3 seemingly best representing social skills, and the latter 5 task effectiveness. With these measures we first confirmed they shared sufficient variation to extract as in the preceding periods - Figure C5 plots the eigenvalues of the factors underlying the measures alongside those from a parallel analysis as outlined in the previous subsection. It shows that, using the same rules-of-thumb as in the EFA of measures at previous ages the data supports extracting either 1 or 2 factors. Although the eigenvalue of the second factor is below 1 another commonly used threshold to decide upon extraction (Kaiser, 1960) - we chose to extract 2 factors in order to disaggregate socio-emotional skills into 2 domains.

Figure C5: Eigenvalues from EFA and parallel analysis of age 22 socio-emotional skill measures

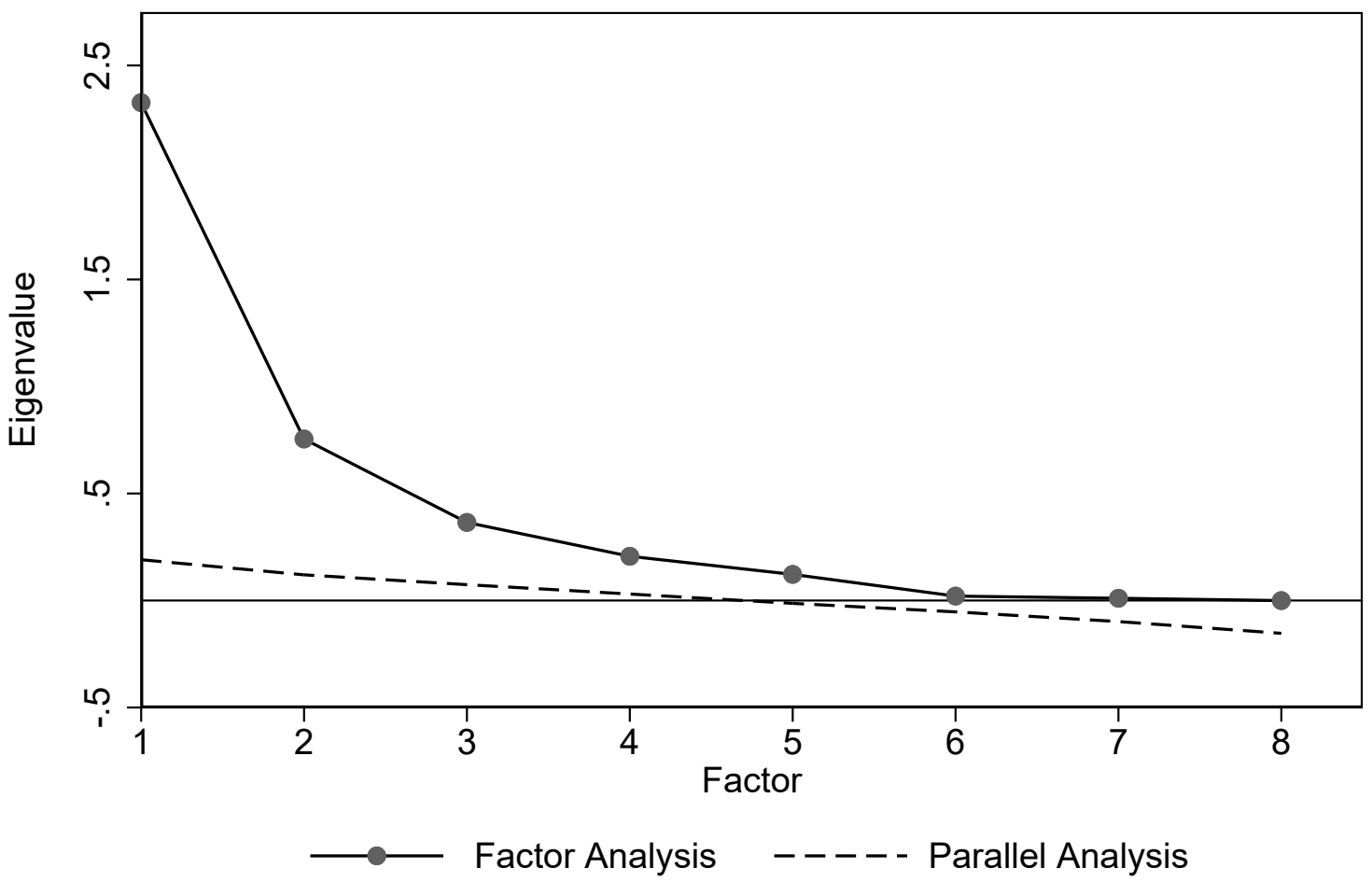

Note: The solid line connects the eigenvalues of the factors underlying 8 measures of socio-emotional skill at age 22 in the YL survey. The dotted line connects the eigenvalues of the 8 factors underlying randomly simulated data of the same dimension (i.e $N \times 8$ ). This figure was generated using Philip B. Ender's -fapra- package in Stata. 
Table C6 then shows the estimated rotated factor loadings and unique variance that correspond to each retained measure and factor at age 22. It shows that, with the exception of self-efficacy, our ex-ante beliefs about the groupings of the skill measures is borned out in the data - leadership qualities, quality of relationships with peers and ability to work in a team load heavily on the first factor, whereas gency, grit, and the Big 5 emotional stability and conscientiousness scales load heavily on the second.

Table C6: Factor loadings and unique variance of observable socio-emotional skill measures at age 22

\section{Factor $1 \quad$ Factor 2 Factor $3 \quad$ Uniqueness}

\section{Social skills}

Leadership

Peer relationships

Teamwork
$0.668 \quad 0.004$

$0.648 \quad-0.091$

$0.583 \quad 0.062$

$0.106 \quad 0.364$

$0.703 \quad 0.054$

$-0.040$

0.643

$-0.047$

0.498

0.161

0.512
0.551

0.648

0.609

\section{Task effectiveness}

Self-efficacy

Big 5 neuroticism

Big 5 conscientiousness 


\section{C.5 Additional Production Function Estimates}

Table C7: Estimates of socio-emotional production function parameters with interacted investment and cognitive skill

\begin{tabular}{|c|c|c|c|}
\hline & $\begin{array}{c}\text { Period } 1 \\
\text { Ages } 8-12\end{array}$ & $\begin{array}{c}\text { Period } 2 \\
\text { Ages } 12-15\end{array}$ & $\begin{array}{c}\text { Period } 3 \\
\text { Ages } 15-19\end{array}$ \\
\hline \multicolumn{4}{|c|}{ Lagged human capital } \\
\hline $\ln H_{s, t-1}$ & $\begin{array}{c}-0.006 \\
(0.057) \\
{[-0.100,0.087]}\end{array}$ & $\begin{array}{c}0.175 \\
(0.682) \\
{[-0.946,1.296]}\end{array}$ & $\begin{array}{c}0.173^{* * *} \\
(0.063) \\
{[0.069,0.277]}\end{array}$ \\
\hline $\ln H_{c, t-1}$ & $\begin{array}{c}0.534^{* * *} \\
(0.107) \\
{[0.358,0.711]}\end{array}$ & $\begin{array}{c}0.683 \\
(0.599) \\
{[-0.302,1.668]}\end{array}$ & $\begin{array}{c}0.508^{*} \\
(0.272) \\
{[0.060,0.955]}\end{array}$ \\
\hline \multicolumn{4}{|c|}{ Parental human capital (fixed over time) } \\
\hline $\ln P_{s}$ & $\begin{array}{c}0.190 \\
(0.154) \\
{[-0.063,0.443]}\end{array}$ & $\begin{array}{c}0.023 \\
(0.652) \\
{[-1.049,1.095]}\end{array}$ & $\begin{array}{c}0.124 \\
(0.273) \\
{[-0.325,0.572]}\end{array}$ \\
\hline $\ln P_{c}$ & $\begin{array}{c}0.012 \\
(0.025) \\
{[-0.030,0.054]}\end{array}$ & $\begin{array}{c}0.092 \\
(0.151) \\
{[-0.157,0.340]}\end{array}$ & $\begin{array}{c}-0.050 \\
(0.034) \\
{[-0.106,0.005]}\end{array}$ \\
\hline \multicolumn{4}{|l|}{ Investments } \\
\hline $\ln I_{t-1}$ & $\begin{array}{c}0.481^{* * *} \\
(0.085) \\
{[0.340,0.621]}\end{array}$ & $\begin{array}{c}0.058 \\
(0.378) \\
{[-0.564,0.680]}\end{array}$ & $\begin{array}{c}0.382 \\
(0.233) \\
{[-0.001,0.764]}\end{array}$ \\
\hline $\ln I_{t-1} \times \ln H_{c, t-1}$ & $\begin{array}{c}-0.210^{* * *} \\
(0.064) \\
{[-0.315,-0.106]}\end{array}$ & $\begin{array}{c}-0.030 \\
(0.343) \\
{[-0.595,0.534]}\end{array}$ & $\begin{array}{c}-0.135 \\
(0.171) \\
{[-0.417,0.147]}\end{array}$ \\
\hline $\begin{array}{l}\sigma_{\eta_{n}}^{2} \\
\mathrm{~N}\end{array}$ & $\begin{array}{l}3.75 \\
602\end{array}$ & $\begin{array}{l}5.22 \\
601\end{array}$ & $\begin{array}{l}.893 \\
565\end{array}$ \\
\hline
\end{tabular}

Notes: Standard errors are in parentheses, and $90 \%$ confidence intervals are in square brackets. Both are calculated using the delta method. $t-1=$ ages $8,12,15$, and 19 for the three columns respectively. The output in each column is socio-emotional skill. The inputs in the left column are are lagged child socio-emotional skill and cognitive skill; parental socio-emotional and cognitive skill; and investment and its interaction with lagged human capital. All inputs are treated as unobservable. The observables used as measures of each are discussed in Appendix Tables B. Appendix A outlines the method used to obtain all estimates in the table. 
Table C8: Estimates of socio-emotional production function parameters with interacted investment and socio-emotional skill

\begin{tabular}{|c|c|c|c|}
\hline & $\begin{array}{c}\text { Period } 1 \\
\text { Ages } 8-12\end{array}$ & $\begin{array}{c}\text { Period } 2 \\
\text { Ages 12-15 }\end{array}$ & $\begin{array}{c}\text { Period } 3 \\
\text { Ages 15-19 }\end{array}$ \\
\hline \multicolumn{4}{|c|}{ Lagged human capital } \\
\hline $\ln H_{s, t-1}$ & $\begin{array}{c}-0.394^{* *} \\
(0.194) \\
{[-0.713,-0.074]}\end{array}$ & $\begin{array}{c}0.524 \\
(0.841) \\
{[-0.858,1.907]}\end{array}$ & $\begin{array}{c}0.162^{* * *} \\
(0.062) \\
{[0.059,0.265]}\end{array}$ \\
\hline $\ln H_{c, t-1}$ & $\begin{array}{c}0.198^{*} \\
(0.102) \\
{[0.031,0.366]}\end{array}$ & $\begin{array}{c}0.416 \\
(0.862) \\
{[-1.002,1.835]}\end{array}$ & $\begin{array}{c}0.452^{* *} \\
(0.194) \\
{[0.134,0.770]}\end{array}$ \\
\hline \multicolumn{4}{|c|}{ Parental human capital (fixed over time) } \\
\hline $\ln P_{s}$ & $\begin{array}{c}0.397^{* * *} \\
(0.134) \\
{[0.176,0.618]}\end{array}$ & $\begin{array}{c}-0.069 \\
(0.492) \\
{[-0.878,0.740]}\end{array}$ & $\begin{array}{c}0.195 \\
(0.198) \\
{[-0.131,0.521]}\end{array}$ \\
\hline $\ln P_{c}$ & $\begin{array}{c}-0.043 \\
(0.028) \\
{[-0.088,0.003]}\end{array}$ & $\begin{array}{c}0.074 \\
(0.128) \\
{[-0.137,0.285]}\end{array}$ & $\begin{array}{c}-0.039 \\
(0.027) \\
{[-0.084,0.005]}\end{array}$ \\
\hline \multicolumn{4}{|l|}{ Investments } \\
\hline $\ln I_{t-1}$ & $\begin{array}{c}0.683^{* * *} \\
(0.207) \\
{[0.343,1.023]}\end{array}$ & $\begin{array}{c}0.145 \\
(0.536) \\
{[-0.736,1.027]}\end{array}$ & $\begin{array}{c}0.219 \\
(0.138) \\
{[-0.008,0.446]}\end{array}$ \\
\hline $\ln I_{t-1} \times \ln H_{n, t-1}$ & $\begin{array}{c}0.158^{* *} \\
(0.076) \\
{[0.034,0.283]}\end{array}$ & $\begin{array}{c}-0.091 \\
(0.213) \\
{[-0.442,0.260]}\end{array}$ & $\begin{array}{c}0.012 \\
(0.075) \\
{[-0.111,0.135]}\end{array}$ \\
\hline $\begin{array}{l}\sigma_{\eta_{n}}^{2} \\
\mathrm{~N}\end{array}$ & $\begin{array}{l}2.4 \\
602\end{array}$ & $\begin{array}{l}11.4 \\
601\end{array}$ & $\begin{array}{l}.902 \\
565\end{array}$ \\
\hline
\end{tabular}

Notes: Standard errors are in parentheses, and $90 \%$ confidence intervals are in square brackets. Both are calculated using the delta method. $t-1=$ ages $8,12,15$, and 19 for the three columns respectively. The output in each column is socio-emotional skill. The inputs in the left column are are lagged child socio-emotional skill and cognitive skill; parental socio-emotional and cognitive skill; and investment and its interaction with lagged human capital. All inputs are treated as unobservable. The observables used as measures of each are discussed in Appendix Tables B. Appendix A outlines the method used to obtain all estimates in the table. 
Table C9: Estimates of cognitive production function parameters with interacted investment and cognitive skill

\begin{tabular}{|c|c|c|c|}
\hline & $\begin{array}{c}\text { Period } 1 \\
\text { Ages 8-12 }\end{array}$ & $\begin{array}{c}\text { Period } 2 \\
\text { Ages } 12-15\end{array}$ & $\begin{array}{c}\text { Period } 3 \\
\text { Ages 15-19 }\end{array}$ \\
\hline \multicolumn{4}{|c|}{ Lagged human capital } \\
\hline $\ln H_{s, t-1}$ & $\begin{array}{c}0.048 \\
(0.039) \\
{[-0.016,0.113]}\end{array}$ & $\begin{array}{c}-0.039 \\
(0.166) \\
{[-0.312,0.234]}\end{array}$ & $\begin{array}{c}0.048^{*} \\
(0.029) \\
{[0.001,0.095]}\end{array}$ \\
\hline $\ln H_{c, t-1}$ & $\begin{array}{c}0.572^{* * *} \\
(0.080) \\
{[0.440,0.703]}\end{array}$ & $\begin{array}{c}0.623^{* * *} \\
(0.120) \\
{[0.425,0.821]}\end{array}$ & $\begin{array}{c}0.874^{* * *} \\
(0.207) \\
{[0.533,1.215]}\end{array}$ \\
\hline \multicolumn{4}{|c|}{ Parental human capital (fixed over time) } \\
\hline $\ln P_{s}$ & $\begin{array}{c}0.121 \\
(0.108) \\
{[-0.057,0.299]}\end{array}$ & $\begin{array}{c}0.210 \\
(0.159) \\
{[-0.051,0.471]}\end{array}$ & $\begin{array}{c}-0.026 \\
(0.159) \\
{[-0.287,0.236]}\end{array}$ \\
\hline $\ln P_{c}$ & $\begin{array}{c}0.011 \\
(0.019) \\
{[-0.020,0.042]}\end{array}$ & $\begin{array}{c}-0.002 \\
(0.014) \\
{[-0.025,0.022]}\end{array}$ & $\begin{array}{c}-0.043^{* *} \\
(0.020) \\
{[-0.076,-0.010]}\end{array}$ \\
\hline \multicolumn{4}{|l|}{ Investments } \\
\hline $\ln I_{t-1}$ & $\begin{array}{c}0.437^{* * *} \\
(0.065) \\
{[0.330,0.544]}\end{array}$ & $\begin{array}{c}0.196^{* *} \\
(0.078) \\
{[0.068,0.324]}\end{array}$ & $\begin{array}{c}0.312^{*} \\
(0.189) \\
{[0.001,0.624]}\end{array}$ \\
\hline $\ln I_{t-1} \times \ln H_{c, t-1}$ & $\begin{array}{c}-0.189^{* * *} \\
(0.051) \\
{[-0.272,-0.105]}\end{array}$ & $\begin{array}{c}0.012 \\
(0.083) \\
{[-0.125,0.149]}\end{array}$ & $\begin{array}{c}-0.166 \\
(0.128) \\
{[-0.377,0.045]}\end{array}$ \\
\hline $\begin{array}{l}\sigma_{\eta_{c}}^{2} \\
\mathrm{~N}\end{array}$ & $\begin{array}{l}.105 \\
598\end{array}$ & $\begin{array}{l}.681 \\
595\end{array}$ & $\begin{array}{l}.843 \\
551\end{array}$ \\
\hline
\end{tabular}

Notes: Standard errors are in parentheses, and $90 \%$ confidence intervals are in square brackets. Both are calculated using the delta method. $t-1=$ ages 8,12 , and 15 for the three columns respectively. The output in each column is cognitive skill. The inputs in the left column are are lagged child socio-emotional skill and cognitive skill; parental socio-emotional and cognitive skill; and investment and its interaction with lagged human capital. All inputs are treated as unobservable. The observables used as measures of each are discussed in Appendix B. Appendix A outlines the method used to obtain all estimates in the table. 
Table C10: Estimates of cognitive production function parameters with interacted investment and socio-emotional skill

\begin{tabular}{|c|c|c|c|}
\hline & $\begin{array}{c}\text { Period } 1 \\
\text { Ages 8-12 }\end{array}$ & $\begin{array}{c}\text { Period } 2 \\
\text { Ages 12-15 }\end{array}$ & $\begin{array}{c}\text { Period } 3 \\
\text { Ages 15-19 }\end{array}$ \\
\hline \multicolumn{4}{|c|}{ Lagged human capital } \\
\hline $\ln H_{s, t-1}$ & $\begin{array}{c}0.043 \\
(0.152) \\
{[-0.208,0.293]}\end{array}$ & $\begin{array}{c}-0.518 \\
(0.854) \\
{[-1.922,0.887]}\end{array}$ & $\begin{array}{c}0.028 \\
(0.027) \\
{[-0.016,0.072]}\end{array}$ \\
\hline $\ln H_{c, t-1}$ & $\begin{array}{c}0.356^{* * *} \\
(0.080) \\
{[0.224,0.488]}\end{array}$ & $\begin{array}{c}1.047 \\
(0.695) \\
{[-0.096,2.191]}\end{array}$ & $\begin{array}{c}0.882^{* * *} \\
(0.169) \\
{[0.604,1.160]}\end{array}$ \\
\hline \multicolumn{4}{|c|}{ Parental human capital (fixed over time) } \\
\hline $\ln P_{s}$ & $\begin{array}{c}0.404^{* * *} \\
(0.139) \\
{[0.174,0.633]}\end{array}$ & $\begin{array}{c}0.277 \\
(0.271) \\
{[-0.169,0.724]}\end{array}$ & $\begin{array}{c}-0.042 \\
(0.144) \\
{[-0.279,0.195]}\end{array}$ \\
\hline $\ln P_{c}$ & $\begin{array}{c}-0.023 \\
(0.023) \\
{[-0.061,0.015]}\end{array}$ & $\begin{array}{c}-0.001 \\
(0.021) \\
{[-0.036,0.034]}\end{array}$ & $\begin{array}{c}-0.030^{*} \\
(0.018) \\
{[-0.059,-0.001]}\end{array}$ \\
\hline \multicolumn{4}{|l|}{ Investments } \\
\hline $\ln I_{t-1}$ & $\begin{array}{c}0.219 \\
(0.163) \\
{[-0.049,0.487]}\end{array}$ & $\begin{array}{c}0.072 \\
(0.240) \\
{[-0.323,0.466]}\end{array}$ & $\begin{array}{c}0.189^{* *} \\
(0.093) \\
{[0.035,0.342]}\end{array}$ \\
\hline $\ln I_{t-1} \times \ln H_{n, t-1}$ & $\begin{array}{c}0.002 \\
(0.061) \\
{[-0.099,0.102]}\end{array}$ & $\begin{array}{c}0.122 \\
(0.207) \\
{[-0.219,0.463]}\end{array}$ & $\begin{array}{c}-0.028 \\
(0.044) \\
{[-0.100,0.044]}\end{array}$ \\
\hline $\begin{array}{l}\sigma_{\eta_{c}}^{2} \\
\mathrm{~N}\end{array}$ & $\begin{array}{l}.0619 \\
598\end{array}$ & $\begin{array}{l}.494 \\
595\end{array}$ & $\begin{array}{l}.878 \\
551\end{array}$ \\
\hline
\end{tabular}

Notes: Standard errors are in parentheses, and $90 \%$ confidence intervals are in square brackets. Both are calculated using the delta method. $t-1=$ ages 8,12 , and 15 for the three columns respectively. The output in each column is cognitive skill. The inputs in the left column are are lagged child socio-emotional skill and cognitive skill; parental socio-emotional and cognitive skill; and investment and its interaction with lagged human capital. All inputs are treated as unobservable. The observables used as measures of each are discussed in Appendix B. Appendix A outlines the method used to obtain all estimates in the table. 